Copyright

by

Noah Joseph Durst

2013 
The Report Committee for Noah Joseph Durst

Certifies that this is the approved version of the following report:

The Rise of Renters and Renting in Texas Colonias

\begin{abstract}
APPROVED BY
SUPERVISING COMMITTEE:
\end{abstract}

Supervisor:

Peter M. Ward

Co-supervisor:

Robert H. Wilson 
The Rise of Renters and Renting in Texas Colonias

$$
\text { by }
$$

Noah Joseph Durst, B.A.

\author{
Professional Report \\ Presented to the Faculty of the Graduate School of \\ The University of Texas at Austin \\ in Partial Fulfillment \\ of the Requirements \\ for the Degrees of \\ Master of Public Affairs \\ and \\ Master of Arts
}

The University of Texas at Austin

May 2013 


\section{Dedication}

This report is dedicated to my former students at Ringgold Middle School in Rio Grande

City, Texas. Thank you for teaching me the importance of community, generosity, and hope. 


\section{Acknowledgements}

I would like to express my deepest appreciation to Dr. Peter Ward of the Lyndon B. Johnson (LBJ) School of Public Affairs for extensive guidance throughout the research process and for providing me with the opportunity to work on a variety of important policy research projects in colonias. I am also grateful for his consistent support and encouragement, for thorough and thoughtful feedback on multiple versions of this report, and, in particular, for inspiring in me an interest in housing and economic development in colonias. I also wish to thank Dr. Robert Wilson for guidance and feedback on the econometric model presented herein, as well as for helpful comments on an earlier draft of the report. I am grateful to Dr. Sasha West of the LBJ School Writing Center, who provided thorough and insightful input as well. Finally, I would like to thank Abigail Lopez, Lucero Morin, and Ana Castillo for their contribution as student research assistants in Starr County in July of 2011. Without their eagerness and diligence, the analysis presented in Chapter 4 would not have been possible. 


\title{
Abstract \\ The Rise of Renters and Renting in Texas Colonias
}

Noah Joseph Durst, MPAff \& M.A.

The University of Texas at Austin, 2013

\author{
Supervisor: Peter M. Ward \\ Co-supervisor: Robert H. Wilson
}

This report documents the growth of renting in Texas colonias, low-income informal settlements along the US-Mexico border. Historically, owner-occupied self-help and self-managed housing has been the norm in these settlements, so scholarly treatment of renting in colonias has been very limited. I begin with a literature review of housing development and housing policy in colonias, before turning, for comparison, to a discussion of renting in the US as well as in informal settlements in the developing world. Chapter 2 draws upon data from the US Census Bureau to describe the nature and extent of the colonia rental market in the six Texas counties with the largest colonia populations: my analysis reveals that renters now make up more than one in five colonia households. I expand on this discussion by examining differences between renter and owner households, paying particular attention to factors that make renters more vulnerable than owners. Chapter 3 employs a variety of regression models to identify the determinants of varying rental rates in colonias. The results suggest that larger, older, and more densely populated colonias have higher rates of renting. In Chapter 4, I utilize a mixed methods 
approach — including household surveys, key informant interviews, and intensive case study interviews - to a) better understand the tenure decisions of colonia renters and to place such decisions within a context of extreme socio-economic vulnerability and b) examine the factors that incentivize a turn toward renting among property owners. I conclude with a discussion of potential policy solutions to ensure that colonia rental accommodation remains affordable, accessible, and of sufficient quality. 


\section{Table of Contents}

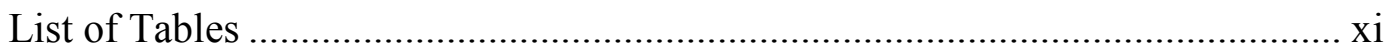

List of Figures .........................................................................................

Chapter 1: The "Invisibility" of Renting in Colonias .......................................1

A Note ON THE ReSEARCh PReSENTED throughout this RePORT .........1

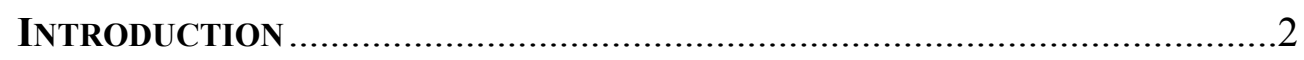

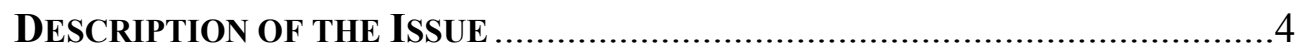

A Brief History of Colonias ............................................................

Why Renting in Colonias Deserves Attention ...................................6

RENTING IN INFORMAL SETTLEMENTS: LESSONS FROM THE DEVELOPING

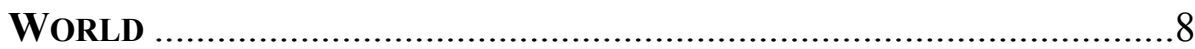

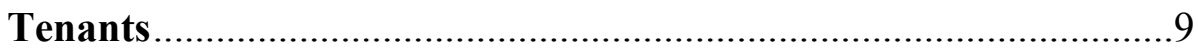

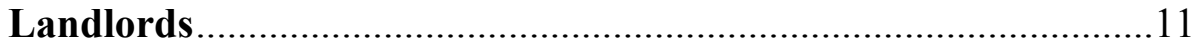

RENTING IN THE UNITED STATES .......................................................

Renter (vs. Owner) Housing Policies................................................11

Characteristics of the National Rental Market ...............................12

REPORT ORGANIZATION AND METHODOLOGY …........................................15

Chapter 2: Renting in Colonias: A Review of American Community Survey

Census Designated Places.....................................................................18

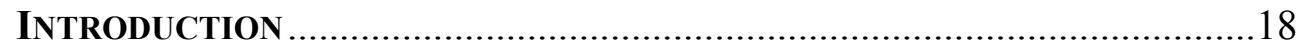

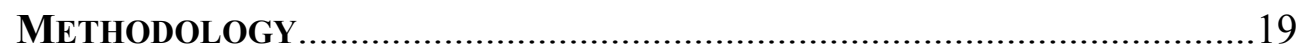

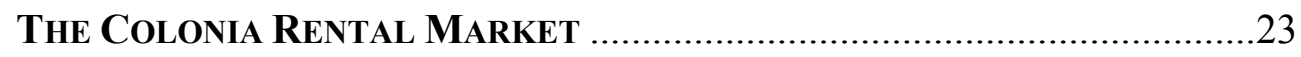

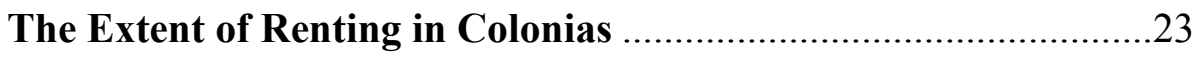

The Nature of the Colonia Housing Market....................................27

RENTER AND OWNER HOUSEHOLDS: A COMPARISON ...............................30

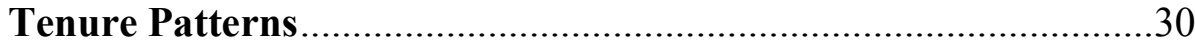

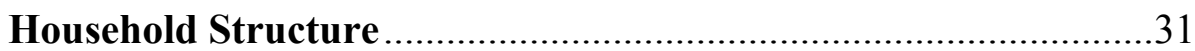

Income, Poverty, and Housing Cost ...................................................

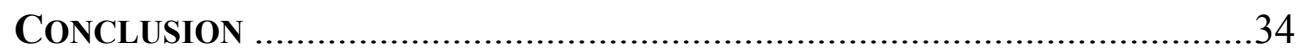


Chapter 3: The Determinants of Rental Rates in Texas Colonias ..................36

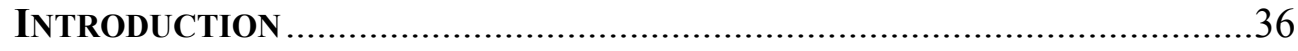

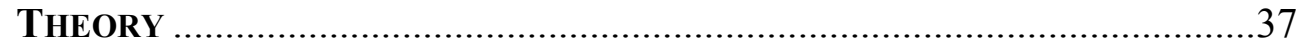

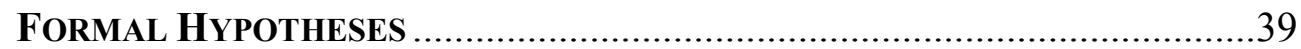

METHODS AND DESCRIPTION OF DATA .................................................4

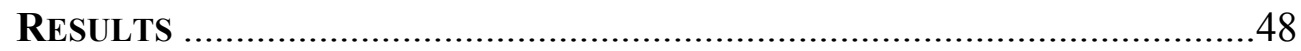

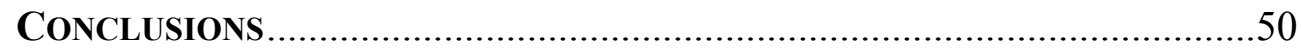

Chapter 4: An Examination of Renters and Renting ...............................55

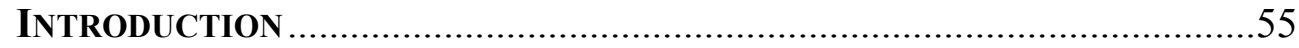

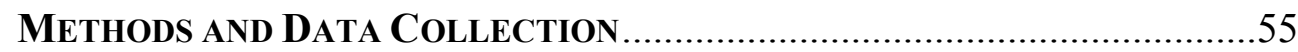

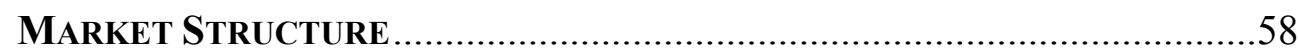

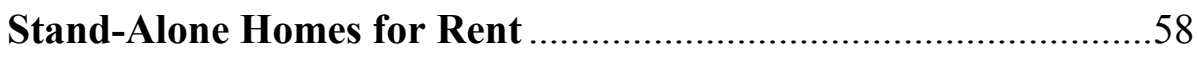

Formal Rental Complexes ......................................................61

Lots for Rent...........................................................................64

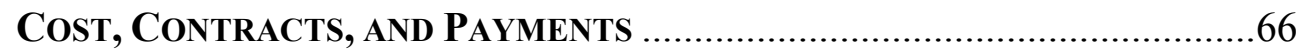

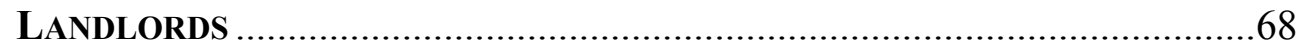

Informal Landlords of Stand-Alone Homes ................................68

Entrepreneurial Landlords of Formal Rental Complexes ............70

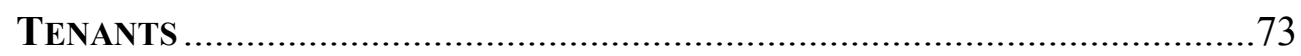

Socioeconomic Status and Housing Choice ................................76

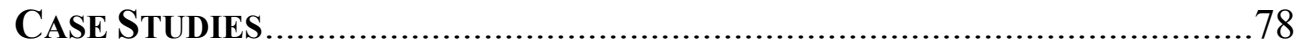

The Martínez Family: A Case of Severe Vulnerability .................79

The Castillo Family: Upwardly Mobile, but Vulnerable Nonetheless

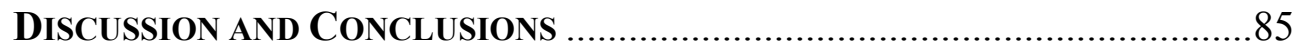

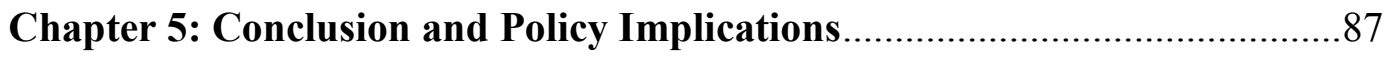

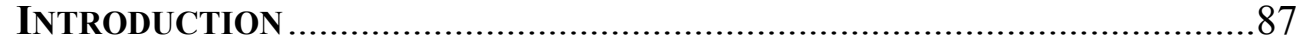

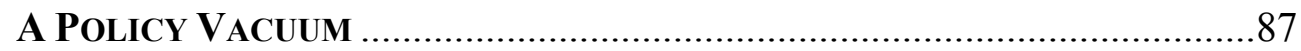

Renting in Colonias: Current Policy Concerns ...........................89

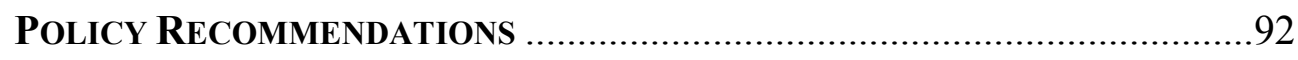


Demand-Side Policies............................................................93

Supply-Side Policies .................................................................. 94

Policies to Enhance Consumer Protection ..................................96

RECOMMENDATIONS FOR FURTHER RESEARCH....................................96

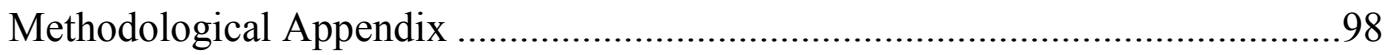

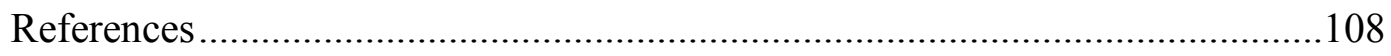




\section{List of Tables}

Table 1.1. Number of Colonias \& Colonia Residents by County......................15

Table 2.1. Rental Rates by County ..........................................................24

Table 2.2. Rental Rates by Settlement Age \& Size. .........................................26

Table 2.3. Structure of the Colonia Rental \& Owner Housing Markets............28

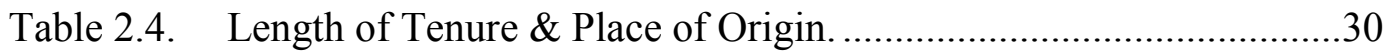

Table 2.5. Demographic \& Housing Characteristics of Renters \& Owners .......32

Table 2.6. Income, Poverty, \& Housing Cost by Tenure..................................33

Table 3.1. Descriptive Statistics for Regression Variables...............................42

Table 3.2. Original OLS Regression Model with Outliers Removed ................49

Table 4.1. The Stand-Alone Colonia Rental Market .....................................60

Table 4.2. Formal Rental Complexes in Colonias ........................................63

Table 4.3. Costs (2011 \& 2012) \& Contracts in Colonia Rental Markets .........67

Table 4.4. SES \& Demographic Data: A Comparison between Renter \& Owner

Households .75

Table 6.1. Logistic Regression of Testing for Selection Bias of Missing Data.98

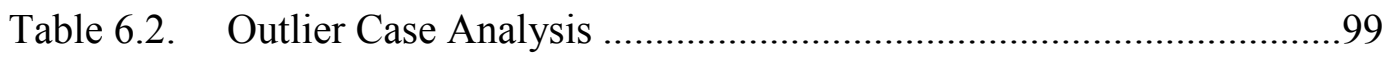

Table 6.3. Truncated Regression with Outliers Removed .............................100

Table 6.4. Revised OLS Regression Excluding Distances of Zero .................100

Table 6.5. Revised OLS Regression Model with Settlement Infrastructure Conditions 101 


\section{List of Figures}

Figure 1.1. Selected Counties \& Texas Office of the Attorney General Designated Colonias 16

Figure 2.1. Example of a Census Designated Place Containing Multiple Colonias .21

Figure 3.1. Sample Distribution of Percent Renter Households (Dependent Variable) 43

Figure 4.1. Example of a Multi-Unit Stand-Alone Home in Hidalgo County, Texas

Figure 4.2. A Large (16-unit) Formal Rental Complex in Starr County, Texas. 61

Figure 4.3. Trailer Park in an Informal Homestead Subdivision: Border of Travis \& Williamson Counties, (Austin) Central Texas. .64

Figure 4.4. "Se Renta 4 Solares" (4 Lots for Rent) in Starr County, Texas........65

Figure 6.1. Scatter Plot: Debt-free Ownership and years since Plat was Recorded 101

Figure 6.2a. Residual Plot: Distance from Nearest Incorporated City...............102

Figure 6.2b. Residual Plot: Settlement Size .....................................................102

Figure 6.2c. Residual Plot: Percent Debt-free Ownership (Proxy for Age).......103

Figure 6.2d. Residual Plot: Population per Square Kilometer (in Thousands) ..103

Figure 6.3. Sample Distribution of Percent Renter Households in Settlements with 20 or More Occupied Units (Dependent Variable). 104

Figure 6.4. Sample Distribution of Percent Renter Households in Settlements with 40 or More Occupied Units (Dependent Variable) 104

Figure 6.5. Histogram of Regression Residuals (Model 1) 105 
Figure 6.6. Diagrammatic Sketch of the Martinez Family Home ....................106

Figure 6.7. Diagrammatic Sketch of the Castillo Family Home .....................107 


\section{Chapter 1: The "Invisibility" of Renting in Colonias}

\section{A Note ON THE Research Presented throughout this RePORT}

This report represents the culmination of more than two years of research on housing in colonias. In the fall of 2010 I began working with Dr. Peter Ward of the Lyndon B. Johnson School of Public Affairs on a Ford Foundation-funded research project exploring lot vacancies and infill in colonias (see Rojas et al. 2012). By January of 2011, Dr. Ward and I began to prepare for a major study on the impact of title regularization ${ }^{1}$ efforts in ten colonias in Starr County (see Durst et al. 2012). Then, in June of 2011, I led a group of ten student research assistants who conducted household surveys with 200 residents in ten colonias in Starr County. One of the most surprising findings from this study was the significant presence of a colonia rental market, a fact which scholars had largely overlooked and which Dr. Ward encouraged me to explore further. I therefore remained in Starr County through July of that year, thanks to a generous grant ${ }^{2}$ from the Teresa Lozano Long Institute of Latin American Studies, and conducted household surveys, key informant interviews, and intensive cases studies with colonia renters and landlords.

The following year I was again fortunate to work for Dr. Ward, this time as a research assistant on a major research project on land title in more than fifty colonias and other informal settlements throughout eight Texas counties (see Ward et al. 2012). Although we once again underestimated the extent of the rental market, we nevertheless

\footnotetext{
1 Title regularization refers to the "cleaning" (i.e. correcting) of title. In these ten counties, the Community Resource Group, a non-profit, undertook a major effort to correct the title (or to issue a new title) to more than 1,000 households in a dozen colonias where developers had engaged in a variety of nefarious titling practices.

2 This was the Lozano Long Summer Research Grant.
} 
captured limited data on renters and renting in these settlements. Combined, these three research projects form the foundation of this report and are referenced throughout, but particularly in Chapter 4.

\section{INTRODUCTION}

Colonias are low-income, informal settlements that are located primarily along the US-Mexico border and have historically lacked basic infrastructure and utility services. Owners in colonias typically purchase lots from developers on a seller-financed basis. Although developer-financing often entails high interest rates, it is the primary way in which low- and very low-income households can get a foothold in the owner-occupied housing market. In these informal settlements, owner-occupied self-built or self-managed housing is the norm, and because of the reliance on self-help construction, housing quality is often extremely poor, at least during the early stages of settlement consolidation (Ward 1999). Indeed, colonias have often been described as having conditions reminiscent of the "third-world" (Davidhizar and Bechtel 1999; Holz 1993). Similar settlements - known as Informal Homestead Subdivisions (IFHS) ${ }^{3}$ - are also found outside of the border region, developed on low-value agricultural land in the hinterlands of cities with a labor market that requires low waged labor in services, food processing and construction (Ward and Peters 2007).

Colonias began to enter public policy discussions in the late 1980s primarily due to increasing concerns over the severe health risks caused by inadequate infrastructure and poor housing quality. Since this time, scholars have focused extensively on the

\footnotetext{
${ }^{3}$ IFHSs are similar to colonias in that they are occupied primarily by low-income households—although not quite as low as colonias. Many residents in IFHSs purchase manufactured homes and place them on poorly serviced lots. Some of the issues common to colonias - such as concentrated poverty, property title insecurity, poor housing quality, and insufficient infrastructure services - are common to IFHSs (Ward and Peters 2007).
} 
owner-occupied nature of colonia housing markets, highlighting the socio-political antecedents that led to their growth; the different housing types and conditions; the use of exploitative land sale procedures and informal titling mechanisms, and the subsequent prevalence of "clouded"4 titles; the dynamics of the colonia land and owner-occupied housing market; and the nature and extent of the self-help home improvement process and how such improvements are financed (Giusti and Estevez 2011; Larson 1995; Ward 1999; Ward and Carew 2000; Ward et al. 2011; Ward et al. 2012). However, we know far less about the nature and extent of non-owner populations living in colonias and IHFSs.

Historically, scholars have assumed that renting in colonias has always been fairly limited, since these informal settlements are viewed exclusively as a path to ownership among the very poor. While renting is common in most states ${ }^{5}$ and is common among low-income households along the US-Mexico border, most renters are believed to have historically resided within the urban area itself, often in apartments in or close to the city. Thus, most rural housing is owner occupied, and rental housing (especially purpose built) is underdeveloped in rural areas, and in colonias in general. In particular, Ward (1999) argues that a number of factors make colonias an unattractive venue for rental housing consumption by would-be renters, or production by would-be landlords: located in the peri-urban areas of cities, colonias are far from employment opportunities and amenities in cities, lack basic infrastructure, and often require that residents build or manage their own house construction. However, more recent research suggests that although relatively small in extent, renting is on the increase (Durst et al. 2012) and that renters and sharers

\footnotetext{
${ }^{4}$ Lawyers refer to properties with unclear or competing claims of ownership as being "clouded."

${ }^{5}$ In Texas, $36 \%$ of households rent. This estimate is drawn from the 2010 Census, Summary File 1.
} 
(those who live rent-free on a property owned by friends or family) ${ }^{6}$ now represent up to one in five of colonia households (Ward et al. 2012), making salient the importance of identifying the significant and growing presence of renters and renting in colonias.

This report seeks to achieve four objectives, namely: to describe the nature and extent of the colonia housing market and to determine the growth in renting in recent years in the six Texas counties with the largest colonia populations; to identify the determinants of the varying rates of renting in colonias; to explain relevant differences between colonia renters and homeowners, paying particular attention to areas in which renters are markedly more vulnerable than are owners; and to suggest potential policy solutions to ensure that colonia rental accommodation remains affordable, accessible, and of sufficient quality.

\section{DESCRIPTION OF THE ISSUE}

\section{A Brief History of Colonias}

Colonias proliferated throughout the border region for a variety of reasons, including: a large low-income population, scarce affordable housing options, lax land-use regulations in unincorporated areas, and the exploitation of low-income residents by local land developers. Often, colonia homeowners purchased vacant and un-serviced land under the promise that developers would eventually provide basic utility services (Ward 1999). While many households move manufactured homes onto their lots, self-help is also quite common among colonia homeowners in the border region: as I report elsewhere in a study of the impact of title regularization efforts, as many as $47 \%$ of

\footnotetext{
${ }^{6}$ The dynamics of the sharing market are not addressed in this report, as the design of the research projects precluded the capturing of much data on this population. In general, those that live on the property rent free constitute a small portion of colonia residents (approximately 2-3\%, according to Ward et al., 2012; my analysis of Census and ACS data - see Chapter 2-provides similar conclusions).
} 
colonia homeowners interviewed in Starr County, Texas built their homes themselves or with the assistance of family or friends (Durst et al. 2012). This reliance on self-help home improvements is characteristic of housing in colonias and IFHSs. In Texas, as in Latin America, the state is active in policymaking to upgrade so called irregular settlements, and state-led and non-profit efforts to support the self-help process have played a significant role in housing provision in colonias. ${ }^{7}$

Despite extensive research on the owner-occupied housing market, self-help home improvements, infrastructure regularization and other issues, scholars have treated renting as a non-issue. Few scholarly works even mention the issue of renting, and when acknowledged, as in Ward (1999), renting is treated as a phenomenon unique to a few larger and relatively consolidated settlements, such as Cameron Park (1,800 plus units at present $^{8}$ ) in Cameron County. Despite limited discussion of renting in US colonias, Ward does acknowledge that renting is common in colonias on the Mexican side of the border, where settlements are more densely populated and closer to urban centers. In these settlements, rental operations tend to be rather small-scale, and they proliferate as the settlements age and become more densely populated (Ward 1999).

Although recent research by Durst et al. (2012) and Ward et al. (2012) collected limited data on the extent of renting in US colonias, these projects were primarily interested in the nature of the owner-occupied housing market and, in particular, in analyzing title irregularities in colonias. For this reason, even in these reports the data on renting are limited to a few key variables. In a ten-year "snapshot" study of colonia

\footnotetext{
7 Notable examples are the State of Texas' Bootstrap Loan Program administered by Colonia Self-Help Centers (see http:/www.tdhca.state.tx.us/oci/bootstrap.jsp) and micro-loans provided by non-profits such as the Community Resource Group (Giusti and Estevez, 2011).

8 According to 2007-2011 ACS 5-Year Estimates.
} 
households, Durst et al. (2012) found that the proportion of renters and sharers had risen from $6 \%$ in 2002 to $12 \%$ in 2011 . Although it is likely that these estimates significantly undercount the proportion of renters in the study settlements, ${ }^{9}$ they are illustrative nonetheless of the significant growth in renting in colonias over the past decade.

A similar study conducted by some of the same authors provides limited data on the extent and nature of the colonia rental market. Drawing upon data from nearly 1,300 surveys conducted with (randomly sampled) households in colonias and IFHSs in eight counties, Ward et al. (2012) found that renters and sharers constitute nearly one in five households (18\%). Seventy-eight percent of the renters interviewed reported that there was only one rental unit on the property, $15 \%$ reported that there were two or more units, and $8 \%$ reported more than two. Additionally, most renters $(90 \%)$ stated that they paid rent directly to the owner, and less than a third (30\%) had a written rental contract with the owner. These data suggest that the colonia rental housing market is run primarily by informal landlords who operate small-scale rental operations, as is common throughout the developing world. Moreover, data collected in that same study show that renters are significantly poorer and younger than are owners, and that they have lived in their homes for a shorter time, suggesting that colonia renters have distinct needs that are likely not addressed by current housing policy in colonias.

\section{Why Renting in Colonias Deserves Attention}

The failure to understand the nature of tenure conditions in colonias has meant that the needs of renters have been largely ignored by lawmakers and housing advocates. Historically, nearly all legislative reforms enacted in Texas - and the majority of public,

\footnotetext{
${ }^{9}$ Because this study was designed to gauge the impact of title regularization on colonia homeowners, the authors specifically targeted residents in stand-alone (detached) dwellings. Large formal rental complexes were therefore excluded from the study, and many renter households were missed in the interview process.
} 
private, and non-profit housing support programs - have focused on issues such as the failure of developers to meet infrastructure provision obligations, infrastructural upgrading, title security, support for self-help home improvement, and financing for the purchase of new homes. ${ }^{10}$ However, as I intend to show, renters not only constitute a significant and growing proportion of colonia residents, but they are by and large in more dire socio-economic circumstances - and therefore in greater need of support.

Similar critiques have been levied against housing policy and research in the developing world (Kumar 1996; UN-HABITAT 2003). The case for renewed attention to rental housing and the needs of renters, especially in less developed countries, is made most strongly by Gilbert (1991):

If households exhibit a wide range of housing needs, governments should seek to create a matching range of housing options. Since it offers the kind of shelter required by certain household types, particularly the young and the mobile, any city which lacks sufficient rental accommodation soon begins to regret it. To simply encourage owner-occupation is neither feasible, given the shortage of land and services, nor desirable... Renting has to be recognized as both a respectable and a necessary housing option (98).

Other factors make even clearer the importance of understanding tenure in informal settlements. As Andreasan $(1996,359)$ argues, "the fact that tenants are less motivated to join community projects has not been adequately acknowledged," (emphasis in original) thereby reducing the viability of settlement upgrading projects, since communities with high levels of renting are less likely to mobilize for government support. Ward (1999) has made similar arguments in regards to the presence of renting in colonias on the Mexican side of the border with the US: more renters means less unity among community members and less support for regularization efforts, since renters will

\footnotetext{
${ }^{10}$ See the Texas Office of the Attorney General for a summary of colonia legislation in Texas: https://www.oag.state.tx.us/consumer/border/history.shtml.
} 
not benefit from increased property values, and may in fact be priced out if rental rates rise. However, as Ward notes, most settlements have substantially consolidated by the time renting is common, and thus community mobilization for infrastructure regularization is less necessary.

\section{RENTING IN INFORMAL SETTLEMENTS: LESSONS FROM THE DEVELOPING WORLD}

Given the significant scholarly research that exists on renting in informal settlements throughout the developing world, and the similarities between these settlements and colonias, it will be useful to review the principal conclusions from this literature. This will also serve to provide a useful comparison with the statistics on renting in the United States, discussed in the following section.

Any effort to understand tenure decisions must take into account the nature of the rental market, and the concerns and needs of both landlords and tenants. Nevertheless, there is considerable variability in the literature on informal settlements regarding how best to classify owners, tenants, and landlords (see Kumar 1996). Throughout this piece I distinguish between a) entrepreneurial landlords of formal rental complexes (large, multi-unit rentals) who pursue landlordism explicitly as a business and often own and operate multiple rental properties, and b) informal landlords that operate informal, smallscale operations. Informal landlords typically rent dwellings that they or family members once occupied, but they may also sometimes rent out units on their lot-this latter category, which I consider a subset of the informal typology, are referred to throughout as petty landlords. For informal landlords, in general, a variety of factors - such as strong kin networks, the poorly functioning land and property market, title irregularities and disputes over inheritance, and the desire for supplemental income-incentivize the turn toward landlordism, but they rarely do so explicitly as a business. Moreover, while 
landlords and informal landlords are technically owners, for clarity I use the term owner to refer only to those who live in a dwelling that they or a household member own. Finally, I use the terms renters and tenants to refer to those who live in dwellings that they do not own - the majority of these households pay monthly rent, although a significant portion of renters in fact pay no rental cost and are thus referred to throughout as payment-free renters, or sharers.

\section{Tenants}

Early discussions of tenure and settlement patterns in Latin American cities were largely shaped by the work of John Turner (1968). In Turner's model of housing mobility, new migrants to Latin American cities sought rental accommodation in the inner city, close to employment centers, before eventually transitioning to homeownership in informal settlements on the urban fringe. More importantly, perhaps, Turner was among the first to assert that unplanned squatter settlements were more of a solution than a problem. Though conceptually elegant and of importance for early policymaking regarding informal housing in Latin America, Turner's model suffers from a variety of inaccuracies or oversights. As Kumar (1996) argues, Turner assumes ex ante the preference for homeownership among urban residents, and fails to anticipate and explain the causes of the growing presence of renting in informal settlements; nor does he explore the complexities of the production process as it relates to rental housing.

Since Turner, a number of authors have documented the nature and extent of the rental market in informal settlements, paying particular attention to the choice of tenure and the transition from renting to owning. For example, some scholars have explored the extent to which housing tenure is a product of individual choice or market constraints. Many urban residents in Latin America do in fact prefer to own (Gilbert and Ward 1982; 
Gilbert and Varley 1990a, 1991), but their ability to do so often depends on a variety of factors outside of their control: these include the rising price and decreasing availability of land, the increasing distance of new informal settlements from urban centers as cities expand outwards, and their low incomes (Gilbert and Ward 1982; Gilbert 1983). Other factors such as the availability of financing for home construction, the nature of the construction process (self-help), and the cost and availability of labor and materials also play an important role in determining the extent and nature of the rental and owneroccupied housing markets (Kumar 1996).

Although most residents profess a strong preference for homeownership, constrained choices alone do not explain why many tenants in Latin America continue to rent, even after many years. According to Gilbert (1991), the disadvantages of renting are often overstated, and renting in fact frequently provides significant benefits: many renters achieve relative security of tenure; renting in or near the city center provides greater access to utility services and transportation, thus improving living conditions and allowing greater accessibility to areas of employment; finally, self-help ownership can be excessively burdensome, with residents often living in poor quality housing for many years. As Gilbert (1991) argues:

There is a significant difference between the general desire for ownership and the practicalities of becoming an owner. When tenants say that they want their own homes, they are expressing their preference for a particular form of ownership. They are saying that they want to own a particular kind of home, maybe similar to the home that they are now currently renting or maybe even a palace. If what the market offers is not this kind of home, some households may choose to forego the opportunity for ownership until their preferred kind of home becomes available (94). 


\section{Landlords}

Once again, results from research on landlords in Latin America will serve as a useful point of comparison. Data collected by Gilbert and Varley (1990b) in Puebla and Guadalajara suggest that most landlords run small-scale rental operations, often as a means of earning additional income and to help facilitate the consolidation of the home. Thus, these are more akin to what I will be referring to as informal landlords. Other research provides similar conclusions and suggests that many such informal landlords are highly dependent upon the supplemental income earned from landlordism (Gilbert 1983; Gilbert and Ward 1985; Gilbert and Varley 1990b). Even with this additional income, Gilbert and Varley $(1990 \mathrm{~b}, 36)$ report that due to the cost of upkeep and the low rental prices, most landlords saw renting as "bad business." Thus, institutional landlords - those that operate large-scale property management and rental operations - tend to be rare throughout Latin America, and only a limited number of landlords own more than a few properties (Gilbert and Varley 1990).

\section{RENTING IN THE UNITED STATES}

\section{Renter (vs. Owner) Housing Policies}

Before discussing the structure and characteristics of rental markets in the US, it will be useful to first explore housing policy in general. In the US, homeownership has occupied a somewhat privileged position in domestic policymaking-for example, according to Schwartz (2010), in 2008 federal housing subsidies in the US benefited approximately 7 million low-income renters, while approximately 155 million homeowners claimed mortgage-interest deductions. Put another way, that same year the federal government spent $\$ 40$ billion dollars on direct housing assistance, while the value of mortgage-interest deductions and tax benefits for homeowners totaled more than $\$ 171$ 
billion (Schwartz 2010). A similar imbalance is between renter- and owner-targeted policies is observable in Latin America as well. However, Latin American governments' efforts to facilitate homeownership have focused primarily on the promotion of self-help, and infrastructure and title regularization, while in the US homeownership has been promoted primarily through tax incentives for homeowners and federal insurance for mortgages.

Despite the privileged position of homeownership policy in the US, the federal government does provide a variety of subsidies targeting both the supply and demand side of the rental market. Supply-side incentives for rental housing include government

owned and operated affordable housing (i.e., public housing), the Low Income Housing Tax Credit (LIHTC) — the largest low-income rental housing subsidy — and a variety of subsidies provided to privately owned rental housing-these include Section 8 and Section 236, administered by the US Department of Housing and Urban Development (HUD) as well rural rental subsidies administered by the US Department of Agriculture (USDA). On the demand side, voucher programs reduce the cost of rent for low-income tenants by paying a portion of the market rent. Notably, while vouchers are in general less expensive than project-based subsidies and (theoretically) offer greater choice of dwellings, use of the voucher depends upon the recipient's ability to find a dwelling of suitable quality that is within the program's allowable rent and whose landlord is willing to accept a voucher (Schwartz 2010).

\section{Characteristics of the National Rental Market}

We now turn to a discussion of the nature of the national rental market. This will provide a useful juxtaposition with conditions in colonias, and will solidify the argument that renting in colonias is not unlike what is found in informal settlements throughout the 
developing world. Across the US, affordability for renters is of greatest concern: more renters than owners face an excessive housing cost burden. According to Schwartz (2010), more than $30 \%$ of homeowners and $45 \%$ of renters had housing cost burdens of $30 \%$ or more in 2007.11 Circumstances were even more dire for poorer households: nationally: $51 \%$ of renters and $43 \%$ of owners in the bottom quartile of income categories spent more than $30 \%$ on housing in 2007 (Schwartz 2010). Interestingly, as many as $5.8 \%$ of tenants pay no cash rent (The New Strategist 2011).

The fact that renters experience higher cost burdens is somewhat counterintuitive, since according to the conventional wisdom owners should be willing to spend more on housing since they are building equity in the process. Indeed, in nominal terms owners do spend more on housing than renters: according to analysis by The New Strategist (2011), national median monthly housing costs for renters are $\$ 808$, somewhat lower than the median costs for owners, at $\$ 909$ per month. However, although owners pay more on average for housing than do renters, their incomes are also significantly higher: in 2008, the median household income for renter households was $\$ 32,700$ (down from an inflation-adjusted median income of $\$ 34,100$ in 1988); this compares to median incomes of $\$ 60,800$ and $\$ 63,700$ for owner households in 1988 and 2008, respectively (Schwartz 2010). Part of this increasing poverty among renters is attributable to the move for many

11 This is by no means a straightforward calculation, since many homeowners benefit from mortgageinterest and property tax deductions, not to mention the fact that though owners may often pay more for housing, they simultaneously build equity through appreciation. However, it is unclear whether low and moderate income families receive the same benefits from homeownership as do upper income families: since many low income families do not itemize their tax return, they receive no benefit from these deductions. Moreover, the location of housing (particularly its desirability and potential for resale) dictates the profit earned by homeowners. In colonias, where property values are depressed due to inadequate infrastructure and an inefficient housing market (Ward and Carew 2000; Ward et al. 2011), homeowners are unlikely to benefit from such capital appreciation. Finally, because many colonia homeowners purchase and construct their homes through informal means (self-help and incremental financing, short-term purchase agreements, etc.), typical measures of affordability, particularly those collected by the Census Bureau, are less useful in regards to colonia homeowners. 
wealthier renters toward homeownership, although increasing inequality and the growth of employment in low-wage service sectors also play a role (Schwartz 2010). A final important factor that affects the affordability of renting versus owning is the fact that housing costs for owners tend to decline over time due to inflation ${ }^{12}$ and to the completion of purchase payments (with the exception, of course, of rising property taxes); the reverse is true for renters, whose housing costs are very susceptible to inflation.

As these statistics illustrate, the primary concern for renters in the US is the issue of affordability. Indeed, issues of overcrowding and poor housing quality are of less concern than in the past. For example, crowding and incomplete plumbing has declined dramatically in recent years, although renters are more likely than owners to live in structurally incomplete dwellings: nationwide, $96.1 \%$ of renter households lived in dwellings with a complete kitchen, compared with $98.4 \%$ of all households (The New Strategist 2011). Most renters (63\%) in the US live in multi-unit dwellings, while $28 \%$ live in detached one-unit structures, $6 \%$ live in attached one-unit structures, and $4 \%$ live in rented mobile homes (The New Strategist 2011). Finally, other characteristics appear to be common to renters in both the US and throughout the developing world: renters, on average, are younger than owners, ${ }^{13}$ have lower levels of educational attainment, ${ }^{14}$ and have fewer household members ${ }^{15}$ than do owners.

\footnotetext{
12 For those with a fixed rate mortgage, inflation significantly reduces the relative value of mortgage interest payments over time.

13 The New Strategist (2011) reports renter households in the US have an average age of 39, compared with 48 for all households.

$1418.9 \%$ of renters nationally do not have a high school diploma, compared with $13.6 \%$ for the population in general, while only $21.3 \%$ of renters have a BA or higher, compared with $29.8 \%$ overall (The New Strategist 2011).

$1537.7 \%$ of renters nationwide live alone, compared with $26.9 \%$ of total households (The New Strategist 2011).
} 


\section{REPORT ORGANIZATION AND METHODOLOGY}

In this report I describe the nature and extent of the colonia housing market, identify some of the determinates of varying rental rates in colonias, explore important differences between colonia renters and homeowners, and describe potential policy solutions to ensure the affordability, accessibility, and sufficient quality of colonia rental accommodation. In order to do so, I draw upon data from the six Texas counties with the largest colonia populations (shown in Figure 1.1; these include Cameron, El Paso, Hidalgo, Maverick, Starr, and Webb counties). ${ }^{16}$ Table 1.1 summarizes baseline data on colonias and colonia populations in these six counties and show that, in total, there are close to 1,700 colonias across the six counties, containing nearly 340,000 residents. Colonias are most prevalent in the Lower Rio Grande Valley (LRGV) (shown enlarged and outlined in dashes in Figure 1.1), which comprises Cameron, Hidalgo and Starr. As shown in Table 1.1, in these three counties alone there 1,250 colonias with close to 220,000 residents.

\begin{tabular}{lcc} 
County & Number of Colonias & Estimated Population in Colonias \\
\hline Cameron & 172 & 46,869 \\
El Paso & 284 & 77,169 \\
Hidalgo & 846 & 138,586 \\
Maverick & 69 & 22,320 \\
Starr & 232 & 34,458 \\
Webb & 55 & 19,916 \\
LRGV & 1,250 & 219,913 \\
Total & 1,658 & 339,318 \\
\hline Note: Data were drawn from the Texas Office of the Attorney General Colonia Internet \\
Viewer and are updated periodically. Data received on September 12th, 2012. Current data \\
are available at https://maps.oag.state.tx.us/colgeog/colgeog_online.html\#
\end{tabular}

\section{Table 1.1. Number of Colonias \& Colonia Residents by County}

\footnotetext{
16 These counties also happen to be those for which the Texas Office of the Attorney General (OAG) provides useful data on infrastructural conditions in colonias (used in Chapter 3).
} 


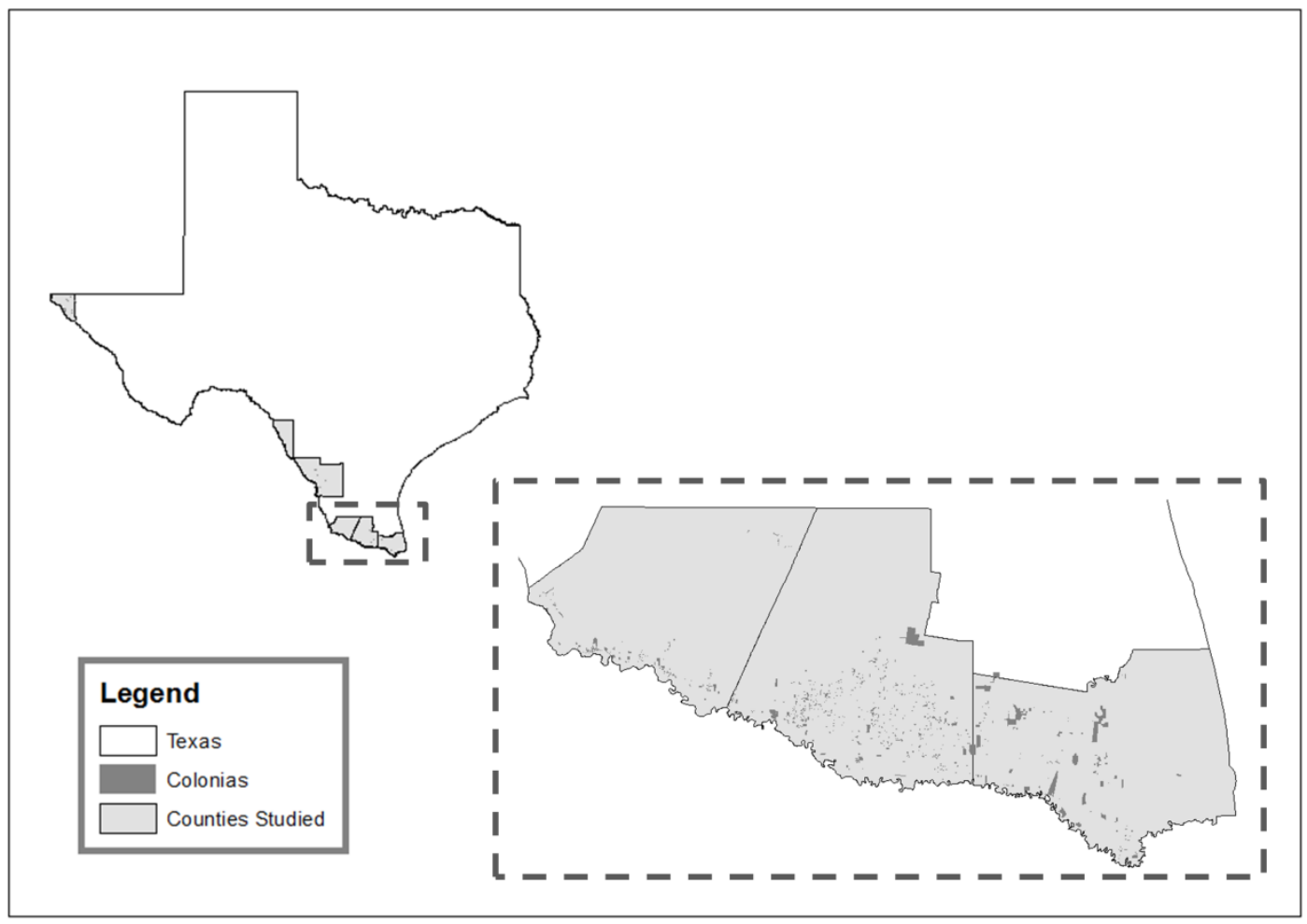

Figure 1.1. Selected Counties \& Texas Office of the Attorney General Designated Colonias

In Chapter 2 I utilize data from the US Census Bureau and the American Community Survey to identify, throughout these six counties, 176 Census Designated Places that are composed primarily of colonia subdivisions. This analysis reveals that renting in colonias has increased significantly in recent years, although rental rates vary considerably between settlements. It is found that, as of 2010, renters represent approximately one in five colonia residents and differ considerably from owners in regards to a number of important socio-economic and demographic characteristics. Chapter 3 expands upon this discussion of the colonia rental market by employing OLS regression to identify the determinants of rental rates in colonias. The results reveal that renting is more common in larger, older, and more densely populated colonias, and 
highlight that these settlements are important areas for policymakers and scholars to begin to focus attention upon renting.

Chapter 4 uses a mixed-method approach in order to deepen the discussion of renting in colonias. The results from three recent survey projects in colonias are used to measure the extent of renting in six Texas counties and to identify additional dwelling and household characteristics not available via the US Census Bureau. Key informant interviews and family case studies also provide unique insights into the dynamics of the colonia rental market, the incentives and motivations which lead property owners to pursue landlordism, and a variety of factors which make colonia renters far more vulnerable than owners. The report concludes with a discussion of the policy implications of these findings, specific policy recommendation to support affordability, access, and quality in the colonia rental market, and suggests the next steps for researchers concerned with issues of renting in colonias. 


\section{Chapter 2: Renting in Colonias: A Review of American Community Survey Census Designated Places}

\section{INTRODUCTION}

Very little research has explored the extent of renting in colonias and the characteristics of renter households. This is due primarily to the fact that scholars have historically believed that renting in colonias was rather limited (Ward 1999). Only recently, in fact, have scholars paid any attention to renting in colonias (Durst et al. 2012; Ward and Peters 2007; Ward et al. 2012), and even these did so to a very limited extent. Two such studies suggest that the proportion of renter households has grown significantly in recent years (Durst et al. 2012) and that renters-who by some estimates now constitute close to one in five colonia households - are significantly smaller, poorer, and have shorter periods of tenure than owners (Ward et al. 2012). As such, renters represent a growing population that is, on average, more vulnerable to issues of affordability and tenure security.

Preliminary and limited data on renting in informal settlements throughout eight Texas counties come from Ward et al. (2012) and suggest that the majority of renters live in single-family homes, typically owned by what I call informal-landlords who run smallscale rental operations. Indeed, few of the renters studied by Ward et al. (30\%) reported having a written rental contract, further illustrating the insecurity that accompanies renting in colonias.

Little else is known about renters in these informal settlements. This chapter seeks to add to this limited knowledge on colonia renting by examining the nature and extent of the rental housing market in colonias, and by identifying substantive differences between renter- and owner-occupied households. To do so, I draw upon data collected from the 
2000 and 2010 US Decennial Censuses and American Community Survey 2007-2011 5Year Estimates for Census Places ${ }^{17}$ within the six counties in Texas with the largest colonia populations.

\section{Methodology}

Because most colonias are fairly small (although some contain more than 1,000 occupied lots, the average colonia contains approximately 50) ${ }^{18}$ the US Census Bureau provides limited data on conditions within individual colonias. At the Census Block level, the smallest geographical area reported on by the Census Bureau, few variables of interest are available. ${ }^{19}$ It is not until the Census Designated Place (CDP) level that data on many of the demographic, socioeconomic, and physical conditions become usable for the purposes of a comprehensive review of renting and renters. Thus, CDPs are a good unit of analysis in order to examine the nature of the colonia rental market and to highlight differences between owner and renter households.

However, there are certain limitations in using data on CDPs. First, many colonias, particularly smaller ones, are not considered CDPs and thus are overlooked by an analysis that focuses solely on this geographic classification. ${ }^{20}$ Second, CDPs often comprise large geographical areas containing multiple colonias and separated by non-

\footnotetext{
17 Places are defined as consolidated cities, other incorporated areas, or Census Designated Places. The latter refers to "settled concentrations of population that are identifiable by name but are not legally incorporated under the laws of the state in which they are located" (US Census Bureau 2013). This analysis relies primarily upon data on CDPs, since most colonias remain unincorporated to date. Thus, of the 176 Places selected for study, 7 were incorporated cities while 169 were CDPs. For more information on Census Bureau definitions for CDPs and Places, see https://www.census.gov/geo/www/cob/pl metadata.html

18 This figure was calculated using data available at the Texas OAG Colonia Internet Viewer.

${ }^{19}$ In Chapter 3, I present an analysis of the determinants of the extent of renting using data from the Census Block level. For purposes of comparison with the Census Place analysis used in this Chapter, Table 2.1 presents preliminary data for these Census Blocks.

${ }^{20}$ For precisely this reason, I include in Table 2.1 an analysis of the rate of renting using data collected at the Census Block level. This data is also used for further analysis in Chapter 3.
} 
colonia subdivisions, ${ }^{21}$ complicating the analysis at hand. This is demonstrated in Figure 2.1. where, in this instance the CDP category comprises multiple colonias as well as a substantial amount of non-colonia territory. This is problematic for two reasons. First, in examples like the CDP shown in Figure 2.1, the inclusion of non-colonia territory means that it is impossible to separate out colonia and non-colonia conditions; in other words, characteristics of renters in a CDP such as this are not necessarily representative of colonia residents in particular. Second, because renting varies by factors such as settlement age, size, and population density, analysis at the CDP level obscures relevant differences in rental rates between settlements. For example, according to data from the Texas Office of the Attorney General (OAG) Colonia Internet Viewer, ${ }^{22}$ the various colonias shown in Figure 2.1 were all platted at different times (between 1974 and 1984) and are of different sizes (the largest has nearly 200 occupied lots, while the smallest has less than 50).

Because of these limitations with data at the CDP level, I also conduct preliminary analysis at the Census Block level. This analysis, although limited, ${ }^{23}$ allows for a more accurate depiction of the settlement-level conditions that are associated with varying rates of renting in colonias. As is clear in Figure 2.1, Census Blocks, in most

\footnotetext{
21 This is more of an issue in certain counties than in others. For example, in Hidalgo County, where the majority of colonias are rather small, CDPs are typically composed of a group of colonias located in close proximity but often separated by other subdivisions. For this reason, even though Hidalgo County has the largest number of colonias in the state, only four CDPs within Hidalgo County were included in this analysis. In other counties where colonias tend to be larger and more tightly spaced, this is less of a concern.

22 These data are available for viewing at https://maps.oag.state.tx.us/colgeog/colgeog_online.html\# and are updated periodically. The data used in this analysis were acquired via the Texas Office of the Attorney General on September 20, 2012.

23 At the Census Block level, data are limited to key population (number, race, ethnicity, age) and tenure variables.
} 


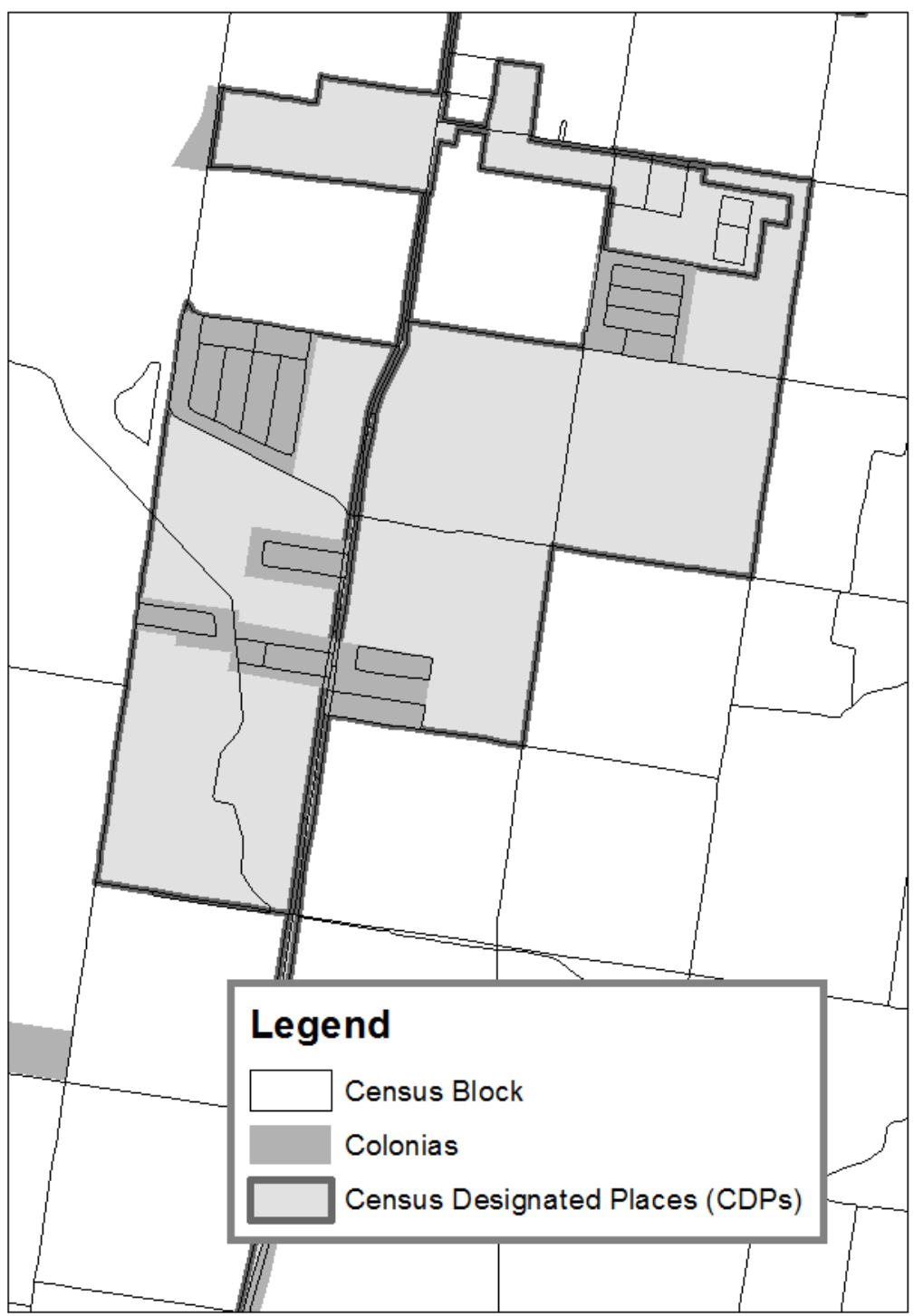

Figure 2.1. Example of a Census Designated Place Containing Multiple Colonias

instances, cover a small enough geographical area that pertains to a single colonia (or often to a section of one colonia). This smaller unit of analysis ensures that estimates of renting at the Census Block level are more reflective of actual settlement conditions. 
For the analysis presented in the current chapter, the first task was to identify which Census Places within the six study counties ${ }^{24}$ contained colonias. To do so, I used GIS software and a combination of US Census Bureau TIGER/Line shapefiles and data on colonias obtained from the Texas OAG. Using GIS software, I then identified 290 Places which comprised at least one colonia. Each of these was then evaluated using satellite imagery to ensure that the area was composed primarily of colonia residents, ${ }^{25}$ resulting in a final count of 176 Places. Analysis of rental rates (see Table 2.1) draws upon data from all 176 of these Places, and results are weighted according to the size of the settlement. ${ }^{26}$ For subsequent analyses, which draw comparisons between renter and owner households, data were drawn from a subset of CDPs which contained at least ten renter- and ten owner-occupied households, thus ensuring that a sufficient number of households were present to calculate with reasonable accuracy various demographic and socio-economic characteristics and compare them across tenure categories. ${ }^{27}$

In order to account for the limitations of data compiled at the CDP level, a similar process was undertaken using data from Census Blocks in 306 colonias. These data are used in the analysis presented in Chapter 3, and are thus discussed in greater detail later, but serve here as a useful comparison between rates of renting at the CDP and Census Block levels.

\footnotetext{
24 Again, these six are Cameron, El Paso, Hidalgo, Maverick, Starr, and Webb counties and were chosen because they contain the largest number of colonias and the largest colonia populations in Texas.

25 If approximately $90 \%$ of the housing units within the CDP also fell within the OAG's boundaries for the colonia, it was considered for analysis. Otherwise, the CDP was excluded.

${ }^{26}$ In other words, the percent renter households represents the sum of all renter households across all colonias divided by the sum of all households (renters and owners).

${ }^{27}$ In practice, the limiting factor was the number of renter households; indeed, in no cases were there more than nine renter households but fewer than ten owners.
} 


\section{The Colonia Rental Market}

\section{The Extent of Renting in Colonias}

Because of the lack of scholarship on renting in colonias, we know very little about the structure of the colonia rental market and its dynamics over the 40 years since colonias first began to proliferate in the border region. In early stages of consolidation, when many services were not yet installed and houses were often unfinished and of poor quality, colonias likely constituted unattractive markets for low-income renters. Moreover, because many colonias were originally located far outside city boundaries, ${ }^{28}$ low-income renters have historically sought accommodation closer to urban centers and, therefore, employment opportunities (Ward 1999). ${ }^{29}$

Determining the growth of renting in colonias over the past many decades is complicated primarily by a lack of data prior to $2000 .{ }^{30}$ Thus, data from the 2000 and 2010 Decennial Censuses provide the best estimate of the extent to which renting has grown in colonias over the past decade: over this time period, renting in selected Census Places $^{31}$ within the six counties studied increased from $18 \%$ to $22 \%$, an increase of $23 \%$ over ten years. Although these data represent only a subsample of the CDPs discussed

\footnotetext{
${ }^{28}$ This undoubtedly has changed significantly in recent decades as municipalities have expanded, often annexing nearby colonias. Chapter 3 provides a brief discussion of the percentage of colonias currently located within the limits of an incorporated city ( $36 \%$ of those studied).

${ }^{29}$ For many colonia homeowners, poor housing quality, limited infrastructure, and distance from employment were no less burdensome, but purchasing land in a colonia often represented the best and only opportunity to gain entry into homeownership.

30 The boundaries of Census Blocks have changed significantly since 1980, particularly in areas with rapid population growth. As a result, longitudinal comparisons of renting at the Block level draw upon different samples in different years. This complicates the analysis of changes in the rate of renting, since differences between various census years may be due primarily to differences between settlements rather than changes over time. Moreover, data on CDPs were first presented in the 2000 Decennial Census, and thus do not provide a long-term portrayal of changes in the colonia rental market.

${ }^{31}$ Fewer colonias were designated as Places for the 2000 Decennial Census. Thus, in order to ensure comparability between the estimates of renting, only those Places for which data was available for both the 2000 and 2010 Censuses (57 in total) were used for this calculation.
} 
below, they suggest that renting in colonias is not an altogether new phenomenon but that the proportion of renters has grown significantly in recent years.

Renters thus appear to represent between one in four and one in five colonia households. For the sake of comparison, Table 2.1 presents data on the rate of renting using estimates taken from analyses of CDPs and Census Blocks across the six study counties. 2007-2011 5-Year Estimates for CDPs suggest that renters make up 20\% of colonia households. These estimates square nicely with those calculated using data from Census Blocks, where $23 \%$ of households rent their dwelling.

\begin{tabular}{|c|c|c|c|c|}
\hline \multirow{3}{*}{\multicolumn{2}{|c|}{ Percent Renter Households by County }} & $\begin{array}{l}\text { lensus Designated Places: } \\
\text { 2006-2011 5-Year Estimates }\end{array}$ & \multicolumn{2}{|c|}{$\begin{array}{l}\text { (Sets of) Census Blocks } \\
2010 \text { Decennial Census }\end{array}$} \\
\hline & & Mean & \multirow[t]{2}{*}{$\mathrm{N}$} & \multirow[t]{2}{*}{ Mean } \\
\hline & & & & \\
\hline Cameron & 26 & $22 \%$ & 31 & $30 \%$ \\
\hline El Paso & 6 & $18 \%$ & 86 & $21 \%$ \\
\hline Hidalgo & 4 & $19 \%$ & 115 & $22 \%$ \\
\hline Maverick & 10 & $23 \%$ & 21 & $20 \%$ \\
\hline Starr & 95 & $15 \%$ & 41 & $17 \%$ \\
\hline Webb & 35 & $23 \%$ & 12 & $20 \%$ \\
\hline Total & 176 & $20 \%$ & 306 & $23 \%$ \\
\hline
\end{tabular}

Notes: All calculations are weighted for the size of the settlement (i.e. they use disaggregated data). All analyses refer to cases with 10 or more occupied units.

\section{Table 2.1. Rental Rates by County}

As Table 2.1 also shows, according to data at the CDP level, there is significant variation in rental rates between counties, with Maverick and Webb Counties having the highest proportion of renters (at 23\%) and Starr County having the lowest, at 15\%. Estimates drawn from the Census Block level are similar to those from CDPs (i.e. within $3 \%$ percentage points), except in Cameron County, where analysis of ACS data on CDPs suggests a level of renting of 22\%, while 2010 Decennial Census data on Census Blocks 
estimate that $30 \%$ of households are renters. Such a discrepancy is likely caused by substantive differences between the settlements contained in each sample. Because of its geographic specificity and more robust sampling, data at the Census Block level from the 2010 Decennial Census are likely more accurate of on-the-ground conditions.

The variation in the rate of renting between (and within) counties raises the question of which factors determine the rate of renting in colonias. This issue will receive further and more explicit attention in Chapter 3. A brief discussion here will serve to contextualize the findings in Table 2.1. Theoretically, older and larger colonias in areas with higher population densities should display higher rates of renter occupation. In older colonias, this is true because more original occupants with have decided to rent out all or part of their homes as changes in the household structure will have reduced the use value of the home. ${ }^{32}$ Because good data for "age" do not exist, ${ }^{33}$ I have chosen as a proxy for settlement age the percent of owner-occupied households that own their property debtfree. ${ }^{34}$ Theoretically, larger and denser colonias should also show higher levels of renting than smaller settlements, as they are more visible, boast larger micro-economies, ${ }^{35}$ and are more heavily populated, thus increasing demand for rental housing.

\footnotetext{
32 In older colonias this is true because more original occupants will have decided to rent out all or part of their homes as changes in the household structure will have reduced the use value of the home. In larger and denser colonias there is greater demand for housing as well as a larger supply of dwellings. These factors likely facilitate and incentivize the renting of homes.

33 Although the Texas OAG provides the date the plat (a formal surveyor's map) was recorded at the county clerk, this date often does not correspond with the year in which the settlement was actually developed. In many colonias, and particularly in those where informal titling practices were common, plats may not have been officially recorded until more than a decade after most residents had purchased their lots. For a further discussion of this issue in context and the problems it presents for title regularization efforts, see Ward et al. (2012).

${ }^{34}$ In older subdivisions one would expect to see higher rates of debt-free ownership, as more owners would have completed purchase payments on their property. This is particularly true in colonias, where the cost of land is cheaper, payment schedules are shorter, many residents pursue self-help and self-financing for home improvement, and most colonia homeowners live for extended periods of time on the property.

35 Many larger colonias show significant economic activity including eateries, convenience stores, mechanics shops, and various home enterprises (see Durst et al. 2012; Giusti 2010)
} 


\begin{tabular}{ccr}
\multicolumn{2}{c}{ Census Designated Places: } & \multicolumn{2}{c}{ (Sets of) Census Blocks: } \\
ACS 2006-2011 & 5-Year Estimates & 2010 Decennial Census \\
N & Mean & N
\end{tabular}

Percent Renter Households by Ownership without Debt on the Property (proxy for settlement age) *

$\begin{array}{lcccc}<70 \% \text { without debt } & 28 & 19 \% & 62 & 17 \% \\ 70-89 \% \text { without debt } & 31 & 21 \% & 100 & 21 \% \\ 70 \% \text { or more without debt } & 63 & 17 \% & 15 & 24 \%\end{array}$

Percent Renter Households by Settlement Size \& Average Settlement Size

\begin{tabular}{lcccc}
$10-149$ & 136 & $17 \%$ & 272 & $19 \%$ \\
$\begin{array}{l}\text { 150 or more } \\
\begin{array}{l}\text { Size of settlement } \\
\text { (\# of occupied units) }\end{array}\end{array}$ & 40 & $21 \%$ & 34 & $27 \%$ \\
\hline
\end{tabular}

Notes: All calculations are weighted for the size of the settlement (i.e. they use disaggregated data). All analyses refer to cases with 10 or more occupied units. *Analysis refers to only to cases with 10 or more owner-occupied units, thus ensuring accuracy in estimating the percentage owning without debt.

Table 2.2. Rental Rates by Settlement Age \& Size.

As I discussed earlier, drawing upon data from the CDP level often obscures relevant settlement-level characteristics of colonias. This is exemplified by the dramatic differences in the rates of renting calculated using data from CDPs and Census Blocks (see Table 2.2). According to data from the CDP level, there are only minimal differences in renting in colonias between settlements with varying levels of debt-free ownership: in those with low debt-free ownership $(<70 \%), 19 \%$ of households were renters; colonias with intermediate levels of debt-free ownership (70-89\%) had rental rates of $21 \%$; and those high debt-free ownership ( $>90 \%$ ) renters made up $17 \%$ of households. This pattern appears to contradict the assertion that older colonias (those with higher rates of debt-free homeownership) should have higher rates of renting. However, as I described earlier, drawing upon data at the CDP level obscures settlement characteristics such as size or age. As a result, data collected at the Census Block level provide a more precise depiction of how renting varies by colonoia age and size. For example, in colonias with low 
$(<70 \%)$ and intermediate $(70-89 \%)$ rates of debt-free ownership, renters made up 17\% and $21 \%$ of households respectively, while in colonias with rates of debt-free homeownership of more than $90 \%$, renters make up nearly one in four households $(24 \%)$.

Similarly, data from CDPs also appear to obscure differences in rental rates by settlement size. According to data collected at the CDP level, smaller colonias (those with between 10 and 149 households) had average rental rates of $17 \%$ compared with $21 \%$ for larger colonias (those with 150 households or more). At the Census Block level, the effect of colonia size on rental rates is clearer: while in smaller settlements renters made up 19\% of households, in larger settlements more than one in four households $(27 \%)$ rented their home.

\section{The Nature of the Colonia Housing Market}

We now turn to a discussion of the nature of the colonia housing market, paying particular attention to issues of dwelling type, housing conditions, and rates of vacancy. ${ }^{36}$ As shown in Table 2.3, the majority (64\%) of rented dwellings in colonias are single-unit consolidated structures, ${ }^{37}$ not wholly unlike the $80 \%$ of owner-occupied units. As I discuss in Chapter 4, most of these single-unit homes were likely originally built as the

\footnotetext{
${ }^{36}$ From this point on, all analyses in this chapter draw upon data from CDPs with a minimum of ten owner-occupied and ten renter-occupied dwellings. These cases were selected precisely for uniformity and to ensure comparability between the characteristics of owner- and renter-households. Data presented represent unweighted estimates (averages of percentages rather than actual counts). While I present weighted estimates of the rental rate, this is unnecessary for the analysis that follows. For estimates of the proportion of renters, weighting was important to avoid the disparate impact of a large number of smaller colonias: because renting is less prevalent in smaller colonias, the high number of small settlements tended to pull the final estimate lower than it would have otherwise been, although not dramatically: for the estimate of renting within Census Places, unweighted rates of renting were $18 \%$ across all counties as opposed to a weighted estimate of $20 \%$; for the analysis of Census Blocks, rates of renting were $19 \%$ (unweighted) and 23\% (weighted). For the analyses that follow, however, there is minimal concern of such skewing of the data, as it is unlikely that factors such as demographic, socioeconomic, and household characteristics would vary significantly between settlements of various sizes.

37 These may include contracted, self-built homes, or modular homes.
} 
primary home for owner-occupiers, and were later converted to rental property. This is substantially different from national rental patterns, where only $34 \%$ of renters live in single-unit dwellings (The New Strategist 2011). Other factors also suggest that renting in colonias is rather different. For example, $20 \%$ of rented units in colonias are temporary dwellings such as trailers, campers, and RVs (see Table 2.3), compared with only 4\% nationwide (The New Strategist 2011). Indeed, only 16\% of renter-occupied units in colonias are located in multi-unit structures such as duplexes or larger formal complexes, ${ }^{38}$ compared with $63 \%$ across the US (The New Strategist 2011).

\section{Owners Renters}

\begin{tabular}{lcccccc} 
& $\mathrm{N}$ & Mean & $\begin{array}{c}\text { Std. } \\
\text { Deviation }\end{array}$ & Mean & $\begin{array}{c}\text { Std. } \\
\text { Deviation }\end{array}$ & $\begin{array}{c}\text { Sig. (2-tailed) } \\
\text { paired means test }\end{array}$ \\
\hline Vacant units (\%) & $(61)$ & $1 \%$ & 0.045 & $4 \%$ & 0.106 & .045 \\
Units with 1 to 2 bedrooms (\%) & $(57)$ & $24 \%$ & 0.176 & $45 \%$ & 0.310 & .000 \\
Units with 3 or more bedrooms (\%) & $(57)$ & $75 \%$ & 0.179 & $55 \%$ & 0.314 & .000 \\
$\begin{array}{l}\text { Units that lack complete kitchen } \\
\text { facilities (\%) }\end{array}$ & $(57)$ & $1 \%$ & 0.020 & $2 \%$ & 0.043 & .246 \\
$\begin{array}{l}\text { Units that lack complete plumbing } \\
\text { facilities (\%) }\end{array}$ & $(57)$ & $1 \%$ & 0.031 & $3 \%$ & 0.103 & .419 \\
$\begin{array}{l}\text { Units with 1 unit per structure (\%) } \\
\text { Units with 2 or more units per }\end{array}$ & $(57)$ & $80 \%$ & 0.243 & $64 \%$ & 0.308 & .002 \\
$\begin{array}{l}\text { structure (\%) } \\
\begin{array}{l}\text { Units in RVs, campers, or trailers } \\
(\%)\end{array}\end{array}$ & $(57)$ & $0 \%$ & 0.008 & $16 \%$ & 0.229 & .000 \\
\hline
\end{tabular}

Notes: Data refer to Places with at least 10 owner-occupied and 10 renter-occupied units. Data are not weighted for the size of the settlement (i.e. they are aggregated at the CDP level).

Table 2.3. Structure of the Colonia Rental \& Owner Housing Markets.

Together, these data suggest that the colonia rental market is far more informal than on average in the US. The majority of owners of colonia rental property are likely to be informal-landlords who run small-scale rental operations (typically only one rental

\footnotetext{
${ }^{38}$ Formal rental complexes are referred to in Chapter 4 as purpose-built dwellings (i.e., built intentionally as rental accommodation) that contain more than 2 rental units.
} 
home). As I will discuss later, renting provides a useful means of supplementing income for owners who are unwilling to part with what is perhaps their largest asset.

There are also significant differences between owner-occupied and renteroccupied dwellings in colonias. For example, on average colonia renters live in smaller dwellings than do owners, with nearly half of all rental units (45\%) comprising one or two bedrooms, compared with only $24 \%$ of owner-occupied units (statistically significant difference at $\mathrm{p}=.000$ ). However, by simple measures of dwelling quality, there are no statistically significant differences between rented and owned units: although rented units do display slightly higher percentages of dwellings with incomplete kitchen and plumbing facilities (2\% and $3 \%)$ compared with owner occupied units $(1 \%)$, this difference is not statistically significant. Nonetheless, as rental homes deteriorate over time, these differences in housing quality are likely to increase, since renters have minimal incentive to improve the quality of their dwellings, compared to owneroccupants, many of whom rely on self-help and invariably do invest in home improvements over time (Durst and Ward forthcoming).

Interestingly, although colonias display high rates of lot vacancy (between 2030\% according to Durst et al. 2012 and Rojas et al. 2012), both renter- and owneroccupied dwellings show relatively low rates of vacancy: owner-occupied dwellings had an average rate of vacancy of $1 \%$, compared with $4 \%$ for rental units, a statistically significant difference $(\mathrm{p}=.045)$. Such low rates of vacancy are indicative of the long-term nature of colonia homeownership (many homeowners have lived in their dwelling for decades and have no intention of selling it) and the high demand for rental accommodation in these settlements. 


\section{RENTER AND OWNER HOUSEHOLDS: A COMPARISON}

\section{Tenure Patterns}

As one would expect, renter households in the colonias studied tended to display shorter periods of tenure than did owners (see Table 2.4). Most renters (70\%) had moved in since 2005 , compared with only $25 \%$ of owner households, suggesting far shorter periods of tenure than owners. Similarly, only $78 \%$ of renters had resided in the same dwelling for 12 or more months, compared with nearly all owners (97\%). Although mobility of this sort is not uncommon among renters, the reasons for changes of residence, the previous tenure status of recent movers, and the monetary and social costs of short-term periods of tenure on very low-income renters are unclear. For example, of the $22 \%$ of renters that had moved into their dwelling in the past year, the majority $(76 \%$, or $17 \%$ of all renters) had moved from within the same county. Thus, for these renters the costs associated with relocation are likely quite limited, but may nonetheless be important to consider given the low incomes of renters in general. Understanding the complexity of the tenure decisions of colonia renters is beyond the scope of this work, although the implications for access, stability, and affordability require consideration by scholars.

Owners

Renters

\begin{tabular}{|c|c|c|c|c|c|c|}
\hline & $\mathrm{N}$ & Mean & $\begin{array}{c}\text { Std. } \\
\text { Deviation }\end{array}$ & Mean & $\begin{array}{c}\text { Std. } \\
\text { Deviation }\end{array}$ & $\begin{array}{l}\text { Sig. (2-tailed) } \\
\text { paired means test }\end{array}$ \\
\hline $\begin{array}{l}\text { Moved from within county } \\
(<12 \text { months })(\%)\end{array}$ & $(61)$ & $2 \%$ & 0.030 & $17 \%$ & 0.263 & .000 \\
\hline $\begin{array}{l}\text { Moved from abroad }(<12 \\
\text { months }(\%)\end{array}$ & (61) & $0.2 \%$ & 0.007 & $0.9 \%$ & 0.048 & .262 \\
\hline $\begin{array}{l}\text { Lived in same dwelling }(>=12 \\
\text { months) }(\%)\end{array}$ & (61) & $97 \%$ & 0.039 & $78 \%$ & 0.302 & .000 \\
\hline Moved since $2005(\%)$ & (57) & $25 \%$ & 0.216 & $70 \%$ & 0.309 & .000 \\
\hline $\begin{array}{l}\text { Moved in between } 2000 \text { and } \\
2004(\%)\end{array}$ & (57) & $21 \%$ & 0.156 & $17 \%$ & 0.246 & .230 \\
\hline
\end{tabular}

Notes: Data refer to Places with at least 10 owner-occupied and 10 renter-occupied units. Data are not weighted for the size of the settlement (i.e. they are aggregated at the CDP level).

Table 2.4. Length of Tenure \& Place of Origin. 
The first step in designing comprehensive housing support programs in colonias is to understand the nature of the colonia housing market as well as the demographic and socio-economic characteristics of residents within various tenure groups.

\section{Household Structure}

As I discussed in Chapter 1, both in the US as well as in less developed countries, homeowners tend to be disproportionately older than are renters. My data suggest a similar trend in Texas colonias (see Table 2.5): while 32\% of renter heads of household were between the ages of 15 and 34, the same is true for only $11 \%$ of owners. Perhaps surprising, however, is the fact that at least one in five $(22 \%)$ renter heads of household were 60 years of age or older. Who these older renters are, the exact structure of their households, and their previous tenure history are all interesting questions worth further attention. My sense is that these elderly households are smaller, and many may live as payment-free renters in housing owned by family and friends.

Although renter households are typically smaller than owner households, interestingly this does not appear to be the case in the colonias studied. Indeed, nearly equal percentages of renter and owner households contain one or two members $(44 \%$ and $43 \%$ for owner and renter households, respectively). Renter households in fact appear to be slightly larger than owner households, with the average renter household containing 4.15 members, compared with 3.72 among owner households $(p=.013)$. These rather counterintuitive findings are most likely due to differences in the age of colonia renters and owners: because renter heads of household are nearly three times as likely than are owners to be under the age of 35 , it is perhaps not surprising that renters households are larger, as this is the age at which families are largest (most children have been born by this point though few have moved out of the home). Finally, given the larger size of 
renter households, and the smaller size of the rented dwellings (discussed earlier), it is not surprising that crowding is of more concern in renter than in owner households: $18 \%$ of renter households had more than one person per room $(16 \%$ had one to two, while $2 \%$ had more than two), compared with only $7 \%$ of owner households.

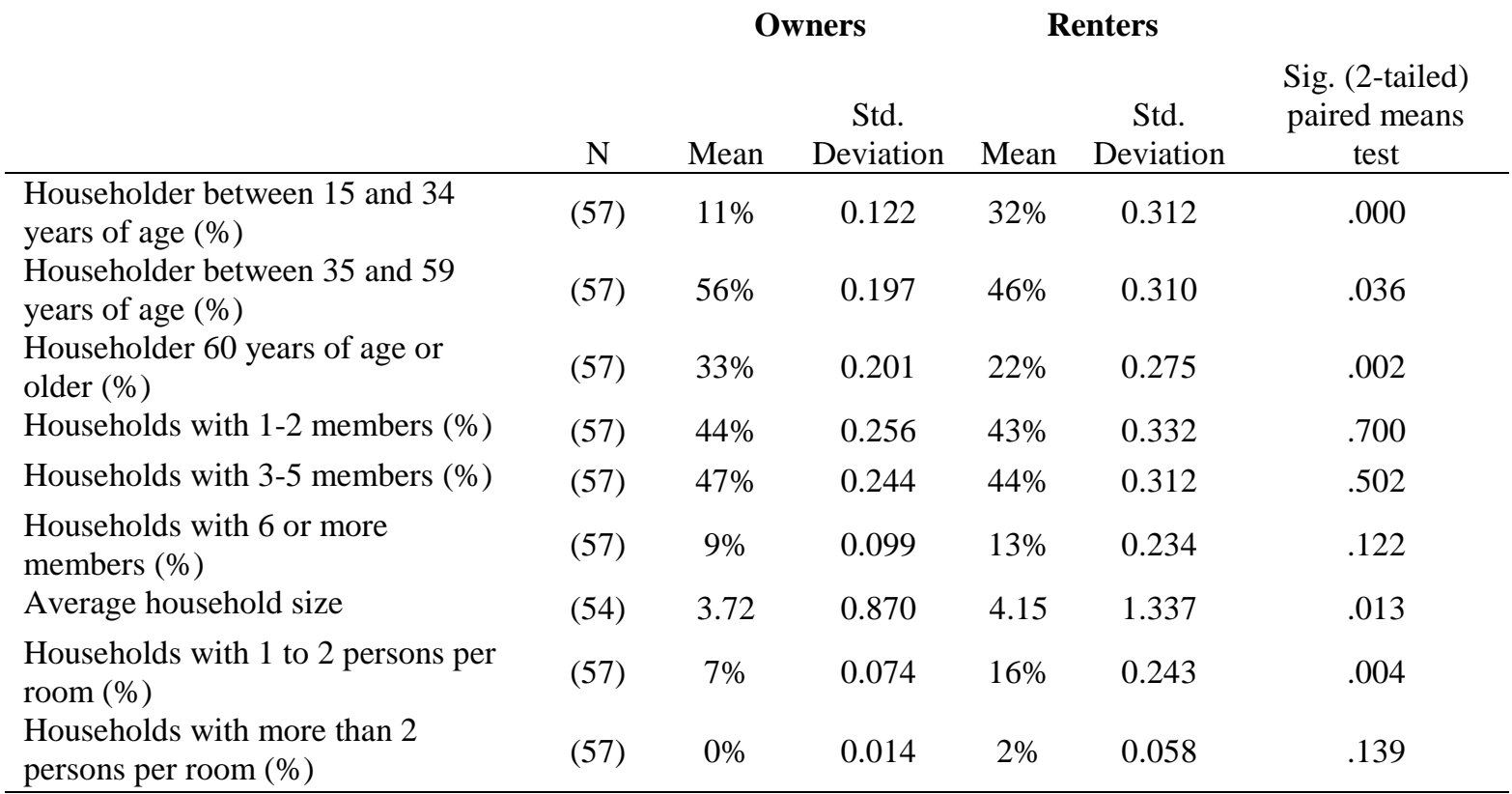

Notes: Data refer to Places with at least 10 owner-occupied and 10 renter-occupied units. Data are not weighted for the size of the settlement (i.e. they are aggregated at the CDP level).

Table 2.5. Demographic \& Housing Characteristics of Renters \& Owners

\section{Income, Poverty, and Housing Cost}

My analysis (shown in Table 2.6) suggests that renter households are, by a variety of measures, statistically significantly poorer and more financially at risk than owner households: the average median household income for renter families $(\$ 18,785)$ is twothirds that for owner households $(\$ 29,819)$, and nearly half $(49 \%)$ of renter households earn less than $\$ 20,000$, compared with one-quarter of owner households. More than twice the proportion of renter families live below the poverty line $(45 \%)$ than do owner families 
(21\%) (Table 2.6). Selective attrition certainly plays some role here, as higher-income families are more able to make the transition to ownership.

\section{Owners}

\section{Renters}

Std. Std

Deviation Mean Deviation (2-tailed)

\begin{tabular}{|c|c|c|c|c|c|c|}
\hline & $\mathrm{N}$ & Mean & Deviation & Mean & Deviation & paired means test \\
\hline $\begin{array}{l}\text { Households paying }>30 \% \text { on } \\
\text { housing }(\%)\end{array}$ & $(57)$ & $25 \%$ & 0.179 & $44 \%$ & 0.335 & .000 \\
\hline Paying no monthly rent (\%) & $(67)$ & -- & -- & $17 \%$ & 0.246 & -- \\
\hline $\begin{array}{l}\text { Households with income } \\
<\$ 20 \mathrm{k}(\%)\end{array}$ & $(57)$ & $25 \%$ & 0.204 & $49 \%$ & 0.328 & .000 \\
\hline $\begin{array}{l}\text { Median household income } \\
\text { during the past } 12 \text { months }\end{array}$ & $(35)$ & $\$ 29,819$ & 10,337 & $\$ 18,785$ & 10,765 & .000 \\
\hline Families below poverty (\%) & $(53)$ & $21 \%$ & 0.196 & $45 \%$ & 0.347 & .000 \\
\hline $\begin{array}{l}\text { Families comprising single } \\
\text { mother heads }(\%)\end{array}$ & $(53)$ & $18 \%$ & 0.153 & $29 \%$ & 0.277 & .012 \\
\hline $\begin{array}{l}\text { Single mother families below } \\
\text { poverty }(\%)\end{array}$ & (34) & $33 \%$ & 0.276 & $61 \%$ & 0.324 & .001 \\
\hline $\begin{array}{l}\text { Heads of household with no } \\
\text { high school diploma }(\%)\end{array}$ & $(57)$ & $37 \%$ & 0.277 & $37 \%$ & 0.347 & .966 \\
\hline $\begin{array}{l}\text { Heads of household with a } \\
\text { BA or higher }(\%)\end{array}$ & $(57)$ & $12 \%$ & 0.178 & $9 \%$ & 0.141 & .129 \\
\hline
\end{tabular}

Notes: Data refer to Places with at least 10 owner occupied and 10 renter occupied units. Data are not weighted for the size of the settlement (i.e. they are aggregated at the CDP level).

Table 2.6. Income, Poverty, \& Housing Cost by Tenure.

Due largely to their lower incomes, renters also allocate significantly more of their income toward housing costs (Table 2.6): $44 \%$ of renters spend more than $30 \%$ of their income on housing, compared with only $25 \%$ of owners. ${ }^{39}$ Interestingly, $17 \%$ of renter households paid no monthly rent at all, a similar estimate to that provided by Ward

39 This is actually slightly better than the estimates nationwide, where $45 \%$ of renters and $30 \%$ of owners spend more than $30 \%$ of their income on housing (Schwartz 2010). It is important to note, however, that this in an imperfect measure of housing expenditures in colonias. First, because many colonia homeowners purchased land that lacked basic infrastructure and utility connections, the initial cost and terms of the purchase agreement were lower and shorter. Thus, due to the extended periods of tenure characteristic of colonia homeowners, many homeowners likely finished making purchase payments many years ago, thus reducing their monthly housing costs. Second, many colonia homeowners pursue self-help construction, or at the very least self management of the home. These costs, though intermittent, are nonetheless significant (see Durst et al. 2012), but are likely overlooked by the ACS estimates. Thus, it speaks to the financial vulnerability colonia homeowners as well that such a high percentage of owner households $(25 \%)$ spend more than $30 \%$ of their income on housing, measurement problems notwithstanding. 
et al. (2012) - and nearly three times the rate nationwide (5.8\%; The New Strategist 2011). This high rate of payment-free renting suggests that many colonia renters gain access to housing via family and friend networks.

Finally, while there were no statistically significant differences in the educational attainment of renter and owner heads of households (37\% of both renter and owner heads had not completed high school, and only $9 \%$ and $12 \%$, respectively, receive a B.A. or higher), colonia heads of household were far less educated than the national average. ${ }^{40}$

Adding to their vulnerability is the fact that renter families are more likely to be single mother households: $29 \%$ of renter families were headed by a single mother, compared with only $18 \%$ of owner families. Moreover, renter families with single mother heads of household were nearly twice as likely to live below the poverty line $(61 \%)$ than were owner families headed by single mothers (33\%). These differing levels of vulnerability among renter and owner households suggest that housing assistance that focuses primarily on colonia owners may risk missing some of the poorest and most needy colonia residents.

\section{CONCLUSION}

As my analysis has shown, renting is fairly common in colonias and has grown significantly in recent years. Most renters currently live in detached, one-unit structures, although a significant portion also lives in rented trailers. Interestingly, rental rates appear to vary significantly by county. In particular, larger and older settlements appear to have higher rates of renting, though more robust statistical analysis at the Census Block level is needed to confirm this conclusion (see Chapter 3).

\footnotetext{
40 As mentioned earlier, according to estimates provided by The New Strategist (2011) $13.6 \%$ of the general population do not have a high school diploma and $29.8 \%$ have a B.A. or higher.
} 
In general, renters are younger, poorer, and more likely to be single women. On average they have lived in their current dwelling for far shorter periods of time than have owners. Finally, despite minimal differences in household size, renter households show higher rates of overcrowding because they are more likely to live in smaller dwellings. These conclusions raise additional question concerning the determinants of the housing market, the future housing plans and needs of renters, and potential policy solutions to address these needs, all of which I take up in the following chapters. 


\section{Chapter 3: The Determinants of Rental Rates in Texas Colonias}

\section{INTRODUCTION}

In the previous chapter I offered a description of the size and nature of the rental market in colonias, and the characteristics of renter households. We now turn to a discussion of the factors that are associated with high levels of renting in colonias, an important first step in understanding changing tenure patterns in what are predominantly homeowner communities. In particular, identifying relevant characteristics of colonias with high rental rates may help policymakers and housing practitioners (non-profits and government programs) to better target their efforts in the areas where renting is most common and where demand for rental accommodation is likely to be highest.

By drawing upon 2010 Decennial Census data and information on settlement conditions provided by the Texas Office of the Attorney General (OAG), this chapter uses an OLS regression model to estimate the effects of a variety of factors on rental rates in colonias. In particular, this model explores the effects of proximity to incorporated cities, population density in the surrounding area, the quality of infrastructure within the settlement, as well as the size and age of the colonia. As we will observe, the results suggest that renting is more prevalent in older, larger, and denser areas with better infrastructure. Interestingly, distance from nearby cities appears to have no statistically significant effect on the proportion of renters, although measurement error may be a concern in this regard.

Indeed, making predictions about the proportion of renters in colonias is complicated by a combination of factors, and not simply that of measurement error. Thus, although the model presented herein provides some conclusions and is, as a whole, statistically significant, additional data on settlement conditions, land values and taxes, 
and the urban structure of colonias and their surrounding areas are required in order to strengthen the utility of the model.

\section{THEORY}

Much of the econometrics literature on tenure approaches the issue at the level of the individual household (known as tenure choice models). Raya and Garcia (2012) provide a comprehensive review of the existing literature on such models. The authors separate these models into those that use as the dependent variable tenure itself and those that use the transition from renting to ownership (Raya and Garcia 2012). Models of this sort suggest that various factors - such as marital status, gender, age, income, education, household size, the cost of owning relative to renting, and the accessibility of land-are correlated with tenure choice (Ahmad 1994; Arimah 1996; Daniere 1992; King 1980; Raya and Garcia 2012; Rosen 1979).

Despite the popularity of tenure choice models, as Englund et al. (2005) argue, drawing a clear line between types of tenure is difficult and often involves significant tradeoffs in terms of simplicity and accuracy: tenants may rent only the land or both the land and the structure; lease agreements and usage rights vary, as does the use of written contracts; renting from various landlords (e.g. from relatives, a private operation, or from the government) can differ dramatically; periods of tenure can vary widely; and tenants' rights and recourses differ as well (Englund et al. 2005).

Much has been written about tenure choice at the household level, but fewer authors have explored the factors (cultural, political, and economic) that are associated with differences in the level of renting across cities and between countries. Some notable conclusions from this literature are: that demography and family structure, the availability of financing, government spending as a percentage of GDP, and inflation all have a 
statistically significant impact on homeownership rates (Angel 2000); that income, percapita GDP, and differences in legal structure are correlated with varying rates of homeownership (Fisher and Jaffe 2003); and that the relative cost of owning versus renting is positively correlated with the proportion or renters (Lerbs and Oberst 2012).

In colonias, as elsewhere, a variety of factors influence the size of the rental market. On the demand side, renting may be preferable to owning, particularly if the cost of purchase is excessively high or if the family prefers flexibility and mobility to security and stability. Many of these variables are unavailable for the current analysis. Instead, I rely upon measures of settlement size, age, and level of infrastructure, as well as population density in the surrounding area and proximity to urban areas in order estimate the rate of renting. In particular, larger, denser, and more proximate (to nearby city) colonias are likely to have higher rates of renting. This is primarily because these communities are more visible, more accessible to areas of employment, ${ }^{41}$ and boast larger micro-economies, ${ }^{42}$ which increases demand for rental accommodation. Finally, settlements with insufficient infrastructure are likely to be unattractive to renters, who have more flexibility to relocate than owners if settlement conditions are unsatisfactory or deteriorate. Thus, in colonias with inadequate water and wastewater services, demand for rental housing is likely to be limited.

On the supply side, a variety of factors result in increased incentives for owners to turn toward informal landlordism. In colonias, most owners display extended periods of tenure, often living on their property for 20 or more years. Thus, in newer settlements rental rates are likely to be fairly low. However, as the original owner-occupants age, the

\footnotetext{
41 See Ward (1999).

42 See Durst et al. (2012); Giusti (2010).
} 
changing family structure leads to greater incentive to pursue other uses of the home; given the inefficiency of the colonia housing market(discussed later), informal and petty landlordism is one of the most viable options.

\section{FORMAL HYPOTHESES}

In this chapter I estimate regression models to account for selection bias as well as potential confounding factors. Selection bias is a particular concern given that data on infrastructure conditions in colonias were available for only 264 of the 306 settlements studied, and it seemed plausible that the 42 settlements for which no data were available might be categorically different than the remaining 264 . In order to test this assumption, I first conducted a logistic regression to determine if the 42 colonias that lacked data on infrastructure conditions were statistically significantly different in regards to the dependent and independent variables. The results, shown in Table 6.1 in the methodological appendix, suggest that more remote colonias were less likely to be missing data on infrastructure conditions..$^{43}$ No other statistically significant differences were found. In order to account for any potential effect that such missing data might have had on the effect of distance on rental rates, I first estimated an OLS model using all 306 cases (i.e., I excluded the variable measuring infrastructure conditions). This model is detailed in Equation 1.

$$
\% \text { Renters }_{i}=\beta_{1}+\beta_{2} \text { Size }_{i}+\beta_{3} \text { Age }_{i}+\beta_{4} \text { Density }_{i}+\beta_{5} \text { Distance }_{i}
$$

The proportion of renter households in a given settlement (expressed as an integer, i) is represented by \%Renters. A variety of relevant explanatory variables are included in the model. First, $S_{i z} e_{i}$ represents the size of each settlement, i, as measured by

\footnotetext{
43 This is a somewhat counterintuitive finding, since one might expect more proximate colonias to be the most accessible and therefore the easiest in which to identify and record colonia infrastructure conditions.
} 
the number of occupied units. $A g e_{i}$ represents a proxy for the relative age of each settlement, i, as measured by the percentage of owners who own their property debt-free. Also included in the model is the population density (in 1,000s of people per square kilometer) in the surrounding area, represented by Density. Finally, I have also included a measure of the distance (in kilometers) from each colonia, i, to the nearest incorporated city, as represented by Distance $_{i}$

Once specified, I set out to assess the potential impact of confounding factors such as settlement conditions. To do so, I estimated the same OLS regression model but included a measurement of the adequacy of the infrastructure in each colonia. This revised model is shown in Equation 2.

$$
\% \text { Renters }_{i}=\beta_{1}+\beta_{2} \text { Size }_{i}+\beta_{3} \text { Age }_{i}+\beta_{4} \text { Density }_{i}+\beta_{5} \text { Distance }_{i}+
$$

\section{$\beta_{5}$ AdequateInfrastructure $_{i}$}

In the amended model, AdequateInfrastructure ${ }_{i}$ represents a dummy variable identifying each colonia, $\mathrm{i}$, which contains adequate water and wastewater services.

Two additional models are presented in the appendix. These include a model that attempts to account for measurement error in the calculation of the distance between each colonia and the nearest incorporated city. This model is shown in Equation 3. In this model, distance is represented by a dummy variable, WithinCity, which identifies whether each colonia, $\mathrm{i}$, is located within the limits of an incorporated city.

$$
\% \text { Renters }_{i}=\beta_{1}+\beta_{2} \text { Size }_{i}+\beta_{3} \text { Age }_{i}+\beta_{4} \text { Density }_{i}+\beta_{5} \text { WithinCity }_{i}
$$

Finally, I estimated a regression model to account for the truncated distribution of the dependent variable, the proportion of renters. Shown in Equation 4, this model is identical to Equation 1 except that it accounts for the unobserved (truncated) values of Renters $_{i}$ which fall below zero. In Equation 4, Renters $_{i} *$ is an unobservable variable with 
continuous values above and below zero. Thus, Renters $_{i}$ is equal to zero when Renters $_{i}{ }^{*}$ is less than zero $\left(\right.$ Renters $_{i}=0$ if Renters $\left._{i}{ }^{*}<0\right)$, and is equal to Renters $_{i}{ }^{*}$ when Renters $_{i}{ }^{*}$ is greater than or equal to zero $\left(\right.$ Renters $_{i}=\operatorname{Renters}_{i} *$ if Renters $\left._{i}{ }^{*}>=0\right)$.

$$
\text { Renters }_{i}^{*}=\beta_{1}+\beta_{2} \text { Size }_{i}+\beta_{3} \text { Age }_{i}+\beta_{4} \text { Density }_{i}+\beta_{5} \text { Distance }_{i}
$$

\section{MeTHODS AND DESCRIPTION OF DATA}

In Chapter 2 I relied upon data from Census Designated Places (CDPs) to examine differences between renter and owner households in more than 100 colonias throughout six Texas border counties. However, because CDPs often comprise a conglomeration of separate colonias, each with its own unique date of establishment, evaluating renting at the CDP level obscures relevant differences in settlement age. Moreover, as noted previously, true settlement size is also obscured at the Census Place level, given that certain apparently large settlements are in fact often simply groups of smaller colonias. ${ }^{44}$ Thus, this chapter draws upon data from the Census Block level in order to both provide a larger sample size and to ensure that data (such as age and settlement size) are as accurate as possible. ${ }^{45}$

The analysis presented in this chapter draws upon TIGER/line and Census data files at the Block level from the 2010 Decennial Census. Using GIS software and a shapefile containing the location and boundary of Texas' colonias created by the Texas Office of the Attorney General, ${ }^{46}$ I identified 1371 Census Blocks located within the

\footnotetext{
44 This conclusion was reached after analysis of satellite imagery of each Census Place.

45 It is important to note, however, that by focusing on the Census Block level, this analysis overlooks potentially significant socioeconomic and demographic data. A more detailed analysis could estimate a regression model predicting the extent of renting using data at the Census Place level. Such an analysis is beyond the scope of this project, but may provide interesting data on a variety of other factors which influence the rate of renting in colonias.

46 These data are available for viewing at https://maps.oag.state.tx.us/colgeog/colgeog online.html\# and are updated periodically. The data used in this analysis were acquired via the Texas Office of the Attorney General on September 20, 2012.
} 
boundaries of one of the OAG specificied colonias. Data from contiguous Census Blocks (i.e., those within the same colonia) were then combined (or "dissolved" in GIS parlance), and any set containing fewer than 10 occupied units was eliminated to prevent excessively skewing the rental rate. ${ }^{47}$ These files were then merged with a number of variables describing settlement conditions (such as infrastructure conditions, year of platting, etc.) acquired from the Texas OAG.

\begin{tabular}{lccccc}
\multicolumn{1}{c}{ Variable } & Obs & Mean & Std. Dev. & Min & Max \\
\hline \% Renter Households & 306 & 18.537 & 13.187 & 0 & 100 \\
Total Occupied Units & 306 & 76.503 & 135.754 & 10 & 1600 \\
\% Debt-free & 306 & 70.861 & 20.679 & 0 & 100 \\
Population per Square Kilometer (1000s) & 306 & 0.698 & 0.473 & 0.022 & 2.325 \\
Distance from Nearest City (Kilometers)* & 306 & 1.720 & 5.193 & 0 & 49.159 \\
Sufficient Infrastructure** & 264 & 0.799 & 0.401 & 0 & 1 \\
Within Incorporated City** & 306 & 0.356 & 0.480 & 0 & 1 \\
\hline
\end{tabular}

Notes: Unless otherwise specified, data and calculations draw upon estimates from the 2010 Decennial Census. *Estimates calculated using GIS software, TIGER/line shapefiles, and data on colonia settlements from the Texas Office of the Attorney General (OAG) Colonia Internet Viewer. **Data drawn from Texas OAG Colonia Internet Viewer.

Table 3.1. Descriptive Statistics for Regression Variables.

I first conducted preliminary descriptive analysis of the data. The results of this analysis are presented in Table 3.1. The dependent variable-the percent of all households that are renters (as an integer) - suggests that the average colonia studied has a rental rate of approximately $19 \%$. This is slightly lower than the $23 \%$ reported in Chapter 2, and the difference is due to the fact that the present estimate is a calculation of aggregate average rental rates (i.e., the average of the proportion of renters for each individual colonia), while the analysis in Chapter 2 presents disaggregated calculations

\footnotetext{
${ }^{47}$ In sets of Census Blocks with fewer than ten units, one additional renter household results in more than a $10 \%$ increase of the rental rate. Such a disproportionate effect on the rental rate would create excessive noise in the predicted values of the regression model.
} 
(i.e., the proportion of all households from all colonias that are renters). The reduced estimate of renting presented in Table 3.1 is due to the predominance of smaller colonias, which on average, have significantly lower rates of renting (see Table 2.1).

Further analysis of the dependent variable reveals that although normally distributed, it is nonetheless truncated at 0 (see Figure 3.1). In other words, unlike the two-tailed bell curve characteristic of a normal distribution, the distribution of the dependent variable ends abruptly at 0 , since no settlement can have lower than $0 \%$ renting. ${ }^{48}$ Distributions of this sort lead to violations of some assumptions of OLS regression models. For this reason, I employ both an OLS and truncated regression model to estimate the determinants for percent renting in colonias.

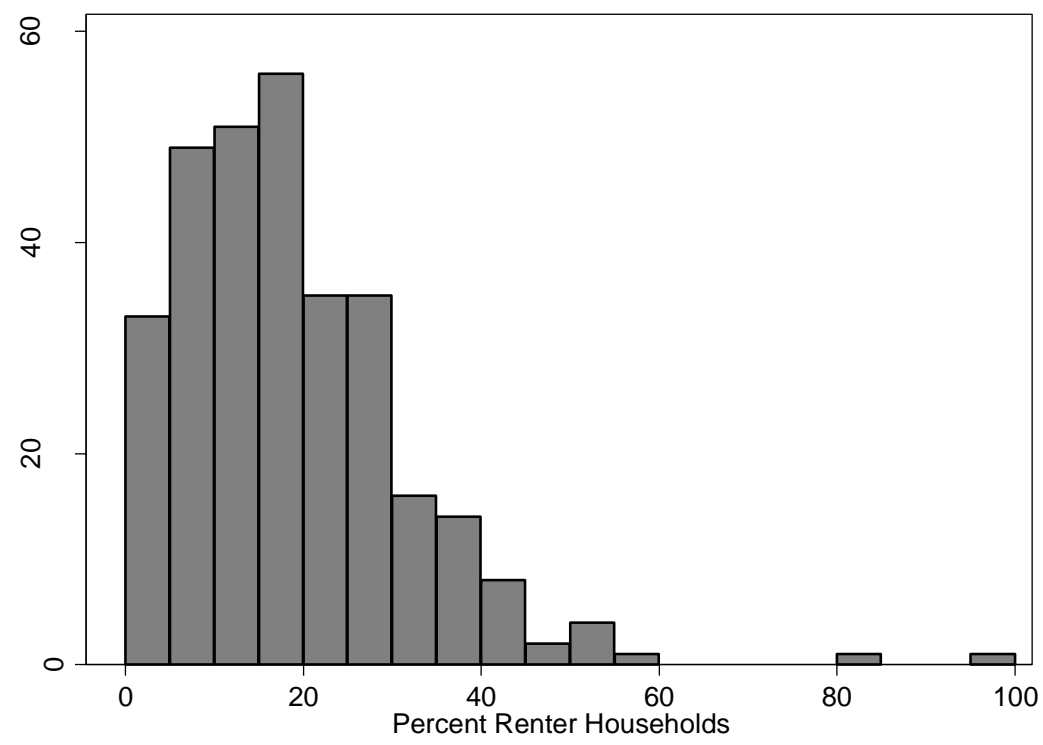

Figure 3.1. Sample Distribution of Percent Renter Households (Dependent Variable)

\footnotetext{
48 It is possible that this truncated distribution resulted from the fact that certain settlements contained only ten occupied units. To test this possibility, I also examined the sample distribution for settlements with 20 or more and 40 or more occupied units. The results, presented in the methodological appendix (Tables 6.3 and 6.4) suggest otherwise, revealing that the sample distribution is truncated even across larger settlements.
} 
As Figure 3.1 clearly shows, the percent renting varies significantly across settlements: while the modal rate of renting appears to fall between 15 and $20 \%$ (note that this "bin" of the histogram shown in Figure 3.1 has the most observations), some colonias have no renters while in others renters make up more than $50 \%$ of residents. ${ }^{49}$ As I have already discussed, this is partially due to the fact that smaller colonias tend to display lower rates of renting than larger settlements. In order to clarify this point, details on the size of each settlement are also provided in Table 3.1. What is immediately apparent upon a review of the data is that there appear to be significant outliers that may skew regression coefficients, or at the very least reduce their efficiency. For example, the average colonia in the sample contains 76.5 occupied units, suggesting that the vast majority of the settlements studied are indeed rather small. However, two settlements in particular (both in Cameron County) have more than ten times the average number of units (Cameron Park ${ }^{50}$ has 1600 units, and Rutherford-Harding has 816 units). ${ }^{51}$ Certainly, for the sample of colonias studied, and for colonias in general, these two large settlements are the exception and not the rule, and they have therefore been removed from the model.

The second explanatory variable used in the model is the percent of owners who have no outstanding debt against their property, which as I proposed in Chapter 2, I

\footnotetext{
49 These very high levels of renting are indeed surprising. This may be partially due to the fact that in a small settlement (e.g. one with ten households in total) a small increase in the number of renters can dramatically inflate the rental rate. In order to test this possibility, I reran the histogram presented in Figure 3.1 using only settlements with 20 or more units (Figure 6.3) and 40 or more units (Figure 6.4). Surprisingly, even in large colonias there are a number of settlements with elevated rates of renting. These settlements would make interesting cases for more in-depth qualitative study that is beyond the scope of this report.

50 Ward (1999) notes that even more than a decade ago, Cameron Park boasted a significant rental market (approximately $40 \%$ of households rent or share their lot).

${ }^{51}$ See the methodological appendix (Table 6.2) for more information on such outlying cases.
} 
include as a proxy for the relative age of the settlement. ${ }^{52}$ In general, the selected colonias studied show high rates of debt-free ownership, with the average proportion of debt-free owners at $70 \%$ across all colonias. This is to be expected, since few colonia residents acquire mortgages, instead purchasing vacant land financed from the developer using Contract for Deed (CfD) agreements in which the buyer agrees to make low monthly payments until the purchase price is paid in full, at which point the contract is converted to a Deed. Unlike mortgages, which typically have repayment schedules of 15 to 30 years, colonia residents often complete their purchase payments within the first decade, and sometimes much sooner. Moreover, because of the heavy reliance on self-help in colonias, the housing consolidation process can often take decades, and as a result, the use of collateralized lending in colonias is relatively low, since housing costs are typically paid for out-of-pocket and intermittently as resources permit (see Durst et al.). Thus, in older colonias we would expect to see higher rates of debt-free ownership, since most colonia homeowners will have will have long since completed their purchase payments, and few will have taken out liens against the property to pay for home improvements.

Population density, as represented by the number of people (in thousands) per square kilometer in a 500-meter radius around the perimeter of each settlement, shows significant variation between settlements. On average, there were 698 people per square

\footnotetext{
52 Although the OAG data on each colonia includes a plat date (the year in which a formal map displaying the lot subdivisions was recorded at the county clerk's office), two factors make this variable of limited reliability. First, some colonias remain unplatted (of the 306 colonias studied, only 250 had a date for the year in which the plat was recorded). For others the official plat was not recorded at the clerk's office until many years after the settlement was first developed. Finally, it is not unreasonable to assume that a colonia may be platted many years before it is in fact developed. Each of these issues makes for significant inconsistency between the plat date and the settlements' functional age. Figure 6.1 in the methodological appendix provides a scatter plot comparing the relationship between the proportion of renter households and these two variables. A clearer upward trend is visible in the scatter plot comparing the percentage of renter households and the percentage of debt-free owners (left plot).
} 
kilometer in the general proximity of each colonia. In more isolated settlements and in smaller settlements, population density in the surrounding area fell to as little as 22 people per square kilometer, ${ }^{53}$ while in more densely populated areas there were more than 2,000 people per square kilometer.

I now turn to the issue of distance from each colonia to the nearest incorporated city. As shown in Table 3.1, there is significant variation between settlements in terms of their proximity to neighboring cities: although the average distance from the nearest incorporated city is 1.7 kilometers, certain settlements are as far as 50 kilometers. Because such outlying cases differ so dramatically from the mean, they have the potential to significantly skew the regression results. More importantly, perhaps, is their substantive relevance within the model. Since the purpose of the distance variable is to measure the effect of relative distance from urban areas, and in particular, places of work and general consumption, 50 kilometers is an excessively large and potentially misleading interval. In other words, while it is reasonable to assume that residents located five to ten kilometers from the city may drive to and from these urban centers for either work or to run errands, the same cannot necessarily be said about those located 50 kilometers from the nearest city. For this reason, I tested the impact of these larger values on the sign and significance of the coefficient by removing cases that were greater than 10 kilometers from the nearest incorporated city and rerunning the model. No substantive or statistical differences were apparent between the two models, so these distant colonias were retained in the working model.

\footnotetext{
53 This is indeed a small and very isolated settlement and is unlikely to be representative of colonias in general. However, this case was not removed from the model given that outlier analysis revealed that it did not have a substantial impact on the results of the model
} 
Also presented in Table 3.1 is a categorical variable that identifies those colonias with sufficient infrastructure and utility services and therefore minimal health risk, as assessed by The Colonias Initiative Program at the Office of the Texas Secretary of State (2010). ${ }^{54}$ In this instance, a value of one (1) signifies that the colonia has adequate basic infrastructure (essentially, water and wastewater services, either public or private). Data on infrastructure quality and health-related risk was available for only 264 of the 306 colonias that make up the focus of this chapter. As shown in Table 3.1, of these 264 colonias, $80 \%$ (211) were classified as having basic water and wastewater services. Due to missing data for 42 of these cases, this variable is excluded from the working model (see Table 3.2) and is added instead to the amended model discussed later (see Table 6.5 in the methodological appendix).

Other factors may play a role in promoting or impeding the spread of renting in colonias. For example, location within an incorporated city may provide residents with an incentive to turn toward renting and landlordism. For tenants, higher property values will mean that homeownership is less affordable, thus leading to increased demand for rental accommodation; for landlords, higher demand will result in increasing incentives for the leasing of property. As Table 3.1 shows, of the 306 colonias studied, 36\% (109) were located within the city limits.

\footnotetext{
54 The Texas Secretary of State sorts colonias into three color-coded categories of health risk depending upon the quality and presence of physical infrastructure, utility services, and potential health and environmental safety risks. "Red" colonias are those with the most severe infrastructural deficiencies, which include problems such as the lack of potable water or wastewater disposal. Colonias that have adequate water and wastewater services (both public or private) but lack paved roads, storm drainage, or solid waste disposal services are classified as "Yellow." Finally, those with all of these services are classified as "Green" (Office of the Texas Secretary of State 2010). For the purposes of this study, I have combined the yellow and green categories because both have adequate services to support a functioning rental market (i.e., the lack of pavement, storm drainage, or trash collection may be a undesirable for some renters, but is unlikely to present a significant enough deterrent to drastically reduce demand for rental housing in these areas).
} 


\section{RESULTS}

After removing seven outlying cases (see Table 6.2 in the methodological appendix), I ran an OLS regression model with the remaining 299 cases. ${ }^{55}$ The results are shown in Table 3.2. ${ }^{56}$ The initial regression results reveal that the model explains $12 \%$ of the variation in the rate of renting across colonias $\left(\mathrm{R}^{2}=11.6\right)$, suggesting that in general the model is a poor predictor of rental rates in individual settlements, ${ }^{57}$ although the model is statistically significant as a whole $(\mathrm{F}=11.6)$.

As shown in Table 3.2, a 1\% increase in the proportion of owners who live debtfree results in a $.14 \%$ rise in the proportion of renters in a given community $(\mathrm{p}<.01)$. This statistically significant result suggests that, to the extent that debt-free ownership is an appropriate proxy for colonia age, older subdivisions (i.e. those with higher rates of debtfree ownership) are more likely to have higher rates of renting than newer subdivisions.

The coefficient for distance (measured in kilometers) from the nearest incorporated city provides little substantive insight into the size of the rental market in colonias. Indeed, the coefficient is positive, suggesting that for each additional kilometer that separates a colonia from its nearest neighboring city, the proportion of renter households increases by $.025 \%(\mathrm{p}=.75)$. This is a statistically insignificant difference. ${ }^{58}$

\footnotetext{
55 The model has been adjusted to account for heterogeneity of the variance of the residuals by using the robust option in STATA.

${ }^{56}$ For dependent variables with a truncated distribution, truncated regression provides more robust and reliable estimates. This appears to be the case for the working model presented earlier, given the statistical significance of sigma in the truncated regression model (see Table 6.3 in the methodological appendix).Truncated regression is limited, however, in that the results do not provide a measure of the proportion of variance explained by the model $\left(\mathrm{R}^{2}\right)$ and are generally less well known than OLS models. Thus, for clarity, I discuss the OLS model in detail. However, in terms of their statistical significance as well as their effect on the proportion of renters (positive versus negative), the results of the OLS regression model are similar to those acquired using truncated regression.

57 The limited explanatory power of the model is likely due to the exclusion of a variety of unobservable characteristics of the selected colonias. These are discussed in greater detail in the following section.

${ }^{58}$ Many (36\%) of the colonias studied are located within the limits of incorporated cities, giving them a value of 0 for this distance variable. As shown in Figure 6.2 in the methodological appendix, this creates
} 


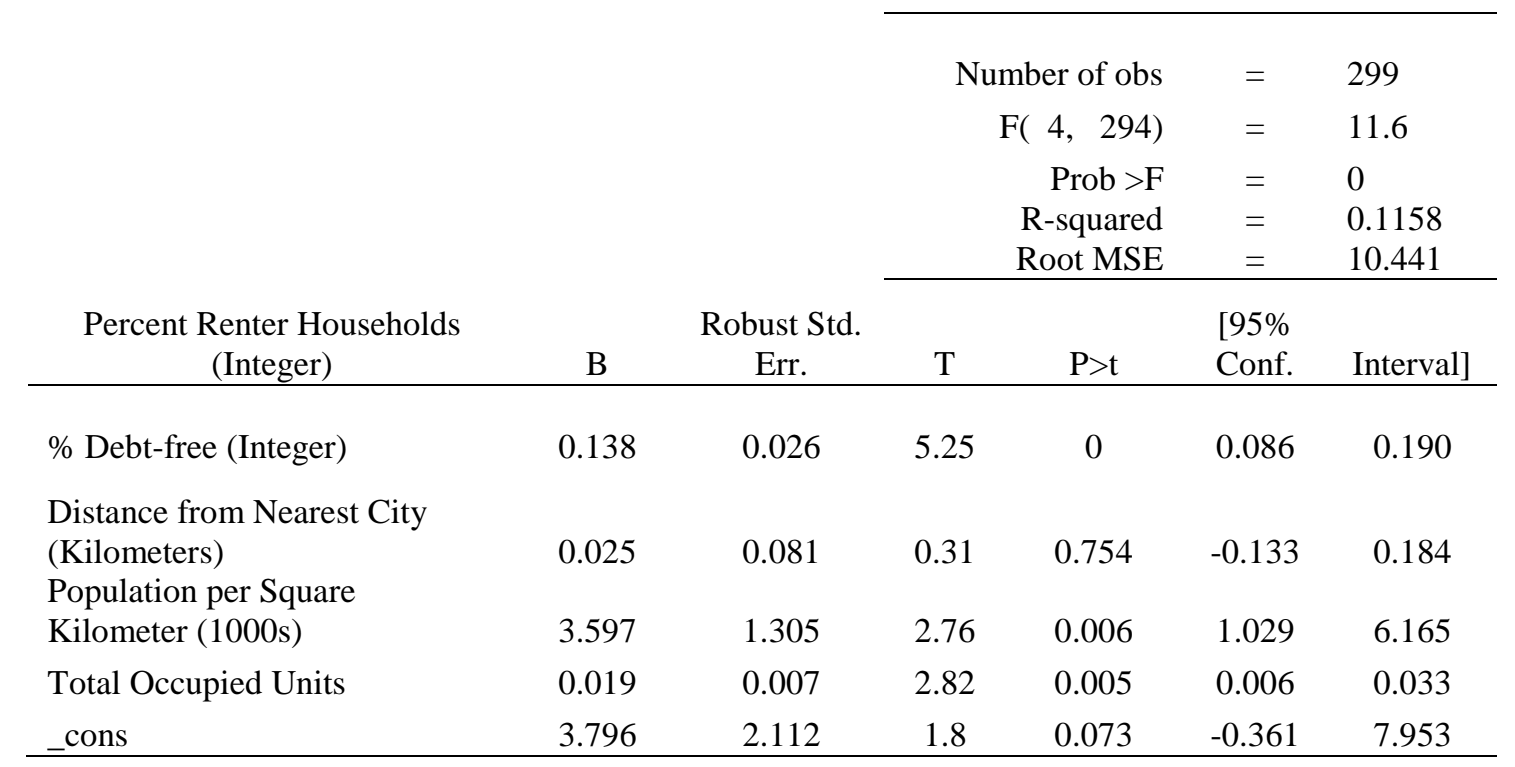

\section{Table 3.2. Original OLS Regression Model with Outliers Removed}

In terms of population density in the surrounding area, ${ }^{59}$ the model provides stronger results. For each additional 1,000 residents per square kilometer, the proportion of renters increases by $3.6 \%(\mathrm{p}<.01)$. This suggests that renting is indeed more prevalent in more densely populated areas, where the demand for housing is higher.

Just as is the case with population density in the surrounding area, colonia size is positively associated with the size of the rental market: for each additional occupied unit in a settlement, the proportion of renters is expected to rise by $.019 \%(\mathrm{p}<.01)$, holding other factors constant. Ostensibly, this appears to be a rather small increase, but at the

significant interference in estimating distance's impact on the percent renting, given the high number of identical values. In this instance, although distance may have a non-linear relationship with the percent renting (likely logarithmic, in fact, with the effect on percent renting decreasing exponentially as distance increases), transformation of the variable is difficult given the high number of zero values. To eliminate this potential non-linearity, I calculated a similar regression model that excluded colonias which were located within the limits of an incorporated city. The results of this model are similar to those of the working model (see Table 6.4 in the methodological appendix).

${ }^{59}$ In other words, within a 500 meter radius around the settlement - arguably a better measure of an urban area than distance from the nearest city. 
settlement level, the impact is substantially larger. For example, the model suggests that a settlement with 600 units will have a rental rate that is nearly $10 \%$ higher than a settlement with 100 units. ${ }^{60}$

\section{CONCLUSIONS}

Having discussed the model, it will be useful to explore further some of its potential limitations and the practical implications of its results. Two broad conclusions drop out of this analysis: first, the relative explanatory weakness of the model(s); and second, the insights that colonia rental markets may largely be an outcome of dysfunctions within the colonia ownership market, rather than a sub-market of renting and landlordism being articulated into colonias.

On the model itself one fairly obvious conclusion is that a variety of confounding factors appear to affect the rate of renting in colonias. One such variable is the condition of the settlement's infrastructure. For example, tenants may be less inclined to seek rental accommodation in neighborhoods that lack water and wastewater services. Using data on the adequacy of infrastructure in colonias, I estimated an amended model to assess the effect of infrastructural conditions on the proportion of renters. Detailed in Table 6.5 in the methodological appendix, the results suggest that colonias with adequate infrastructure (i.e., water and wastewater services) have rates of renting that are approximately $3 \%$ higher than colonias that lack these services, although this difference is just beyond the $5 \%$ level of statistical significance $(\mathrm{p}=.07)$. Importantly, the inclusion of infrastructural conditions did not drastically alter the effect of the other independent variables in the model. ${ }^{61}$

\footnotetext{
$60600-100=500 ; 500 \times .019 \%=9.5 \%$.

61 Inclusion of this variable did reduce the significance of the intercept, though in this model the intercept has limited substantive meaning.
} 
In order to better estimate the effect of various factors on the rate of renting in colonias, one would want to measure the local property tax rate and average property values within the settlement, ${ }^{62}$ the presence or absence of other affordable rental or forpurchase options in the general vicinity, the dynamics of the colonia land and housing market, and the availability of financing for purchase in nearby neighborhoods, ${ }^{63}$ among other things.

In each of the models estimated, distance from the nearest incorporated city appeared to have an insignificant effect on the proportion of renters. This is probably due, at least partially, to the difficulties in taking meaningful measurements of distance. For example, $36 \%$ of colonias (109) were located within the city limits and an additional 14\% (44) were contiguous with cities. This creates a skewed distribution that may obscure the effect of distance on more remote colonias. Even controlling for this fact, however, no statistically significant effect of distance was seen on the proportion of renters. Two factors make this measurement of distance less accurate. First, as-the-crow-flies measurements between colonias and the nearest city do not accurately capture relative travel time from urban areas, since the condition and direction of roads is not taken into account. Second, measuring distance from the nearest incorporated city may not account for the size of that city, nor the presence of other unincorporated urban areas nearby.

\footnotetext{
62 Both of these values could be acquired through analysis of County Appraisal District (CAD) records. Some of these records are accessible in GIS shapefiles on the CAD websites, which would greatly facilitate such an analysis. In particular counties (Starr), property records are neither accessible online nor easily searchable at the county offices. For further discussion of such issues, see Ward et al. (2012).

${ }^{63}$ In particular, one would want to have data on nearby Model Subdivisions. In these settlements, built after 1995, developers are required to build (or to finance the building of) infrastructure and utility services prior to selling any lots. In many of these Model Subdivisions, developers provide the financing for the purchase of the lot, often at very exploitative rates and with high rates of default (Ward et al. 2012). Given the stagnant nature of the colonia owner-occupied housing market, Model Subdivisions are one of the few ways in which low-income colonia residents can afford to purchase a home. Thus, proximity to a Model Subdivision may result in lower demand for rental accommodation, as lower-income residents seek opportunities for purchase instead.
} 
For each of these reasons, population density appears to be a better estimate of proximity to urban areas. Not surprisingly, then, the population per square kilometer within a 500 meter radius is the factor that best explains the proportion of renters in the colonias studied. In general, one can assume that more densely populated areas are more urban in nature and are likely closer to incorporated cities; in turn, renters are more common in such areas because of increased demand for housing. Moreover, even accounting for population density in the surrounding area, rental rates are significantly higher in larger settlements perhaps because larger settlements are both more visible and offer greater diversity in the types of housing available, which may facilitate renting. The fact that larger and denser areas have higher rates of renting is important for two reasons. First, is the fact that due to increased demand for rental housing, the cost is likely to be significantly higher in more densely populated areas, and tenants in these communities are therefore likely in greater need of housing support, particularly as concerns issues of affordability. Moreover, for policymakers and nonprofits, focusing on more densely populated areas will ensure the greatest efficiency in the administration of any housing support program for colonia renters.

Finally, the conclusion that older subdivisions display higher rates of renting is to be expected. As colonias age, their owner-occupants age as well, and over time the home serves different purposes. In later years, elderly couples often live on their own, since their children have moved out of the home, many times locating nearby, not uncommonly on a shared or adjoining lot. For many homeowners who see their homes as a "patrimony for their children" (Ward 2012), selling the home is out of the question.

This leads us to the second set of insights, namely, that elevated rental rates are due, at least partially, to market dysfunction in the land and housing markets. For 
example, even were owners (or informal landlords) interested in selling the property, the inefficient housing market makes this a difficult process. First and foremost, the lowincomes of potential homebuyers in colonias severely limit effective demand in the market; although many residents may be interested in buying a colonia home, most would not qualify for traditional mortgages — and banks may in fact be reticent to lend to buyers in colonias, given that widespread underdevelopment and the inefficiency of the market make resale in the event of foreclosure quite difficult (Durst et al. 2012; Ward et al. 2011). As has historically been the case in colonias, most buyers purchased their property through seller-financing, in which the seller transfers title to the buyer (typically through a Contract for Deed agreement, sometimes referred to as a poor man's mortgage). The buyer then agrees to make monthly payments until the cost of the property is paid in full. Similar transactions occur in newer informal subdivisions (MSRs), although developers rely primarily on Deeds (Ward et al. 2012). Thus, while seller financing is the primary means of housing acquisition in the early stages of settlement formation, it is simply not feasible in older colonias (i.e. in settlements where the developer is no longer selling lots), since many low-income property owners have no desire to transfer property rights to a buyer without payment in full.

Chapter 4 provides a more detailed discussion of the various factors that lead toward the decision to rent. Suffice to say over time the use value of the home may diminish significantly, leading owners to resort to petty landlordism for supplemental income, to provide support for kin, or as an alternative to selling at a reduced price given widespread market dysfunction in colonias.

Importantly, as colonias age, rental rates within them will continue to rise over time. Indeed, as discussed in Chapter 2, rental rates in colonias rose from $18 \%$ in 2000 to 
$22 \%$ in 2010. If this trend continues—which the model discussed above suggests it will— rental rates over the coming two decades may reach $30 \%$ or more. Current estimates suggest that 400,000 people currently reside in colonias in the Texas-Mexico border region. ${ }^{64}$ At these numbers, an increase in the proportion of renters by as little as $5 \%$ over the next 20 years means that 20,000 more residents will be renting their homes in colonias. Clearly, the time has come for policy makers and non-profits to begin to explore the needs of renters in colonias.

64 See http://www.sos.state.tx.us/border/colonias/faqs.shtml. 


\section{Chapter 4: An Examination of Renters and Renting}

\section{INTRODUCTION}

We now have a better understanding of the extent and nature of the rental market in colonias and have identified various factors that appear to shape varying rates of renting across settlements. This chapter seeks to expand on this foundation by a) exploring differences between renting in formal rental complexes and single-unit, standalone structures, b) exploring nuanced socio-economic and demographic characteristics of renter households in formal rental complexes, and c) documenting various forms of economic and social vulnerability among colonia renters.

\section{Methods AND Data Collection}

In this chapter I draw upon a combination of household surveys, key informant interviews, and case study interviews in order to provide a deeper portrayal of renters, landlords, and the rental market in colonias. The chapter begins with a discussion of the dynamics of the colonia rental market drawing upon three recent surveys of colonia households. The largest of these projects (Ward et al. 2012) collected data on approximately 1,300 households in colonias and IFHSs in eight Texas counties. I was fortunate to work as a Graduate Research Assistant on this major project commissioned by the Texas Department of Housing and Community Affairs, which, to date, provides the most comprehensive picture of renting in colonias - albeit partial since the study was directed at owners. In particular, this project is unique in that colonia settlements and households in six Texas counties (the same six counties discussed at length throughout this report) were randomly selected for study in order to allow extrapolation of conditions to the county level. As I show later, this provides for the accurate predictions of rental rates and the number of renter-households at the county level. 
The second project (Durst et al. 2012)_funded by the Ford Foundation and supervised by Dr. Peter Ward of the Lyndon B. Johnson School of Public Affairs - was a unique "snapshot" study which sought to expand upon a 2002 survey of 270 randomly selected households in ten colonias outside Starr County, Texas. Thus, in 2011 I had the opportunity to lead a team of researchers in surveying approximately 200 households in ten Texas colonias: approximately 150 of these were households that had participated in the 2002 study, allowing us to draw comparisons across the two time periods. In order to compensate respondents for their time, we distributed \$15 gift cards from the local grocery store, HEB. In order to expand our sample size, we also distributed mail surveys to each household in the ten colonias that had not participated in the 2002 study. In total, approximately 50 surveys were returned by mail, representing $8 \%$ of those distributed.

These two reports serve as an interesting comparison with the aggregate ACS presented in Chapter 2. However, because both projects were concerned primarily with informal titling mechanisms, the data collected on the rental market is limited to only a few key variables. For this reason, in this Chapter I use these data to offer additional household-level (rather than settlement-level) data on renters and renting and to set the stage for a more in-depth and extended analysis that I undertook using targeted household surveys and key informant interviews.

In order to complement these surveys conducted by Durst et al. (2012) and Ward et al. (2012), I also draw upon my own mixed methods research conducted in 18 purposively selected colonias in Starr County where there was a notable presence of formal rental complexes of varied size and quality. Thus care must be taken not to generalize overly from these preliminary findings. I began by conducting 47 household surveys with renters in formal rental complexes containing a total of 193 units throughout 
the selected colonias. I was fortunate to have three Texas A\&M student research assistants who I trained and employed to assist with the conducting of these household surveys (these assistants were local residents, and one in fact lived in one of the colonias surveyed). Once I had completed these surveys, I returned with a research assistant to four purposively selected colonia households in order to conduct more intensive conversational case study interviews. These cases were selected precisely to better understand key components of housing tenure, issues of housing insecurity, and tenant vulnerability. While the two case studies presented in this chapter are not "representative" of all colonia renters, they do provide more detailed insights into the myriad factors that often make renters a more vulnerable demographic.

Finally, I draw upon various key informant interviews with landlords of formal rental complexes in a number of the colonias studied. These interviews provide interesting insights into the rental housing production process, the dynamics of the rental market, and the motivations and incentives for turning to landlordism. Landlords were contacted either via conversations with tenants or by contacting directly both by phone and in person.

Each of these studies offers a unique perspective on colonia renter households and the nature of the rental market. Beyond those data collected by Ward et al. (2012), which were randomly selected to allow extrapolation to the colonia conditions countywide, care should be taken not to generalize too broadly from the data presented in this chapter. However, that point understood, these data nonetheless provide an intriguing glimpse of the needs of renters and suggest the need for further qualitative research into renting in colonias. My results show that: renting appears to take a variety of different forms in colonias, each of which is managed by a distinct set of landlords; that renters differ 
significantly from owner households in terms housing trajectories and demographic and socio-economic characteristics; and that renters have distinct needs and experience greater vulnerability than do owner households.

\section{MARKET STRUCTURE}

\section{Stand-Alone Homes for Rent}

As demonstrated in Chapter 2 using data from the ACS, in both the owner- and renter-occupied colonia housing markets, the majority of homes are stand-alone, singleunit structures. Data collected by Ward et al. (2012) confirm this conclusion. The authors found that rental units sometimes but rarely contain more than one unit: across the eight counties studied, $78 \%$ and $15 \%$ of renters reported one or two rental units, respectively, on the lot. ${ }^{65}$ Thus, unlike in the national rental market—where the majority of renters live in multi-unit structures - most colonia renters live in stand-alone homes. When multiple rental units are present on one lot, the additional unit is often a separate structure, such as a temporary dwelling (trailer or camper) or a consolidated home. Figure 4.1 shows an example of a lot with two separate stand-alone homes in a colonia in Hidalgo County, Texas.

Although I have already described the extent of the colonia housing market in Chapter 2, I will return to this topic in order to expand upon this discussion. Durst et al. (2012) report a significant increase over the past decade in the percentage of non-owners in stand-alone homes in ten colonias in Starr County: while renters made up only $6 \%$ of

\footnotetext{
${ }^{65}$ Because of the methodology used to identify potential cases, some multi-unit stand alone homes fell within the selected sample. For accuracy, therefore, I use the term "stand-alone" rather than the classification used by the Census Bureau, which distinguishes between one-unit detached structures and multi-unit structures. In the majority of case, however, the term stand-alone is synonymous with a one-unit structure.
} 


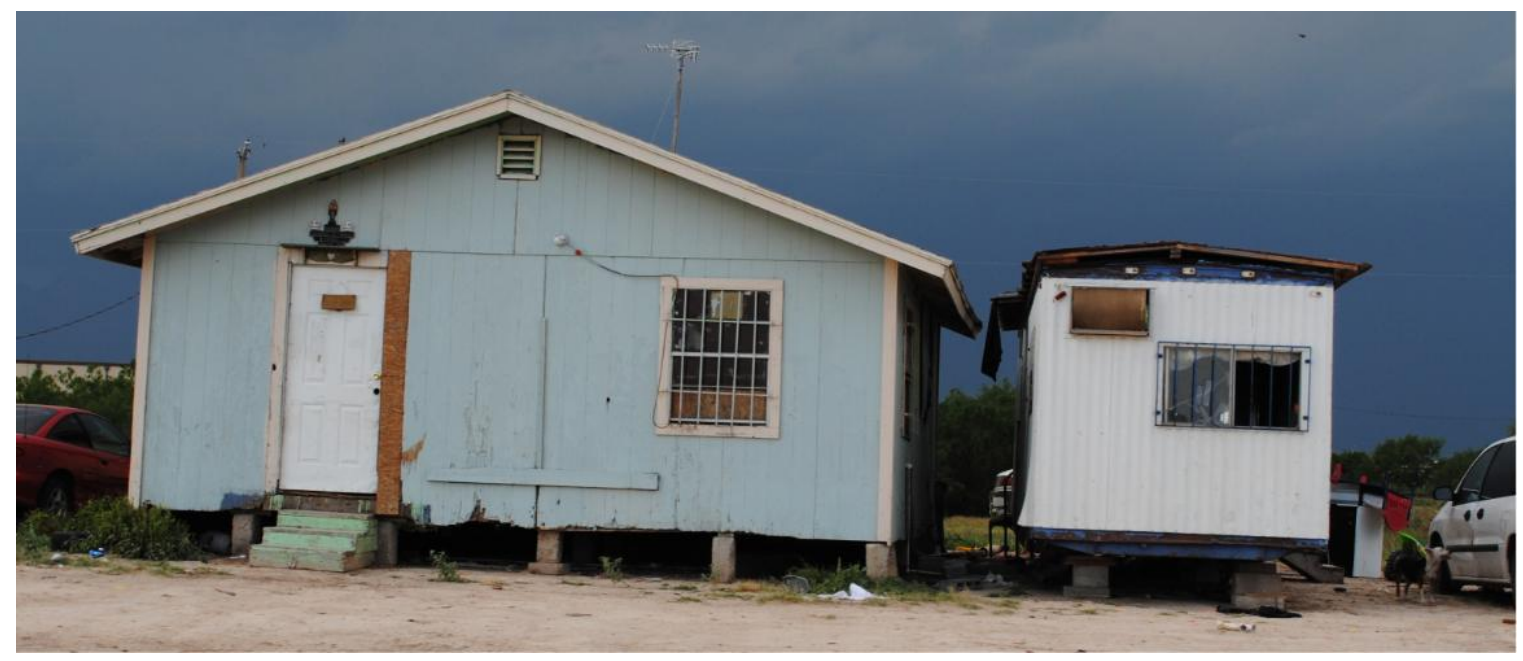

Figure 4.1. Example of a Multi-Unit Stand-Alone Home in Hidalgo County, Texas

those interviewed in 2002, they represented $12 \%$ by 2011 . These figures confirm that renting is indeed on the rise in colonias; other data suggest that renting in colonias is even more common. Table 4.1 provides data on the extent of renting across all six counties studied by Ward et al. (2012). Using weights designed for extrapolation to the county level, these estimates suggest that there are 65,302 households living in stand-alone homes in colonias across these six counties, and 10,856 (or 17\%) ${ }^{66}$ of these are renter households. ${ }^{67}$ As Table 4.1 shows, the percentage of households in stand-alone homes that rent varies significantly by county, with as little as $9 \%$ in Maverick County and as many as $18 \%$ in Starr and El Paso Counties. Notably, estimates of the proportion of renter households provided by Ward et al. (2012) are higher than those reported by Durst et al. (2012) for ten colonias in Starr County. This is due in part to the sampling frame used by Durst et al. which targeted homeowners who had previously participated title

\footnotetext{
${ }^{66}$ Differences between my estimates and those provided by Ward et al. (2012) (16\%) are negligible. These estimates have a margin of error that varies between \pm 6.81 and $8.61 \%$. For a detailed description of the weights used for this calculation, see Ward et al. (2012).

${ }^{67}$ Each household had an average of 3.97 people.
} 
regularization program (Ward et al., 2003). As a result, the Starr County study likely underestimates the extent of renting within these colonias. Taken together, however, these estimates suggest that renting in stand-alone homes is on the rise and that renters now constitute a significant portion of colonia households.

Renter Households in Stand- Number of Households Total Estimated Renter Alone Homes $(\%)^{\mathrm{a}}$ Interviewed Households in Colonias

\begin{tabular}{lccc}
\hline Maverick & 9.3 & 174 & 510 \\
Starr & 17.6 & 128 & 1,452 \\
El Paso & 17.5 & 164 & 2,400 \\
Webb & 15.5 & 181 & 360 \\
Hidalgo & 14.9 & 167 & 4,374 \\
Cameron & 15.7 & 119 & 1,760 \\
\hline All Counties & 16.6 & 933 & 10,856 \\
\hline
\end{tabular}

Notes: Margins of error of \pm 6.81 and $8.61 \%$. Source: Data collected by Ward et al. (2012) and are available at http://www.lahn.utexas.org/. Analysis conducted by the author.

Table 4.1. The Stand-Alone Colonia Rental Market

In the stand-alone rental market, issues of dwelling quality are likely of concern. Unlike entrepreneurial landlords, who typically pursue landlordism explicitly as a business, informal landlords may lack the financial resources or incentives to upgrade or maintain homes converted to rental property. For example, five out of eleven tenants surveyed by Durst et al. (2012) reported that their dwelling was unfinished. Similarly, almost all (ten out of twelve) respondents reported problems with the dwelling, including: deteriorating walls and flooring; poorly functioning or non-existent air conditioning, heating, or ventilation systems; insufficient insulation; inadequate plumbing; and poor quality bathroom and kitchen fixtures. ${ }^{68}$ If these admittedly limited data are illustrative of

68 These conclusions and analysis are the author's and are drawn from data collected by Durst et al. (2012), available at lahn.utexas.edu. 
housing conditions in other colonias, renting in stand-alone homes may present far more problems than renting in formal complexes.

\section{Formal Rental Complexes}

I define formal rental complexes as structures built intentionally as rental housing and containing a minimum of two clearly distinct rental units; these structures may range from modest duplexes to apartment complexes with more than a dozen units. Figure 4.2 shows an example of a large formal rental complex (constructed in the 1990s) in Las Lomas, located just outside of Rio Grande City, in Starr County, Texas. The data collected do not provide information on the characteristics of individual households in formal complexes within the six counties, but do show: a) the number of formal rental complexes as a percentage of all residential lots; and b) the number of units in such complexes as a percentage of all residential units. The results of this analysis are presented in Table 4.2 .

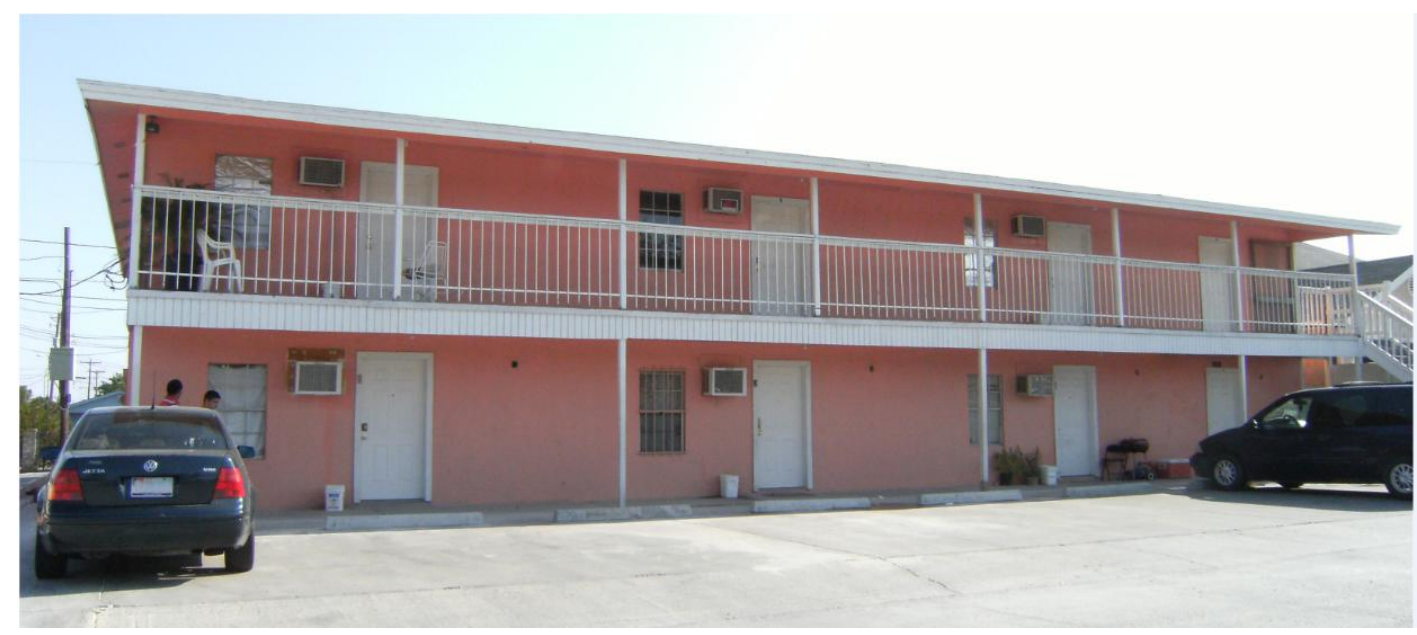

Figure 4.2. A Large (16-unit) Formal Rental Complex in Starr County, Texas. 
While renting in formal complexes represents only $1.2 \%$ of all occupied residential lots visited ${ }^{69}$ in the six study counties (see Table 4.2), the total proportion of households who rent in such complexes is likely to be significantly higher, since each complex has multiple units (the average being 3.4 units per complex). Thus, it is probably more useful to discuss the number of units in formal rental complexes as a percentage of all residential units visited within the colonia. In the selected colonias across all six counties, my estimates suggest that approximately $4 \%$ of all residential units were in formal rental complexes, with rates being highest in Hidalgo and Cameron Counties (5.7\% and 6.7\%), and lowest in El Paso County (1.4\%).

In order to better understand conditions in formal rental complexes, which were overlooked by both Durst et al. (2012) and Ward et al. (2012), I conducted targeted surveys with 47 tenant households in formal rental complexes in 18 colonias in Starr County. Although generally small-15\% of units had one bedroom, $83 \%$ had two, and only one unit had three bedrooms - the quality of the dwelling in the formal rental complexes studied in Starr County is not of primary concern. Most respondents $(85 \%)$ stated that they were either "very content" or "content" with their rental accommodation, and only $15 \%$ stated that they were "more or less content" to "very discontented." Only one respondent $(2 \%)$ reported that there were unfinished parts of the dwelling, although $30 \%$ did report problems with the physical structure; the most common problems were the lack (or poor quality) of an AC unit or other appliance; fixture and design or structural problems such as building quality, flooding, and exterior accommodations. For

\footnotetext{
${ }^{69}$ I refer to those lots "visited" because a different sampling frame was utilized in each colonia. Therefore, estimates regarding the presence of formal rental complexes refer to different proportions of the total number of visited lots in the selected colonias. For more information, see the detailed methodology provided in the report by Ward et al. (2012).
} 


\begin{tabular}{lccccc} 
& $\begin{array}{c}\text { Formal Rental Complexes } \\
\text { as a Proportion of } \\
\text { Occupied Residential Lots }(\%)\end{array}$ & $\begin{array}{c}\text { Formal Rental Units } \\
\text { as a Proportion of } \\
\text { All Dwelling Units (\%) }\end{array}$ & $\begin{array}{c}\text { Total Occupied } \\
\text { Residential Lots }\end{array}$ & $\begin{array}{c}\text { Number of Formal } \\
\text { Rental Complexes }\end{array}$ & $\begin{array}{c}\text { Number of Units in } \\
\text { Formal Rental } \\
\text { Complexes }\end{array}$ \\
\hline Maverick & 1.3 & 2.7 & 701 & 9 & 19 \\
Starr & 1.6 & 4.5 & 431 & 7 & 20 \\
El Paso & 0.5 & 1.4 & 439 & 2 & 6 \\
Webb & 1.1 & 3.6 & 348 & 4 & 13 \\
Hidalgo & 1.3 & 5.7 & 541 & 7 & 32 \\
Cameron & 1.4 & 6.7 & 368 & 5 & 26 \\
\hline All Counties & 1.2 & 3.9 & 2,828 & 34 & 116 \\
\hline
\end{tabular}

Source: Data collected by Ward et al. (2012) and are available at http://www.lahn.utexas.org/. Analysis conducted by the author.

Table 4.2. Formal Rental Complexes in Colonias 
most respondents, these problems were minor, and $89 \%$ of interviewees said that their landlord responded quickly when needed.

\section{Lots for Rent}

The third and final component of my threefold typology of colonia rental housing entails the placement of a temporary form of housing, such as a camper (recreational vehicle) or trailer (manufactured home) on a lot that is rented. None of the three studies explicitly collected data on the frequency of this sort of renting, and of the options we observed it appears to be the least common of the three and can take a variety of forms: a) landlords may operate makeshift trailer parks with a dozen or more units parked on one or two lots (see Figure 4.3) — clearly a formal business enterprise; b) in other instances, a landlord rents a vacant lot in order to gain some supplemental income until the property is used for another purpose (see Figure 4.4); and c) owner-occupants may rent an unused unit (a trailer, for example) or part of the lot upon which they live, allowing a tenant to place a temporary structure on the property.

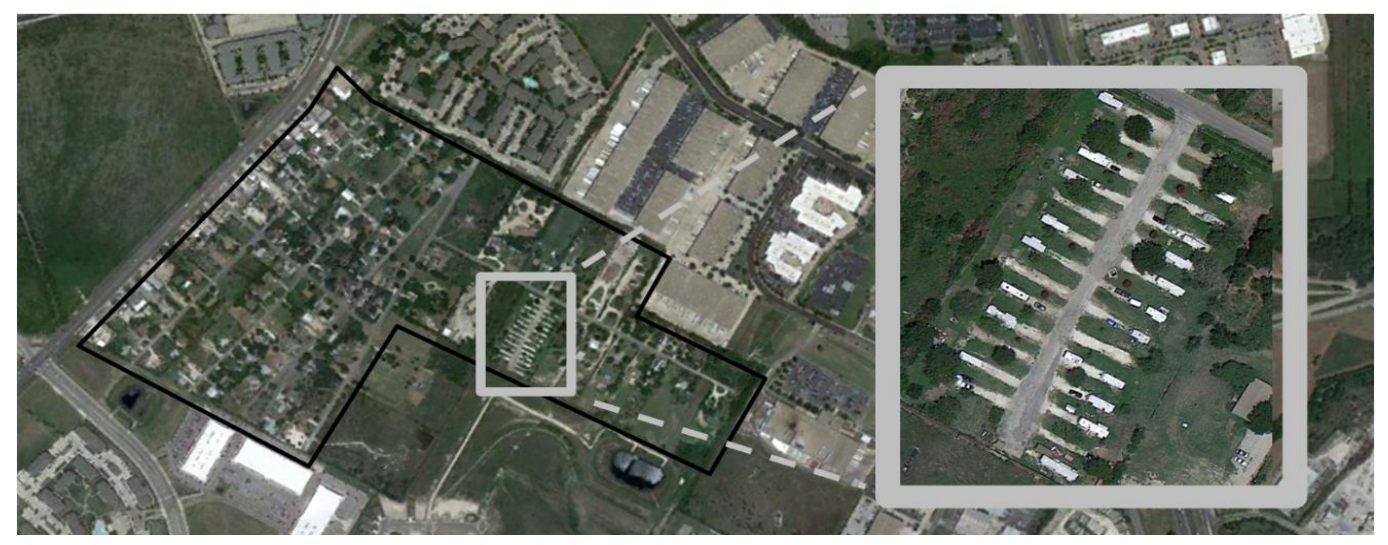

Figure 4.3. Trailer Park in an Informal Homestead Subdivision: Border of Travis \& Williamson Counties, (Austin) Central Texas. 


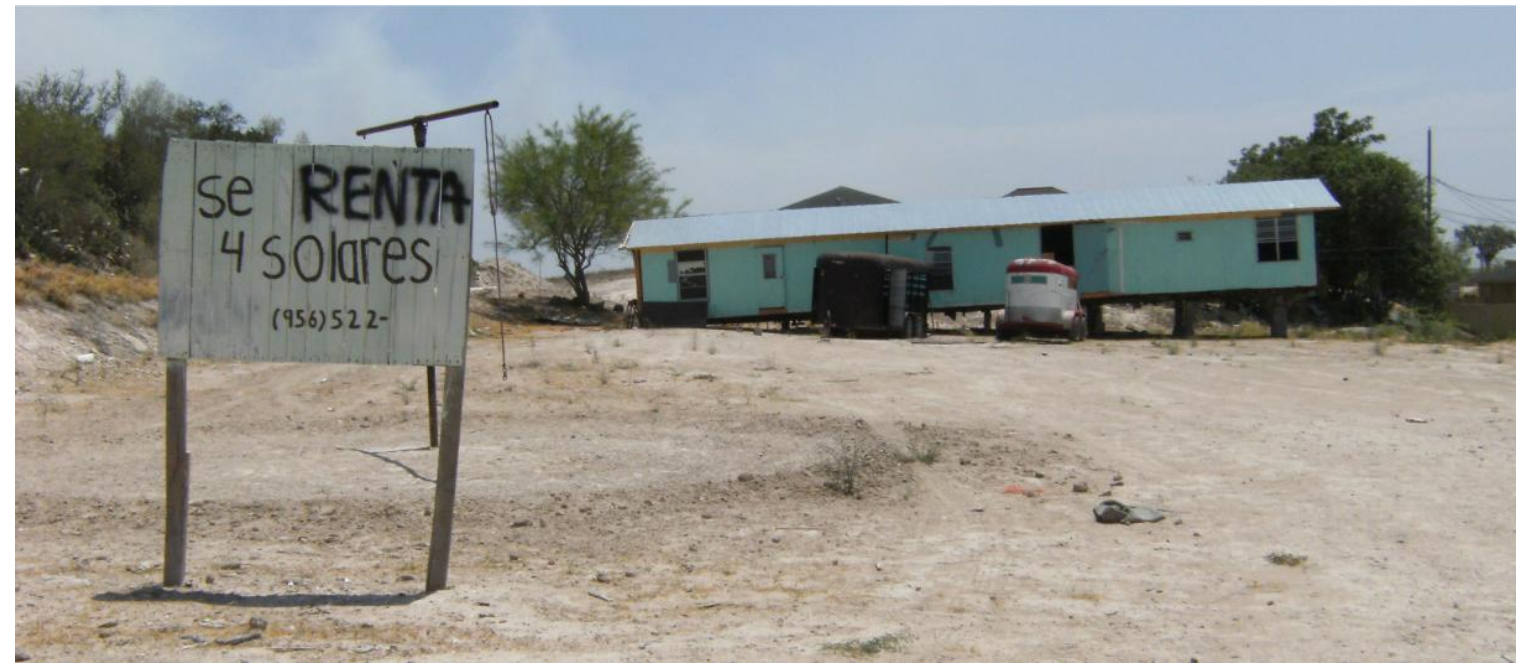

Figure 4.4. "Se Renta 4 Solares" (4 Lots for Rent) in Starr County, Texas.

This latter form of renting provides an interesting example of a creative solution to the inefficiency of the land and housing markets in colonias, where some lots remain vacant for many years (Rojas et al. 2012; Ward and Carew 2000) — this suggest that the renting of vacant land may be a feasible solution to the large number of unoccupied lots in colonias. However, how tenants and landlords might negotiate the installation and provision of utility services is unclear. While utility (electricity, water, and wastewater) services are now common in most colonias, the connections often do not extend onto vacant lots themselves; raising the question of who is responsible for covering the cost of linking the installation of such services onto the lot itself. Moreover, many colonias use septic tanks rather than sewage systems which require the pumping, cleaning and maintenance of the system every 12-18 months (this process is often not undertaken regularly in colonias due to cost, and can result in clogging of the septic system — see LBJ School of Public Affars 2010). Such maintenance is likely to be even more complicated and tenuous under landlord-tenant relationships. 


\section{Cost, Contracts, and Payments}

One particular component of the rental market that illustrates the informal nature of renting in colonias concerns the issue of cost, contracts, and payments. As Table 4.3 shows, average rental costs are fairly uniform across counties and in various segments of the rental market: in stand-alone homes across all six counties, average rental costs were \$339 per month, compared with $\$ 308$ in the stand-alone homes studied by Durst et al. (2012) and \$333 in the formal rental complexes surveyed. Although this is less than half the average national rent $(\$ 808)$, the cost of rent in colonias is on par with that of homeowners. For example, Ward et al. (2012) found that rents in colonias and IFHS in eight Texas counties were $\$ 375$ (trimmed mean) across all eight counties; this being higher than the current monthly payments paid by would-be owners for developer-sold properties $(\$ 302)$, though it is lower than the monthly cost of properties sold by a previous consumer or resident $(\$ 444) .^{70}$

Upon renting a home, most tenants are asked to pay a deposit, though few sign a written rental agreement. In my study of 47 renter households in formal complexes (not shown in Table 4.3), 51\% of respondents paid a deposit of one month's rent, $25 \%$ paid a smaller deposit, $17 \%$ reported that their landlords requested no prerequisites (monetary deposit, references, or otherwise), and another two respondents reported that they had cleaned up or completed repairs on the unit as a prerequisite for moving in. As shown in Table 4.3, despite the fairly widespread use of deposits (in the formal rental market, at least), the use of written rental contracts is low, with only $43 \%$ of households in formal

\footnotetext{
70 Note that the results from the eight counties studied by Ward et al. (2012) differ slightly from those provided in the table. This is due to the fact that the results presented in Table 3 include only those renters located in randomly selected colonias in the border region. The higher estimates provided by in the report by Ward et al. are likely due to the inclusion of renters from two counties in central Texas, where rental costs are higher.
} 


\begin{tabular}{|c|c|c|c|c|c|c|c|c|c|}
\hline & \multicolumn{7}{|c|}{ Stand-Alone Rentals Across Six Counties ${ }^{\mathrm{a}}$} & \multirow{2}{*}{$\begin{array}{c}\begin{array}{c}\text { Formal Rental } \\
\text { Complexes }\end{array} \\
\begin{array}{c}\text { Starr } \\
(n=47)\end{array} \\
\end{array}$} & \multirow{2}{*}{$\begin{array}{c}\begin{array}{c}\text { Stand-Alone } \\
\text { Rentals }\end{array} \\
\text { Starr } \\
(\mathrm{n}=13)\end{array}$} \\
\hline & $\begin{array}{c}\text { Maverick } \\
(\mathrm{n}=17)\end{array}$ & $\begin{array}{c}\text { Starr } \\
(\mathrm{n}=21)\end{array}$ & $\begin{array}{c}\text { El Paso } \\
(\mathrm{n}=30)\end{array}$ & $\begin{array}{l}\text { Webb } \\
(\mathrm{n}=30)\end{array}$ & $\begin{array}{c}\text { Hidalgo } \\
(\mathrm{n}=27)\end{array}$ & $\begin{array}{c}\text { Cameron } \\
(\mathrm{n}=19)\end{array}$ & $\begin{array}{c}\text { Total } \\
(\mathrm{n}=144) \\
\end{array}$ & & \\
\hline $\begin{array}{l}\text { Use a Written Rental } \\
\text { Contract }(\%)\end{array}$ & 12 & 35 & 44 & 13 & 30 & 15 & 26 & 43 & -- \\
\hline $\begin{array}{l}\text { Average Monthly Rental } \\
\text { Cost }\end{array}$ & $\$ 381$ & $\$ 307$ & $\$ 341$ & $\$ 335$ & $\$ 350$ & $\$ 322$ & $\$ 339$ & $\$ 333$ & $\$ 308$ \\
\hline $\begin{array}{l}\text { Rent Paid Directly to } \\
\text { Owner }(\%)\end{array}$ & 88 & 81 & 97 & 97 & 89 & 95 & 92 & 79 & -- \\
\hline
\end{tabular}

Notes: ${ }^{a}$ Dollars reflect 2012 values. ${ }^{b}$ Dollars reflect 2011 values. Source: Stand-Alone Rental data across six counties collected by Ward et al. (2012) and are available at http://www.lahn.utexas.org/. Formal Rental Complexes data collected by the author. Stand-Alone Rental data in Starr county collected by Durst et al. (2012) and are available at http://www.lahn.utexas.org/. Analysis conducted by the author.

Table 4.3. Costs $(2011 \&$ 2012) \& Contracts in Colonia Rental Markets 
complexes reporting having signed a written contract. In the stand-alone homes surveyed by Ward et al. (2012) contracts were even less common, with only $26 \%$ having signed a written contract. This is likely due to the fact that informal landlords are more likely to rent to family and friends, thus obviating the need for a written 'contract. Nevertheless, the use of written contracts varied significantly by county, suggesting that other factors may also inform decisions to put rental agreements in writing: the use of contracts was as low as $12 \%$ in Maverick County and as high as $44 \%$ in El Paso County.

One final sign of the informal nature of colonia renting is the method of payment. As one might expect, $92 \%$ of renters in stand-alone homes across all six counties reported paying rent directly to the owner, supporting the argument that most landlords of standalone homes operate small-scale rental operations. However, most tenants (79\%) in formal rental complexes also paid directly to the owner, suggesting that many complexes are also managed by landlords with small-scale operations.

\section{LANDLORDS}

\section{Informal Landlords of Stand-Alone Homes}

Certain distinctions can be drawn between the informal landlords of stand-alone homes and rented lots, and the entrepreneurial landlords that typically operate formal rental complexes. Most informal landlords of stand-alone homes originally built, bought, and subsequently occupied the home before deciding to rent it. As a result, these are small-scale operations, most commonly with only one or two rental units per lot. This appears to be the most common form of landlordism in colonias. In some cases, however, the informal landlord still occupies the home, and thus shares or rents out a portion of the home or an additional structure on the lot. I refer to these as "petty landlords." This is a 
less common, though important form of renting in colonias. In general, most of the informal landlords of stand-alone homes appear to live locally: Ward et al. (2012) found that according to County Appraisal District data, 86\% of more than 200 colonia informal landlords had permanent residences in the same county.

A variety of factors make renting stand-alone colonia homes an attractive option for homeowners. One of the most likely causes of the turn to renting is homeowners' desire not to sell properties into which they have invested significant amounts of time and money, but where changes in the life course (death or divorce) or employment necessitate a residential move. This conclusion is supported by limited data from Ward et al. (2012), who conducted a small number of follow up mail surveys (12 in total, representing a 5\% return of those approached) with absentee owners of stand-alone rental property in the colonias of eight Texas counties. Although a very small subsample, the authors found that most had never tried to sell (although close to half considered doing so in the future).

As Ward (2012) demonstrates in a separate study, many colonia residents view their home as a patrimony for their children and have no intention of selling. However, this desire to keep the home within the family is complicated by the absence of wills: Ward et al. (2012) found that in 89\% of all owner-occupied homes studied (across all eight counties), neither spouse had a will. As the authors argue, intestacy may lead to renting since families who cannot settle disagreements regarding inheritance may resort to renting the property in order to gain some financial benefit in the meantime.

For owners who wish to sell, renting may function as an interim solution while the house sits on the market. Some owners turn to landlordism due to the widely reported inability of homeowners to sell their dwellings as a result of insufficient effective demand in the colonia housing market. In particular, the lack of formal financing for would-be 
homebuyers means that few can afford to buy even a modest home outright. Thus, those who wish or need to sell are forced to choose between financing the sale themselves (i.e., selling the home through a Contract for Deed agreement in exchange for monthly purchase payments), renting the property, lending it to friends or family, or leaving it unoccupied or abandoned.

\section{Entrepreneurial Landlords of Formal Rental Complexes}

The development and management of larger rental complexes differs markedly from that of stand-alone rental units. The following discussion, which draws upon five key informant interviews I conducted with entrepreneurial landlords in Starr County, provides a preliminary glimpse of these landlords and how they differ from the informal landlords of stand-alone units.

The owners of formal rental complexes that I interviewed primarily pursued landlordism as a business (i.e., with profit as the primary motive), thus warranting the name "entrepreneurial landlords." Despite this emphasis on profit, these landlords employed a variety of means of constructing and managing the operations. Several operated a variety of businesses in the area-including residential home constructionand most saw rental property management as a means of diversifying their investments. Nevertheless, these operations remain rather small-scale and local: four out of five entrepreneurial landlords that I interviewed were colonia residents themselves; and only one interviewee had used a formal loan to finance the construction of the rental complexes, while the rest relied on the proceeds from other businesses. Furthermore, while some landlords had contracted out the construction of the rental complexes, another had built the units himself with the help of his two nephews. Finally, while two of the landlords I interviewed owned enough rental property that they had hired someone to 
oversee the management of the properties, the rest were small-scale operations managed directly by the owner.

Due to the informal nature of the colonia housing market, rental operations present certain problems for entrepreneurial landlords. Many complained of tenants missing payments or refusing to pay for damages. However, as will be discussed in greater detail in the following section, few entrepreneurial landlords seem to require that tenants pay security deposits or sign written rental contracts. One interviewee suggested that many potential tenants are reticent to sign a lease-a fact that may reflect both an aversion to signing written contract agreements in general, a desire for more flexibility in housing tenure, or possibly reticence toward signing a written contract due to undocumented status. Thus, despite the risks of informal rental agreements, written rental contracts seemed to be of limited use to landlords - one key informant thought that even with a contract it would be difficult or impossible to track down a former renter and seek compensation for back rent or damages.

Notwithstanding these challenges, entrepreneurial landlords viewed the construction and management of formal rental complexes as good business. This is likely due to the high demand for rental accommodation and the inefficiency in the owneroccupied market in colonias. Two interviewees had also built stand-alone homes for resale, and both reported that the stagnant owner-occupied housing market-and the lowincomes of potential buyers - made these difficult to sell. One landlord reported that while his new home construction business (in colonias, primarily) had fallen off completely since the 2008 housing crisis, demand for rental housing continued to grow. ${ }^{71}$

\footnotetext{
71 Similar views were expressed by all of the landlords of formal complexes that I interviewed, and two were in the process of building additional units.
} 
Another had built various stand-alone homes for sale, but had decided to rent them until she could find a qualified buyer. Thus, for some local business owners, the construction and management of formal rental complexes has arisen as a viable option in a stagnant owner-occupied market.

Although it is possible that some formal rental complexes in colonias are operated by larger property management companies (these might be called institutional landlords), I am unaware of any examples and believe this is probably uncommon. First, since colonias are located in the rural hinterlands and most colonia residents have very low incomes, colonias are unlikely areas for investment by firms with better access to capital and more interest in higher-income tenants. Second, the informal nature of the colonia housing market and the poor quality of utility services presents certain barriers to conducting business as usual. Only one of the entrepreneurial landlords I interviewed was not also a colonia resident, and he expressed frustration with the unreliability of buying and operating rental property in colonias. The absence of wastewater service in the colonia had forced him to install ten individual septic tanks, one for each residential unit; and he found the need for yearly cleaning and maintenance of these tanks to be impractical and inefficient. This same landlord also cited informal titling practices as a limitation in developing rental property in colonias; he reported that during the construction process, a local resident had approached him and claimed to have ownership rights to the property. After confirming that he (the interviewee) did in fact have clear title, the landlord moved forward with the construction, but said that he was dissatisfied with the lack of clarity and potential risk associated with purchasing land in a colonia.

While I have labeled these properties "formal" rental complexes-because they are typically purpose-built and are run explicitly as a business - the management and 
operation of such complexes is often rather informal, thus blurring the line between entrepreneurial and informal landlords. Other cases also suggest that it is difficult to draw clear distinctions formal rental complexes and stand-alone homes for rent. For example, one local landlord recounted that she had originally built a duplex with the express purpose of letting her daughter live there. When that did not pan out, the owner converted it to rental property. Another landlord in a different colonia converted his old home into a duplex once he had completed the construction of a much larger home across the street. In this way, some formal rental complexes-duplexes, at least-may in fact begin as owner-occupied housing. Thus, the typology that I present here is one that arose primarily as a result of the methodologies used in collecting data on various parts of the rental market. Given the significant overlap between entrepreneurial and informal landlords, more explicit and targeted research is needed to better understand the characteristics of all colonia landlords and the nature of rental operations they oversee.

\section{TenanTS}

The goal of this section is to provide a detailed description of the socio-economic status, family structure, and housing trajectory of renters. Because no comprehensive and in-depth survey of renters exists, I will construct this portrayal of renter families using data from the studies conducted by Ward et al. (2012) ${ }^{72}$ and my own earlier research (Durst et al. 2012), as well as from surveys of renters in formal complexes in Starr County that I conducted in 2011.

\footnotetext{
72 It is important to note that estimates provided in this report will differ slightly from those provided by Ward et al. (2012), since the latter provide data on all renters in randomly and non-randomly selected colonias, as well as in model subdivisions in the border region and informal homestead subdivisions in two interior counties. Where large differences exist between my estimates and those by Ward et al., I clarify potential causes.
} 
Ward et al. (2012) report that renter households across all eight counties have lower incomes than owner households. My analysis, shown in Table 4.4, suggests similar conclusions. Data collected by Ward et al. (2012) suggest that 44\% of renter households had household incomes of less than $\$ 12,000$ per year, compared with only $34 \%$ of owner households. These figures are mirrored by data collected by Durst et al. (2012) in standalone rentals in Starr County, where $55 \%$ of renters and $31 \%$ of owners earned less than $\$ 12,000$ per year. Finally, of respondents in formal rental complexes that I surveyed, 57\% had incomes below this threshold.

In terms of workers per household, Ward et al. (2012) found no significant difference between owners and renters in randomly selected colonias across all six counties, with averages of 1.09 and 1.12 workers per household for renter and owner households, respectively. Data in Starr County (Durst et al., 2012) show some difference in this regard, with renter households having on average .74 workers, compared with 1.13 for owner households, although this difference is likely due to the limited number (19) of renter households interviewed.

In general, the greatest difference between renters and owners appears to relate to their life course and housing "trajectory"-in short, their age and the length of tenure in their current dwelling. For the most part renters are younger and have been at their current residence for much shorter periods of time. On average renters across all six counties had lived in their dwellings for 4 years at the time of the interview, compared with an average tenure of 19 years for owners. These data are nearly identical to those presented by Durst et al. (2012) and my data from formal rental complexes in Starr County. Similarly, Ward et al. found that $32 \%$ and $66 \%$ of renter heads of households across all six counties were less than 30 and 40 years old, respectively, while the same is 


\begin{tabular}{|c|c|c|c|c|c|c|c|c|c|c|}
\hline & & \multicolumn{7}{|c|}{ Stand-Alone Rentals Across Six Counties ${ }^{\mathrm{a}}$} & \multirow{2}{*}{$\begin{array}{c}\text { Formal Rental } \\
\text { Complexes }^{\text {b }} \\
\text { Starr } \\
\end{array}$} & \multirow{2}{*}{$\begin{array}{c}\begin{array}{c}\text { Stand-Alone } \\
\text { Rentals }^{\mathrm{b}}\end{array} \\
\text { Starr } \\
\end{array}$} \\
\hline & & Maverick & Starr & El Paso & Webb & Hidalgo & Cameron & Total & & \\
\hline \multirow{2}{*}{$\begin{array}{l}\text { Income Below } \$ 12,000 \\
\text { per Year }(\%)\end{array}$} & Renter & 36 & 45 & 41 & 50 & 50 & 32 & 44 & 57 & 55 \\
\hline & Owner & 20 & 36 & 33 & 41 & 44 & 27 & 34 & -- & 31 \\
\hline \multirow{2}{*}{$\begin{array}{l}\text { Workers per Household } \\
\text { (mean) }\end{array}$} & Renter & 1.13 & 0.90 & 1.21 & 0.97 & 1.08 & 1.32 & 1.09 & 1.00 & 0.74 \\
\hline & Owner & 1.32 & 1.16 & 1.10 & 0.96 & 1.15 & 0.99 & 1.12 & -- & 1.13 \\
\hline \multirow{2}{*}{$\begin{array}{l}\text { Years of Residence } \\
\text { (mean) }\end{array}$} & Renter & 3 & 4 & 4 & 3 & 3 & 7 & 4 & 3 & 3 \\
\hline & Owner & 18 & 19 & 16 & 17 & 20 & 24 & 19 & -- & 18 \\
\hline \multirow{2}{*}{$\begin{array}{l}\text { Head of Household } 30 \text { or } \\
\text { Younger }(\%)\end{array}$} & Renter & 25 & 39 & 48 & 23 & 26 & 30 & 32 & 41 & 50 \\
\hline & Owner & 3 & 8 & 6 & 4 & 10 & 4 & 6 & -- & 4 \\
\hline \multirow{2}{*}{$\begin{array}{l}\text { Head of Household } 40 \text { or } \\
\text { Younger }(\%)\end{array}$} & Renter & 56 & 70 & 79 & 57 & 74 & 55 & 66 & 86 & 65 \\
\hline & Owner & 28 & 31 & 22 & 23 & 30 & 19 & 26 & -- & 23 \\
\hline
\end{tabular}

Notes: ${ }^{a}$ Dollars reflect 2012 values. ${ }^{b}$ Dollars reflect 2011 values. Source: Stand-Alone Rental data across six counties collected by Ward et al. (2012) and are available at http://www.lahn.utexas.org/. Formal Rental Complexes data collected by the author. Stand-Alone Rental data in Starr county collected by Durst et al. (2012) and are available at http://www.lahn.utexas.org/. Analysis conducted by the author.

Table 4.4. SES \& Demographic Data: A Comparison between Renter \& Owner Households 
true for only $6 \%$ and $26 \%$ of owner heads of household (see Table 4.4). Again, my results and data in Durst et al. (2012) show similar trends, with renter heads of household being much younger on average than owner heads of household. These findings are also similar to those reported by Gilbert (2012) throughout the developing world.

\section{Socioeconomic Status and Housing Choice}

This section will draw upon data from household surveys of 47 renters in formal complexes throughout Starr County in order to illustrate how poverty precludes the transition toward homeownership and means that renting-despite its lower costspresents certain risks of affordability. Although these surveys were not randomly selected and therefore are not representative of residents in formal complexes in colonias across all six counties, they nonetheless provide a useful discussion of issues of tenure choice and housing mobility.

I begin with the issue of housing mobility. The majority of respondents (95\%) lived in Starr County prior to moving to their present dwelling, with nearly three-quarters (73\%) residing previously in nearby Rio Grande City. More than two-thirds (68\%) rented their prior residence; $21 \%$ lived in shared housing with a family or friend or resided in a borrowed dwelling; and 11\% (5 in total) previously owned their home. Notably four out of the five residents who were previous owners chose to rent for financial reasons (one had in fact lost her home due to lack of payment), while the fifth resident reported that renting was only a temporary solution while she looked for another home to buy. In general, nearly all respondents (90\%) reported having decided to rent for financial reasons: most reported that they could not afford to buy, although, in a limited number of cases, respondents chose to rent because they did not qualify for loans, had lost their home, or wanted to save money. 
Consistent with other findings, the renters surveyed in formal rental complexes displayed short periods of tenure and high inclinations for moving elsewhere. Most renters $(60 \%)$ had plans to move within the next two years. When asked about their motive for moving, $26 \%$ declared that they had plans to buy a home (or were in the process of doing so), $30 \%$ planned on moving for financial reasons, and $30 \%$ were unhappy with their current dwelling or wanted additional space. This suggests considerable "churn"- or turnover in the rental market—and is another major difference to owners.

Despite the lower costs associated with rental housing in colonias discussed earlier, many renter households $(60 \%)$ reported that they regularly had difficulty in meeting the costs of rent. Moreover, almost one-fifth (19\%) of respondents used a Section 8 housing voucher ${ }^{73}$ to assist in covering the rental cost. Given that so many colonia residents struggle to cover the cost of rent, it is unlikely that many will successfully transition toward homeownership.

Nevertheless, my data suggest a strong preference for homeownership among renter households; because renters are younger on average than owners, most aspire to eventually own their own home. Notwithstanding this inclination toward homeownership, out of all 47 respondents, only three had actually already begun making purchase payments on a home or lot and all three had relied on seller financing (in which the buyer makes monthly payments to the seller for a period of time). Most others (70\%) had thought about buying, and only $24 \%$ had no plans to buy a home. Of those who had plans

\footnotetext{
${ }^{73}$ Section 8 vouchers (also known as Housing Choice Vouchers) are a federally funded program that assists low-income, elderly, and disabled residents in finding affordable, safe, and sanitary housing. Voucher recipients are free to choose any housing unit that meets Public Housing Authority quality and cost requirements (including privately owned single-unit homes). Once a dwelling unit is inspected and approved, the landlord is provided with a subsidy on behalf of the resident, who pays the difference.
} 
to purchase, the average respondent hoped to buy the house or lot by late 2012 (i.e. within 1-2 years), and estimated that their anticipated purchase costs would be more than $\$ 35,000$; most were looking to buy both a house and a lot, while some planned on buying a vacant lot and either contracting someone to build the home or doing so themselves via self-help. The majority of respondents (58\%) expected to pay for this future home with cash, using either income or savings, while 33\% hoped to get financing from the seller. Only two of 25 respondents who planned to purchase a lot intended to seek a loan from a bank, and only four of those who had plans to buy were actively saving for the purchase payments.

\section{Case Studies}

Having completed the surveys of renter households in formal rental complexes, I set out to better understand the more nuanced components of tenancy in these complexes, focusing in particular on issues of dwelling conditions, tenure choice, and future housing plans. To do so, I utilized an innovative qualitative case study methodology used successfully in both Latin American consolidated settlements (Ward and Jimenez, unpublished manuscript) as well as in colonias (Durst et al. 2012). ${ }^{74}$ I returned in August of 2011 to particular households (four in total) that exemplified varying degrees of vulnerability. Over the course of an hour or two, a research assistant and I interviewed the head of household and took measurements and photos of the dwelling. These qualitative interviews allowed me to gain a deeper understanding of the family history and their relationship with the dwelling.

The case studies reported herein portray two households of varying degrees of social and economic variability. They are therefore not representative of the typical

\footnotetext{
${ }^{74}$ See also the Latin American Housing Network at http://www.lahn.utexas.org/method.html.
} 
colonia renter, but instead provide an idea of the different obstacles facing both highly vulnerable and (relatively) well-off renters. As a result, care should be taken not to generalize too broadly from the discussion that follows. Moreover, because these case studies were conducted with tenants in formal rental complexes, dwelling conditions, landlord-tenant relationships, etc. may vary significantly between those interviewed and tenants in stand-alone homes. Nevertheless, these case studies provide an interesting anecdotal portrayal of the way in which poverty, housing choices, and changes in the family structure (e.g. through marriage, the birth of children, and death) combine to create areas and moments of vulnerability or relative security for colonia renters.

\section{The Martínez Family: A Case of Severe Vulnerability}

Although they now rent, the Martínez ${ }^{75}$ family lived for a number of years in their own home. In 2000, Maria and Eulogio Martínez purchased a home from a previous resident for three payments totaling approximately $\$ 40,000$ in Las Lomas, one of the larger and more consolidated colonias outside of Rio Grande City, Texas. At the time of purchase, the family consisted of the couple and their four children. In 2001 the family grew by two after their youngest daughter, Cecilia, had a daughter and her husband, Juan, moved into the family home.

Until 2008 the family's housing and economic circumstances were relatively secure: they owned their own home and, with multiple paid workers, were financially relatively secure. That year, however, the Martínez lost their home due to circumstances that remain unclear: Maria claimed that her husband's signature had been falsified on the purchase agreement, although she were unsure of the details (or at least unwilling to share them given that the dispute was apparently still in progress) and would not

75 All names have been changed to ensure confidentiality. 
comment further. ${ }^{76}$ After losing their home, the Martínez family returned to Miguel Aleman, Mexico, located just across the Rio Grande. Two years later, both Eulogio and Juan were murdered while living in Mexico. Again, the details of the murders are unclear, as Maria and Cecilia were, understandably, reticent to discuss the event.

What is apparent, however, is the fact that following the deaths of Eulogio and Juan, the family's economic and tenure security was severely compromised. Cecilia, Maria and their children returned to the United States (this time without the second oldest daughter, Elena, who remained in Mexico) in order to receive government assistance. Even with such assistance, however, the Martínez family was vulnerable - for instance, when we arrived to conduct the interview, Cecilia was on the phone attempting to determine why her SNAP ${ }^{77}$ transfer had not arrived for the month of August.

When they first moved back to the US, the Martínez family sought temporary rental accommodation in another colonia in nearby Roma, Texas. At the time, the family consisted of seven people-Maria and her two sons, her daughter Cecilia, and Cecilia's three children - in a two-bedroom, one-bath apartment for which they paid $\$ 250$ per month. To cover the cost of rent and living expenses, both Maria and Cecilia began working in the food service industry.

After 8 months the Martínez family moved back into Las Lomas to a different two-bedroom, one-bath apartment, owned by the husband of a family friend in a threeunit complex next door to his home. Although Maria and Cecilia reported that they liked

\footnotetext{
76 Regardless, the circumstances demonstrate the complex social and legal difficulties that result from informal property transfers.

77 The Supplemental Nutritional Assistance Program, formerly the Food Stamp Program, uses an Electronic Benefit Transfer (EBT) to issue payments directly to beneficiaries.
} 
the colonia, since it was "tranquilo" (calm), and there were schools and stores nearby, ${ }^{78}$ the new dwelling posed several problems for the Martínez family. Initially, the family had no electricity in the apartment. After three weeks, the owner strung an extension cord over the fence dividing his home and the rental property, although this impromptu solution was largely unsuccessful, since the electricity often cut out daily. According Maria and Cecilia, even when the electricity did work well, the AC unit barely functioned and the lights were dim.

Shortly thereafter, the landlord actually moved out of his home on the adjacent lot and into the apartment complex due to a marital dispute between him and his wife. The Martínez family continued to live in the unit with intermittent electricity until they eventually switched to the apartment occupied by the landlord (and he, in turn, occupied the apartment with electrical problems). It was here that the Martinez family resided at the time of the interview. ${ }^{79}$ This unit was also a two-bedroom, one-bath that the family rented for $\$ 275$ per month, with no written rental contract. Maria slept in the living room, her two sons slept in one bedroom, and Cecilia and her children slept in the second bedroom. Although it had a more reliable electricity supply, this new unit also suffered from a variety of structural and functional problems: both the shower and bathroom sink clogged frequently; the AC unit did not work well; one of the two exterior doors did not lock; and the refrigerator had stopped working at various points, causing the family to lose a significant amount of food due to spoilage. ${ }^{80}$

\footnotetext{
78 Being rather large (approximately 1,000 or more households) Las Lomas has both a Head Start center and an elementary school, as well as a variety of stores and other locally-owned businesses.

79 See Figure 6.6 in the methodological appendix for a diagrammatic sketch of the home.

80 This is problematic for a couple of reasons. First and foremost is the fact that the family's budget for food is already limited given their low incomes and utilization of the SNAP transfers. Second, the health risk involved in food spoilage presents a serious concern, particularly for young children. Eventually, the
} 
The Martínez family was rather unhappy with the quality of their current unit, although they reported that it was nicer than either of their two previous dwellings (the one next door and the one in Roma). Their largest complaint, in fact, was not the quality of the dwelling but the landlord's unresponsiveness and, at times, stubbornness, regarding the structural and functional problems. According to Maria and Cecilia, he forbade them to make repairs themselves, since he was unwilling to compensate them for the cost, although he also failed to make the improvements himself. Often he brushed their concerns aside, claiming they were too particular and asserting that the apartment had passed inspection prior to lease to the previous resident, who had used a housing voucher. ${ }^{81}$ The dwelling had not, however, been inspected prior to leasing by the Martínez family, and had deteriorated significantly by that point. In this instance, it is important not to view the landlord as either malicious or exploitative, but rather as vulnerable as well; dependent upon the Martínez' rental payment for his income, the landlord was reticent to allow the family to make upgrades to the dwelling in exchange for a reduction in the rental cost, though he also lacked the resources to make the improvements himself. Given that they had not signed a written contract, the Martinez family had limited recourse to object to poor housing conditions.

Finally, the Martínez family's housing decisions were fairly constrained by financial circumstances, which prevented them from moving dwellings. The family had looked for rental accommodation elsewhere in the colonia, but claimed that the cost of rent in nicer units was prohibitively expensive (one unit that they had looked at cost more

landlord traded his more reliable refrigerator for theirs, although even this one did not cool adequately: at the time of the interview, all of the items in the freezer had thawed.

81 The Housing Choice Voucher (Section 8) requires that a dwelling be of sufficient quality in order to qualify as a residence for a voucher user. 
than $\$ 400$ for a two-bedroom apartment). Eventually, Maria hoped to purchase another house, although she acknowledged that for the time being this was simply a wistful dream, and she had no concrete plans to do so in the near future.

\section{The Castillo Family: Upwardly Mobile, but Vulnerable Nonetheless}

Rosalia and Miguel Castillo's experience differed dramatically from that of the Martínez family. When they married in 1997, they moved in with Miguel's parents in Houston. In 1999 they had a daughter, and two years later, a son. Since Miguel worked in the construction and dredging industry, and was therefore gone for weeks at a time, the Castillos decided in 2003 to move to Starr County, close to Rosalia's family. The Castillos desire to be homeowners also drew them to Starr County, where land is less expensive. Although homeownership is a common aspiration among colonia renters, the Castillos were in a unique position to realize this dream given their higher incomes - the family earned $\$ 35,000$ a year, placing them in the top ten percent of renters interviewed in the formal rental complexes.

Upon arriving in Starr County, the Castillos moved in a one-bedroom apartment - for which they paid $\$ 250$ per month - in a colonia just north of Rio Grande City. At the time, all four family members slept in the same room, but by 2005 they needed more space and so moved to their current dwelling, a two-bedroom, one-bath apartment $^{82}$ in Los Olmos, a medium-sized colonia (100 or so lots) just outside of Rio Grande City. Rosalia and Miguel shared one bedroom, and their three sons (the third was born in 2009) shared the second bedroom. In general, the apartment was in good condition and the family was happy with their accommodation. At the time (2008), they paid $\$ 400$ per month and had put down a $\$ 400$ deposit, with no written contract.

8282 See Figure 6.7 in the methodological appendix for a diagrammatic sketch of the home. 
In 2008 the Castillos began looking for a house or lot of their own. They did not consider getting a mortgage, mostly because they were doubtful that they would qualify. Instead, the Castillos began looking for lots in Model Subdivisions ${ }^{83}$ (MSRs). For lowincome prospective homeowners, the allure of MSRs is simply the fact that the developers finance the sale themselves and provide services. Developers of MSRs often have much more flexible qualification standards than do traditional banks, ${ }^{84}$ although they often charge very high interest rates (see Ward et al. 2012).

In 2010 the Castillos agreed to purchase a fully serviced lot (water, electricity, and drainage) in a Model Subdivision a few miles north of Rio Grande City. The lot cost them $\$ 39,000$ ( $\$ 80,000$ if interest payments are factored in) with a down payment of $\$ 1,500$ and monthly payments of $\$ 456$ for 15 years. ${ }^{85}$ At the time of the interview in August of 2011, the Castillos had paid $\$ 4,000$ (approximately 5\% of their total expected payments). Soon, the Castillos hope to purchase a used trailer or camper to place on the lot, and to leave their apartment, although at present simply covering the cost of both their rent and lot purchase payments consumes most of their discretionary income. Indeed, on two occasions they were unable to cover both payments. When asked which payment she failed to make, Rosalia replied emphatically that she missed her rent payment, but would never miss the lot payment.

\footnotetext{
${ }^{83}$ MSRs are those subdivisions developed after the passage of legislation known as Model Subdivision Rules in 2000 that sought to limit the growth of informal settlements along the Texas-Mexico border. In particular, these laws required the installation of water and wastewater services.

84 See Ward et al. (2012) for an excellent discussion of the high rates of foreclosure in some Model Subdivisions. Periods of tenure in some of these subdivisions were so short that Ward et al. have begun referring to them as owning-to-rent circumstances.

85 The Castillos purchased using what they believed was a written Contract for Deed agreement, but may in fact have been a Warranty Deed with Vendor's Lien (again see Ward et al. 2012).
} 


\section{DiscuSSION AND CONCLUSIONS}

It is my hope that these case studies put a face on the data and analysis presented thus far. These cases provide two distinct portrayals of renting in colonias, both of which are likely extreme in terms of the vulnerability or upward mobility of the families surveyed. The Martínez case clearly illustrates how a variety of social and economic factors can disrupt a family's housing trajectory and can dramatically increase their vulnerability. For many very low-income families (and perhaps especially for singlemother households), renting is the most affordable tenure choice. ${ }^{86}$ However, renting a low-priced dwelling imposes significant social and economic costs, such as the loss of food (and subsequent risk of illness) experienced by the Martínez family.

However, the Martínez case also highlights the vulnerability of colonia landlords and provides useful insights into the complexities of the landlord-tenant relationships. Sometimes landlords are equally as poor their tenants, and many may be highly dependent upon the rental payments, as was the Martínez's landlord. Moreover, poor landlords may wish to improve the condition of their property, but simply may not have the economic means to do so. This is undoubtedly more of a concern in stand-alone rental homes operated by small-scale landlords, but as the Martínez case shows, it applies as well to some formal rental complexes.

Even among renters such as the Castillo family who have substantial income and are clearly upwardly mobile, a variety of factors continue to threaten the economic security and housing trajectory of colonia renters. For families such as the Castillos, making purchase payments while also renting an apartment is a serious financial burden, but also a catch twenty-two: Rosalia and Miguel cannot move onto their lot until they

\footnotetext{
86 Other than payment-free renting or sharing of the dwelling.
} 
save enough money to purchase a used trailer, although they cannot afford the trailer because they are making dual payments. Regardless, when they do save enough to purchase a mobile home, it will likely be small and of poor quality. Thus, in making the transition from renting to owning, the Castillos' dwelling condition may decline significantly.

The qualitative studies discussed in this chapter point towards a clear picture of the structure of the colonia rental market, the characteristics of renter households, their housing plans, and a variety of factors that constrain the tenure choices of low-income residents. In the following chapter, I conclude with a discussion of the policy implications of these findings as well as a description of various issues regarding renting in colonias that deserve further attention from scholars. 


\section{Chapter 5: Conclusion and Policy Implications}

\section{INTRODUCTION}

Given the recent rise in renting in colonias it is appropriate that policymakers and scholars begin exploring potential policies to support colonia renters. This chapter begins with a brief review of legislative efforts in order to demonstrate how the concerns of renters have been largely ignored by policymakers. Expanding upon points made elsewhere in this report, I synthesize current policy concerns regarding renting in colonias before offering specific policy recommendations to address supply- and demand-side constraints and to reduce the risks experienced by tenants, landlords, and informal-landlords. The chapter concludes with a discussion of future issues regarding renting in colonias that deserve the attention of scholars.

\section{A Policy Vacuum}

Over the past 25 years, lawmakers in Texas have passed legislation addressing a variety of issues of underdevelopment in colonias. These include, but are not limited to:

- The establishment of Model Subdivision Rules (MSRs) that require the platting of new subdivisions, limit the connection of utility services to unplatted subdivisions (these were later relaxed in 1997 to allow preexisting subdivisions access to utility connections), and require developers to build or bond water and wastewater infrastructure.

- The expansion of the power of municipalities to regulate land use in their extraterritorial jurisdiction (ETJ).

- The forming of the Economically Depressed Areas Program (EDAP) in order to provide funding for infrastructure improvements (contingent upon 
the adoption of the MSRs) in border counties. This was later expanded to other parts of Texas.

- The expansion of the authority of the Office of Attorney General (OAG). In particular, the OAG was given the ability to pursue criminal and civil prosecution of developers that violate MSRs.

- Increased restrictions on the use of Contract for Deed agreements in order to reduce the risks to buyers.

- The establishment of an Owner-Builder Loan Program (now known as the Texas Bootstrap Loan Program) and Colonia Self-Help Centers to support self-help construction for homeowners.

- The creation of the Colonias Initiative Program in the Texas Secretary of State's Office, which coordinates, via colonia ombudspersons, initiatives in the six counties with the largest colonia populations.

- Coordination between various health and human services agencies to integrate employment, education, and health services in colonias, including the establishment of a training and certification program for promotoras $^{87}$ and community health workers who work as a liaison between colonia residents and health care providers (Texas Office of the Attorney General 2013; Texas Office of the Secretary of State 2013).

As I hope is clear from this brief review of legislative efforts to address underdevelopment in colonias, most of this legislation has focused on issues that primarily affect homeowners or homebuyers, striving to a) reduce the risks associated

\footnotetext{
87 Promotoras are lay community members that receive specialized training to provide basic health education and services in colonias.
} 
with purchasing in a colonia, b) provide financial assistance with the purchase process, and c) provide technical and financial support for the self-help construction process. Thus, despite the large and growing minority of renter households in the colonias reviewed in this study, the lack of renter-focused policy is indeed surprising.

\section{Renting in Colonias: Current Policy Concerns}

In general, because colonias are located outside of municipalities, and because counties have limited ordinance creation abilities, few institutional channels exist at the local level to monitor and regulate colonia rental housing conditions. This situation is exacerbated by the fact that oversight, enforcement, and assistance is divided between a number of departments and organizations including, but not limited to, the Texas OAG, the Texas Office of the Secretary of State, the Texas Department of Housing and Community Affairs, the Texas General Land Office, the Texas Health and Human Services Commission, as well as non-profits and education institutions. Moreover, since colonias and informal subdivisions are invariably isolated from public view, located as they often are in remote rural areas, poor housing conditions in rental property may go unnoticed and unaddressed for years into the future - and the relatively low use of written rental agreements means that renters may have limited means for objecting to the poor quality of the dwelling.

In years to come, issues of affordability (of both renting and owning/purchasing) will be of serious concern. As colonias densify (due to the infill of vacant lots as well as increases in the sharing of lots), as they are incorporated into neighboring municipalities, and as demand for rental accommodation rises, it is unclear whether rental housing will remain equally affordable and accessible for lower-income colonia residents. By reducing the supply of land, densification and infill of vacant lots may eventually result in higher 
land costs, though at present this is of limited concern given the high rates of lot vacancy in colonias (20-30\%; see Rojas et al. 2012). Of more concern is the fact that a significant number of colonias are currently located on or near the border of neighboring municipalities, making the annexation of some colonias likely. In the event that annexation does occur, ${ }^{88}$ any subsequent infrastructure improvements will result in increased property values, while incorporation into the municipality will result in the levying of additional property taxes. In these instances, rental costs are likely to rise substantially.

This fact points to an issue of concern for renters in general, namely, that rental costs are more subject to inflation, making renting less affordable than home purchase in the long run. Although in colonias renters pay lower housing costs than most owners, the difference is not substantial, and is largely eliminated by the fact that renters have significantly lower incomes than do owners - thus, despite paying less nominally, renters spend significantly more of their income on housing.

Indirectly the future of renting in colonias will largely be shaped by the level of access that prospective homebuyers have to acquiring a home. This, in turn, requires expanded financial literacy and financial assistance for would-be buyers. Many of the renters surveyed for this project reported that they had chosen to rent specifically for financial reasons and due to limited options for the purchase of homes. Because these households are younger, their incomes are likely to grow over the coming decade,

\footnotetext{
88 The extent to which these colonias will indeed be annexed is questionable. A separate research project found that Census Blocks containing colonias were significantly less likely to be annexed than were Blocks that did not contain colonias. This is due to the fact that there is a clear disincentive for municipalities to annex colonias with poor infrastructure, since they are required to complete improvements to such facilities within a few years of annexation. Despite these disincentives, in areas such as Cameron and Hidalgo counties, where municipalities have grown significantly over the past three decades and therefore experience significant competition with neighboring cities over land, annexation of colonias does in fact occur, though only to a limited extent.
} 
making purchase more feasible; given the high aspirations for home ownership among the renters studied, these populations are ideal targets for not-for-profit or state support for home purchase. However, the absence of financing mechanisms for home purchase and the lack of financial planning by these households mean that many would-be buyers will continue to find it difficult to purchase a home, unless the seller is willing to finance the sale.

Issues of dwelling quality are also a concern. Although my research suggests that the quality of many formal rental complexes is better than expected (and most residents are content with their accommodations), as properties age and require significant investment, there is the concern that some will slip into disrepair. In the stand-alone rental market, conditions may be much worse, since low-income property owners have limited financial resources with which to maintain the property. This is particularly likely given the prevalence of self-help housing in colonias, where roughly half $(47 \%)$ of all owners built their homes via self-help (Durst et al. 2012). Whereas as owner occupiers have a clear incentive to capitalize on their own "sweat equity" via self-help, renters are less likely to engage in self-help improvement of rented dwellings.

Also of concern is the fact that a variety of factors limit the accessibility of rental accommodations in colonias. First, because they are located primarily in the hinterlands of cities, colonias typically lack access to public transportation. This makes them less accessible to very low-income residents, or at the very least imposes additional financial constraints on residents. Second, although a number of renters in formal rental complexes appear to use housing vouchers, stand-alone homes that were originally constructed via self-help are unlikely to meet the quality standards for participation, meaning that fewer 
low-income voucher recipients will utilize their voucher. ${ }^{89}$ Finally, the fact that few renter households had signed a written rental agreement means that renters face serious threats to housing access and tenure security: they have only limited recourse to object to eviction or spikes in rental cost, and, to my knowledge, no government or non-profit organization currently assists colonia renters in this regard.

Other factors present unique challenges to policymakers, residents, and landlords. In particular, for tenants who have rented the land and then placed a temporary dwelling on the property, the issue of access to and the cost of utility services may be of concern. It is unclear who should cover the cost of connecting the utility services from the street to the dwelling, or who should ensure upkeep of the septic system. For those owners who have no intention of occupying the property (at least not in the short term), paying for the utility connection may be an unwanted and excessive burden, while for tenants there is little incentive to invest in the installation of infrastructure since they have no financial stake in the property.

\section{Policy Recommendations}

Each of the factors just discussed makes the exploration of potential policy solutions for renting and renters in colonias an important first step for scholars and housing advocates. A mix of demand- and supply-side policies would help to expand access to safe and affordable rental accommodation in colonias, and increased consumer protections and community outreach could help to reduce the vulnerability of the tenant population. Finally, in the interest of efficiency, policymakers and scholars should focus

\footnotetext{
${ }^{89}$ Nationwide, declines in rates of voucher utilization have been a significant problem, largely due to the unavailability of dwellings of sufficient quality within the program's maximum allowable market rent. In $1993,81 \%$ of voucher recipients were successful in utilizing them; by 2000 , this had decreased to $69 \%$.
} 
attention on areas where renting is likely to be highest, namely, in larger, older, and more densely populated colonias.

\section{Demand-Side Policies}

I begin first by discussing potential demand-side policies to support access to safe and affordable rental housing in colonias and to facilitate the transition toward homeownership. First, the use of housing vouchers is the primary, if not the only, housing assistance currently provided to colonia renters. Efforts to expand the allocation of vouchers, or to target them more effectively to low-income renters in colonias (perhaps through expanded outreach and education), would assist the lowest-income colonia residents to obtain adequate housing. In addition, improved public or private transportation systems between colonias and neighboring municipalities would facilitate commuting to work and would free up the incomes of colonia residents (and in particular, renters, who are poorer and spend a greater proportion of their income on housing). Finally, financing to assist with the installation of utility services on vacant land would incentivize the renting of unused lots by facilitating the placement of temporary dwellings on these properties; any effort to do so, however, should be accompanied by measures that ensure that owners cannot charge excessive rents or sell the property in order to reap a financial windfall.

Other demand-side policies can improve the lives of renters by facilitating the transition toward homeownership. The first of these entails an effort to facilitate rent-toown agreements, in which a portion of the tenant's monthly rent is allocated toward a down payment, and after a designated period of time the tenant has the option to buy the property. In colonias, rent-to-own schemes would be particularly useful in regards to vacant land, since the value of the property will be significantly lower (and thus more 
affordable for low-income renters) than lots with existing dwellings. One drawback to this option, however, is that both tenants and owners need to be fully informed of the terms of the agreement, particularly given the high level of informality in colonia housing contracts (both for purchase and for rental) at present. Thus, for rent-to-own schemes to work effectively, efforts must be taken to provide technical assistance in drafting and enforcing rent-to-own contracts. Other mechanisms can also help to facilitate the purchase process. For example, state and non-profit organizations can assist renters in building equity through Individual Development Accounts ${ }^{90}$ (IDAs). Other steps to improve financial literacy and consumer credit scores would help higher-income potential buyers to seek out and qualify for traditional mortgages.

\section{Supply-Side Policies}

A variety of supply-side policies would help to increase the availability of affordable rental accommodations in colonias; the first and most obvious are financial incentives targeted at entrepreneurial landlords. Reduced-interest loans, tax credits, and lower tax rates would incentivize the construction of additional multi-unit complexes in colonias. It is important to note, however, that any effort to incentivize the construction of rental housing in colonias should take steps to ensure that such housing is affordable for very low-income residents. Moreover, because colonias developed (at least partially) due to a general lack of affordable housing options along the Texas-Mexico, efforts to assist colonia renters should not overlook the expansion of affordable housing in cities.

\footnotetext{
90 IDAs are matched savings accounts that assist low-income participants in building equity, often toward the purchase of a home and toward education expenses. Provided typically by banks, credit unions, and non-profit organizations, participants agree to make regular contributions which are then matched in equal amounts by the lending institution.
} 
As I have already discussed, a variety of factors complicate the inheritance process in colonias. The limited use of wills and (relatively) high probate costs make it difficult to sell colonia homes, even if the owners are interested in doing so. As Ward et al. (2012) found, some families turned to renting the property since they could not come to agreement regarding who should inherit it. Thus, free or reduced-cost legal assistance to provide wills or probate the will in court would facilitate the sale of colonia homes and would prevent a reversion to informality in terms of property title.

Finally, other measures are needed to ensure that the rental accommodation available in colonias is of sufficient quality, although the ideal policies differ for formal rental complexes and owner-rented stand-alone homes. Without financing sources to assist landlords in renovating and upgrading formal rental complexes, many of these structures may slip into disrepair or even abandonment. If these complexes deteriorate excessively, they will no longer be of sufficient quality to qualify for housing vouchers. Finally, for the owners of stand-alone homes for rent, many of whom likely have low incomes as well, there is no clear mechanism by which these owners can finance necessary improvements to the dwelling; renters, who have no financial stake in the property, are unlikely to invest significant time or money into making improvements. Currently, self-help financing and technical support is targeted only at owner-occupants, and thus misses between one-fifth and one-quarter of colonia households. These programs should be expanded to assist with the upgrading of rental dwellings as well, although any such effort should also ensure that the dwelling remains affordable and accessible for low-income renters in the future and, once again that owners do not attempt to capitalize on the improvements by selling the property. 


\section{Policies to Enhance Consumer Protection}

A variety of policies address neither demand- nor supply-side factors, but instead would ensure that tenants and owners have equal and adequate protection from financial and social risks. For example, community outreach and education, and in particular the dissemination of bilingual written rental contracts, would protect tenants from factors such as eviction, rising rental costs, and poor quality dwellings. Colonia ombudspersons, Colonia Self-Help Centers, and local promotoras already provide significant support for colonia homeowners, and expanding these services to include the concerns of renters would be beneficial. For landlords and informal-landlords, the increased use of written contracts would be helpful as well, as it would probably reduce the likelihood of damages to the dwelling, and would provide them with further legal recourse when excessive damages do occur.

\section{RECOMMENDATIONS FOR FURTHER RESEARCH}

This report has demonstrated that renting in colonias is more common than was previously thought (particularly, in larger, older, and denser settlements), that renters are considerably more vulnerable than are owners, and that current policy largely ignores the needs of colonia renters. Given the little that has been written on renting and renters in colonias, there is still much research to be done.

At present, we have only a tentative understanding of the demand for rental housing and the interventions needed to support demand in the colonia rental market. Thus, more research should focus explicitly on colonia tenants and their concerns. We also know too little about the conditions of the housing stock, the development process for the construction of (or conversion to) rental property, and the concerns and needs of landlords and informal-landlords. Moreover, because colonia housing has typically been 
viewed through the lens of owner-occupied self-help assistance, we have a poor understanding of the various forms of rental or non owner tenure choices that might be open to renters-for example, rent-free sharing. Sharing is not discussed in this piece due to methodological constraints, but this remains an important and poorly understood component of the rental market. We also know too little about transitions between rentfree sharing, renting, and home-ownership; or indeed about those who drop out of ownership and move elsewhere. Work should also be done to explore the feasibility of rent-to-own and other financing options for the purchase of homes in colonias.

In short, if we are to begin to provide more effective assistance for housing access in colonias, we must first explore the housing trajectory of all colonia residents-renters, sharers, and owners-in greater detail. 


\section{Methodological Appendix}

\begin{tabular}{|c|c|c|c|c|c|c|}
\hline \multirow{5}{*}{ Log likelihood $=-108.59603$} & & & & Number of obs & $=$ & 306 \\
\hline & & & & LR chi2(5) & $=$ & 14.81 \\
\hline & & & & Prob $>$ chi 2 & $=$ & 0.0112 \\
\hline & & & & Pseudo R2 & $=$ & 0.1127 \\
\hline & $\begin{array}{l}\text { Odds } \\
\text { Ratio }\end{array}$ & $\begin{array}{c}\text { Robust Std. } \\
\text { Err. }\end{array}$ & $\mathrm{z}$ & $\mathrm{P}>\mathrm{z}$ & $\begin{array}{l}{[95 \%} \\
\text { Conf. }\end{array}$ & Interval] \\
\hline Population per Square Kilometer (1000s) & 1.90949 & 0.6895438 & 1.79 & 0.073 & 0.94088 & 3.875237 \\
\hline Total Occupied Units & 0.999088 & 0.0010724 & -0.85 & 0.395 & 0.99699 & 1.001192 \\
\hline$\%$ Debt-free (Integer) & 0.993762 & 0.007553 & -0.82 & 0.41 & 0.97907 & 1.008676 \\
\hline$\%$ Renter Occupied Units & 1.003181 & 0.0116746 & 0.27 & 0.785 & 0.98056 & 1.026326 \\
\hline Distance from Nearest City (Kilometers) & 0.400848 & 0.1406636 & -2.61 & 0.009 & 0.2015 & 0.797406 \\
\hline _cons & 0.223631 & 0.1486215 & -2.25 & 0.024 & 0.06079 & 0.822671 \\
\hline
\end{tabular}

Table 6.1. Logistic Regression of Testing for Selection Bias of Missing Data 


\begin{tabular}{cccccccccc} 
Residuals & $\begin{array}{c}\text { Standardized } \\
\text { Residual }\end{array}$ & Dfits & $\begin{array}{c}\text { Predicted } \\
\text { Value }\end{array}$ & $\begin{array}{c}\text { Distance from } \\
\text { Nearest City } \\
\text { (Kilometers) }\end{array}$ & $\begin{array}{c}\text { \% Renter } \\
\text { Households } \\
\text { (Integer) }\end{array}$ & $\begin{array}{c}\text { \% Debt- } \\
\text { free } \\
\text { (Integer) }\end{array}$ & $\begin{array}{c}\text { Total } \\
\text { Occupied } \\
\text { Units }\end{array}$ & $\begin{array}{c}\text { Low } \\
\text { Health } \\
\text { Risk } \\
(1=y e s)\end{array}$ & $\begin{array}{c}\text { Population per } \\
\text { Square Kilometer } \\
(1000 \text { s) }\end{array}$ \\
\hline 33.70496 & 2.64419 & 0.174374 & 19.86504 & 0 & 53.57 & 76.92 & 84 & 1 & 0.854784 \\
34.48879 & 2.709909 & 0.235656 & 19.21121 & 0 & 53.7 & 92 & 54 & 1 & 0.582509 \\
36.35574 & 2.863711 & 0.32308 & 18.03426 & 6.99007 & 54.39 & 96.15 & 57 & 1 & 0.224993 \\
41.58548 & 3.26869 & 0.299468 & 15.99452 & 0 & 57.58 & 78.57 & 33 & 0 & 0.224656 \\
62.87224 & 5.037094 & 1.143501 & 21.33776 & 0 & 84.21 & 8.89 & 285 & -- & 1.602584 \\
-13.0479 & -1.338127 & -1.13391 & 47.42792 & 0 & 34.38 & 73.9 & 1600 & 1 & 1.824259 \\
81.50961 & 6.574064 & 1.758043 & 18.4904 & 0 & 100 & 0 & 31 & -- & 1.930343 \\
\hline
\end{tabular}

Table 6.2. Outlier Case Analysis 


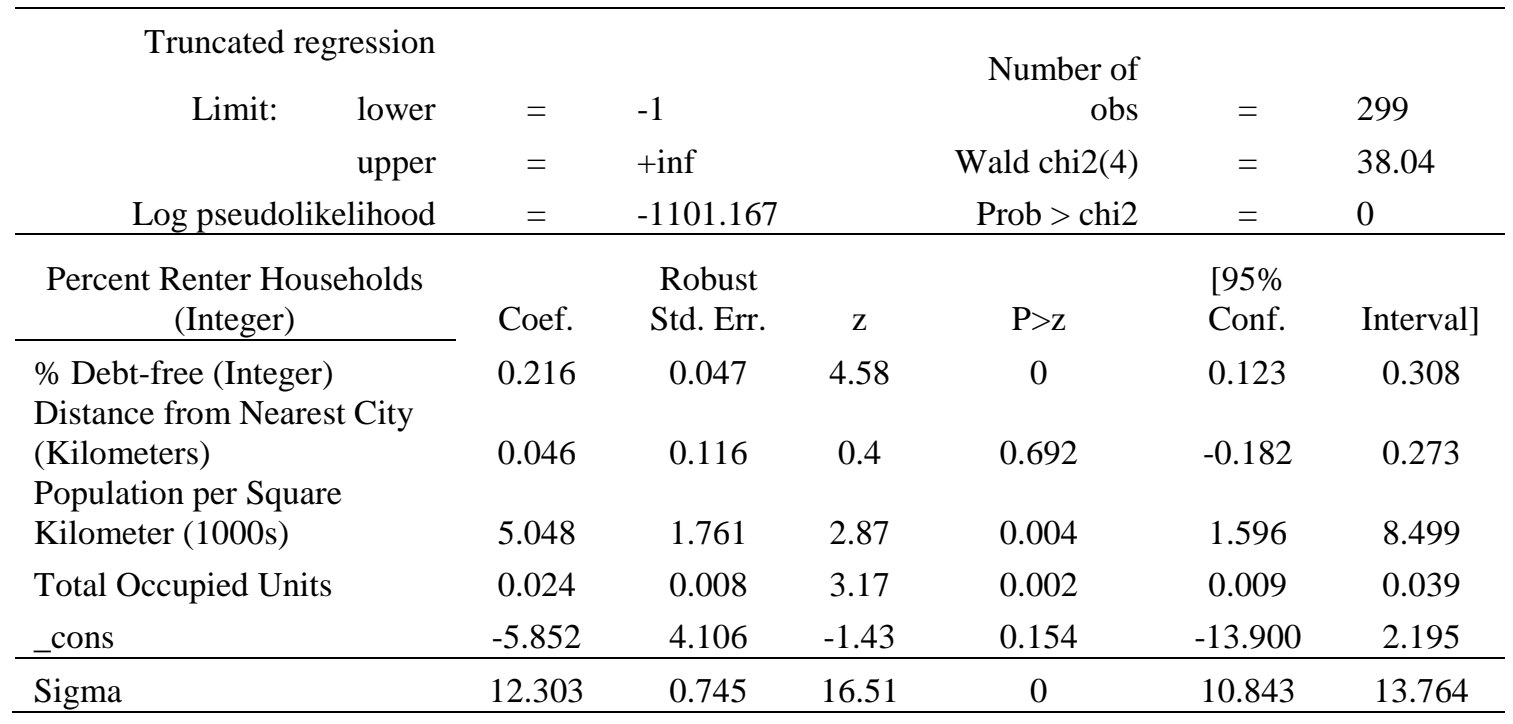

Table 6.3. Truncated Regression with Outliers Removed

\begin{tabular}{|c|c|c|c|c|c|c|}
\hline & & & & & & \\
\hline & & & Numb & r of obs & $=$ & 144 \\
\hline & & & & $5,138)$ & $=$ & 5.18 \\
\hline & & & & rob $>$ F & $=$ & 0.0002 \\
\hline & & & & squared & $=$ & 0.1322 \\
\hline & & & & ot MSE & $=$ & 10.869 \\
\hline $\begin{array}{c}\text { Percent Renter Households } \\
\text { (Integer) }\end{array}$ & $\mathrm{b}$ & $\begin{array}{l}\text { Robust } \\
\text { Std. Err. }\end{array}$ & $\mathrm{t}$ & $\mathrm{P}>\mathrm{t}$ & $\begin{array}{l}{[95 \%} \\
\text { Conf. }\end{array}$ & Interval] \\
\hline$\%$ Debt-free (Integer) & 0.134 & 0.046 & 2.89 & 0.004 & 0.043 & 0.226 \\
\hline $\begin{array}{l}\text { Distance from Nearest City } \\
\text { (Kilometers) } \\
\text { Population per Square }\end{array}$ & 0.190 & 0.112 & 1.7 & 0.091 & -0.031 & 0.411 \\
\hline $\begin{array}{l}\text { Population per square } \\
\text { Kilometer (1000s) }\end{array}$ & 8.316 & 3.174 & 2.62 & 0.01 & 2.040 & 14.593 \\
\hline Total Occupied Units & 0.011 & 0.010 & 1.11 & 0.268 & -0.008 & 0.030 \\
\hline Low Health Risk & 3.238 & 2.142 & 1.51 & 0.133 & -0.996 & 7.473 \\
\hline _cons & -0.653 & 4.048 & -0.16 & 0.872 & -8.657 & 7.351 \\
\hline
\end{tabular}

Table 6.4. Revised OLS Regression Excluding Distances of Zero 


\begin{tabular}{|c|c|c|c|c|c|c|}
\hline & & & \\
\hline \multirow[b]{6}{*}{$\begin{array}{l}\text { Percent Renter Households } \\
\text { (Integer) }\end{array}$} & & & \multicolumn{2}{|c|}{ Number of obs } & $=$ & 259 \\
\hline & & & \multirow{2}{*}{\multicolumn{2}{|c|}{ 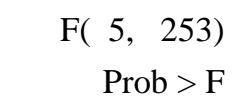 }} & $=$ & 9.21 \\
\hline & & & & & $=$ & 0 \\
\hline & & & \multicolumn{2}{|c|}{ R-squared } & $=$ & 0.1348 \\
\hline & & & \multicolumn{2}{|c|}{ Root MSE } & $=$ & 10.566 \\
\hline & $\mathrm{b}$ & $\begin{array}{l}\text { Robust } \\
\text { Std. Err. }\end{array}$ & $\mathrm{t}$ & $\mathrm{P}>\mathrm{t}$ & $\begin{array}{l}{[95 \%} \\
\text { Conf. }\end{array}$ & Interval] \\
\hline$\%$ Debt-free (Integer) & 0.155 & 0.029 & 5.37 & 0 & 0.098 & 0.211 \\
\hline $\begin{array}{l}\text { Distance from Nearest City } \\
\text { (Kilometers) } \\
\text { Population per Square }\end{array}$ & 0.081 & 0.095 & 0.85 & 0.398 & -0.107 & 0.268 \\
\hline Kilometer (1000s) & 3.307 & 1.461 & 2.26 & 0.024 & 0.430 & 6.184 \\
\hline Total Occupied Units & 0.018 & 0.008 & 2.27 & 0.024 & 0.002 & 0.034 \\
\hline Sufficient Infrastructure & 3.188 & 1.751 & 1.82 & 0.07 & -0.260 & 6.636 \\
\hline _cons & 0.438 & 2.683 & 0.16 & 0.87 & -4.845 & 5.721 \\
\hline
\end{tabular}

Table 6.5. Revised OLS Regression Model with Settlement Infrastructure Conditions
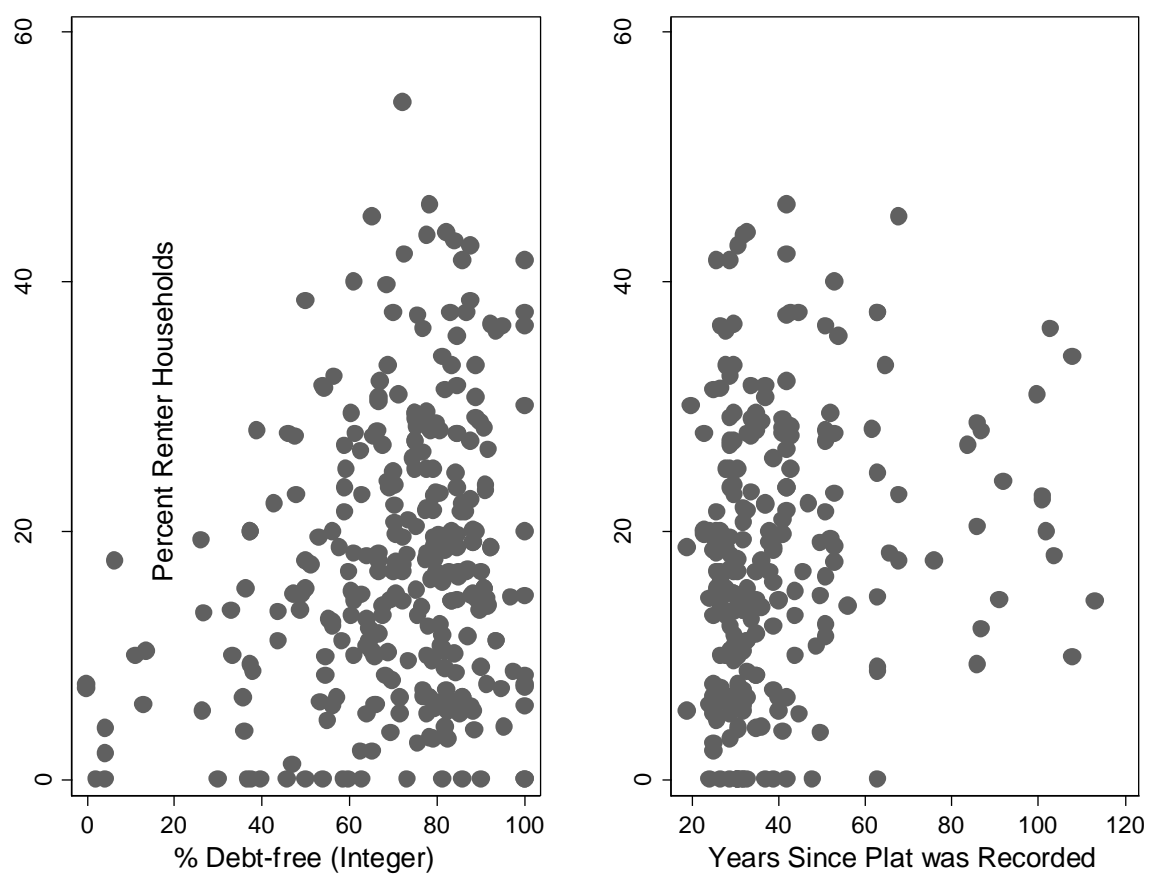

Figure 6.1. Scatter Plot: Debt-free Ownership and years since Plat was Recorded 


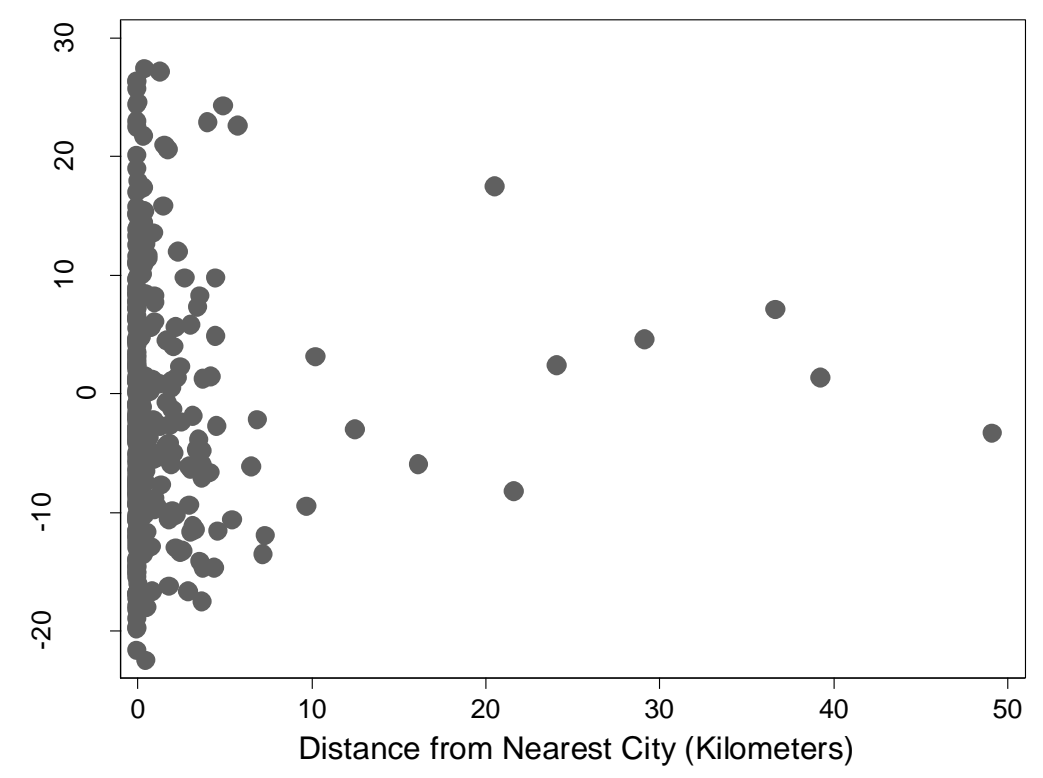

Figure 6.2a. Residual Plot: Distance from Nearest Incorporated City

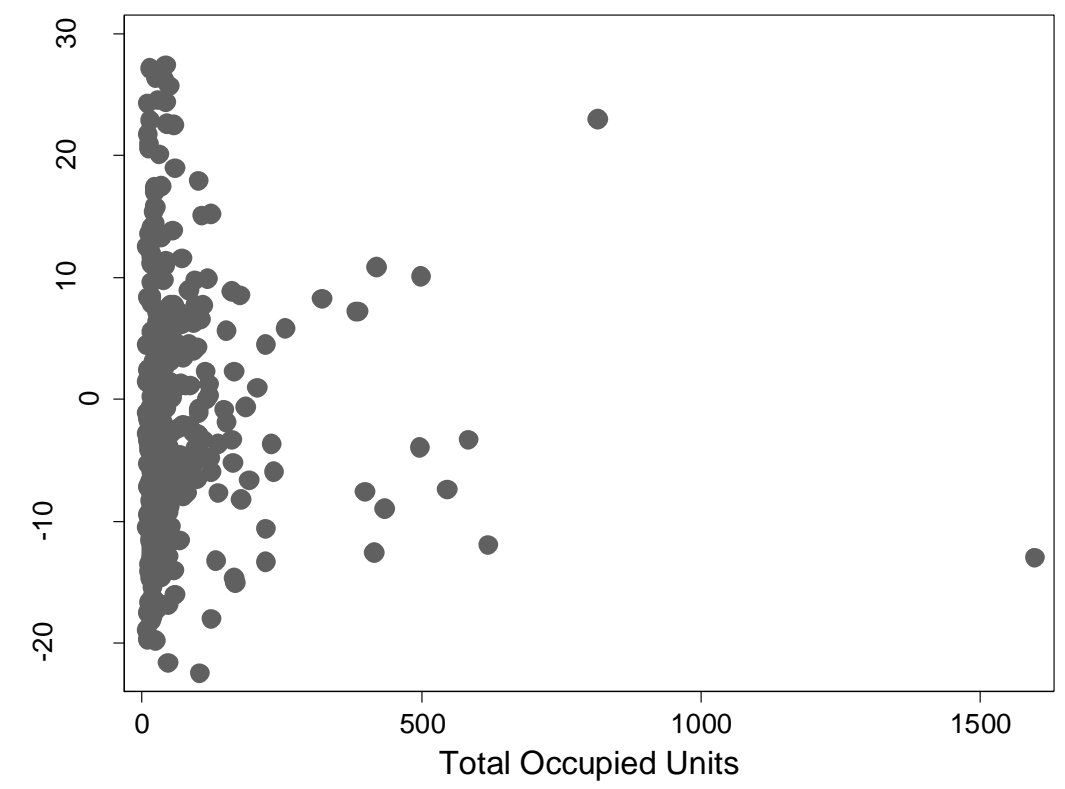

Figure 6.2b. Residual Plot: Settlement Size 


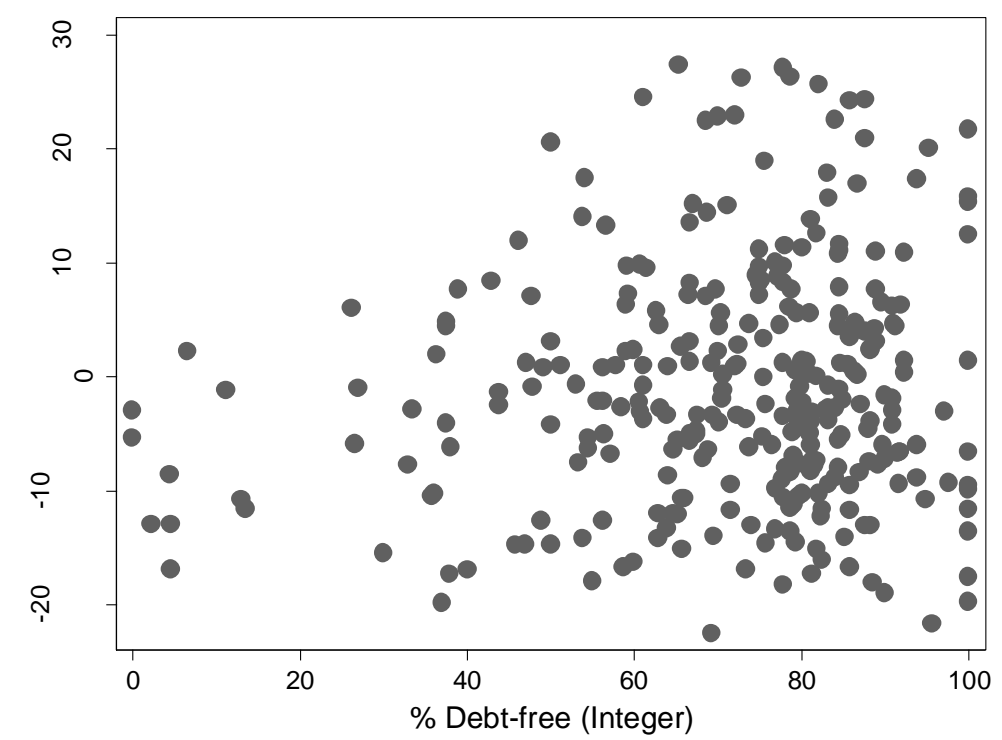

Figure 6.2c. Residual Plot: Percent Debt-free Ownership (Proxy for Age)

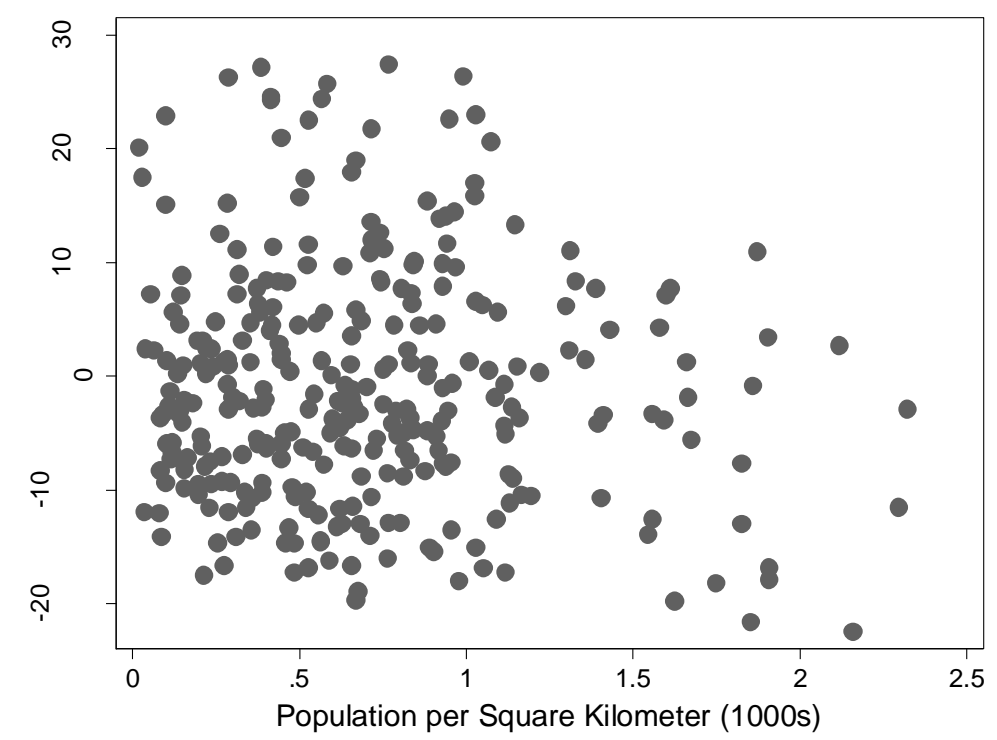

Figure 6.2d. Residual Plot: Population per Square Kilometer (in Thousands) 


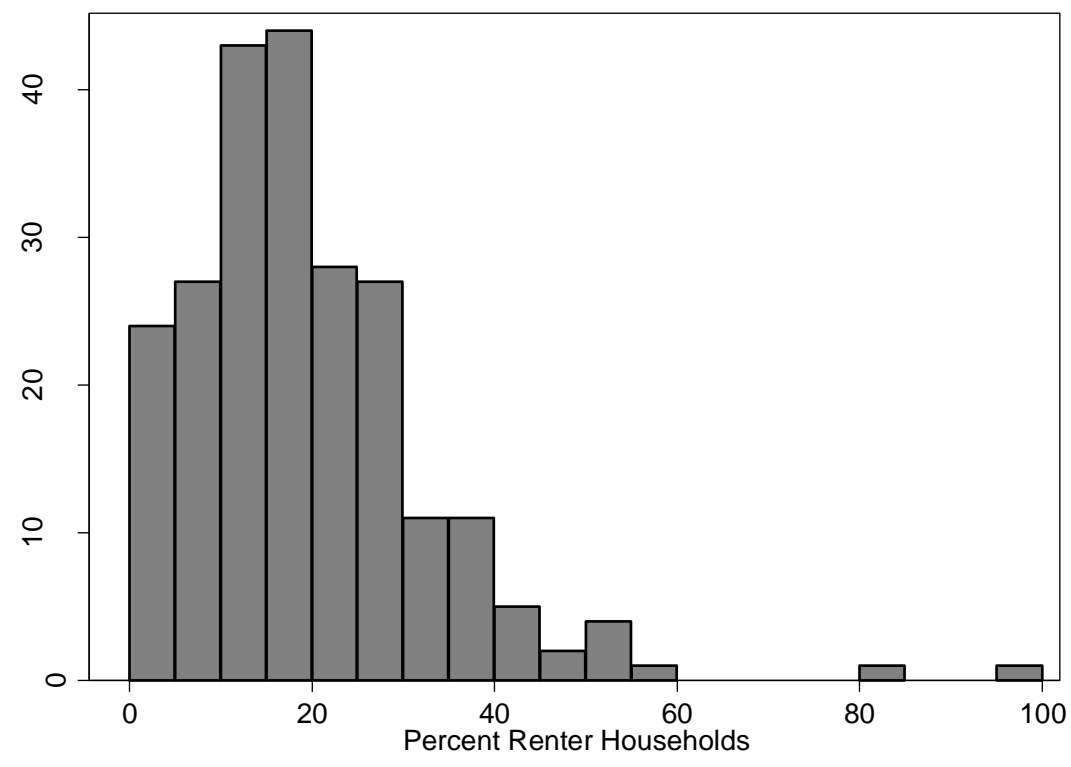

Figure 6.3. Sample Distribution of Percent Renter Households in Settlements with 20 or More Occupied Units (Dependent Variable)

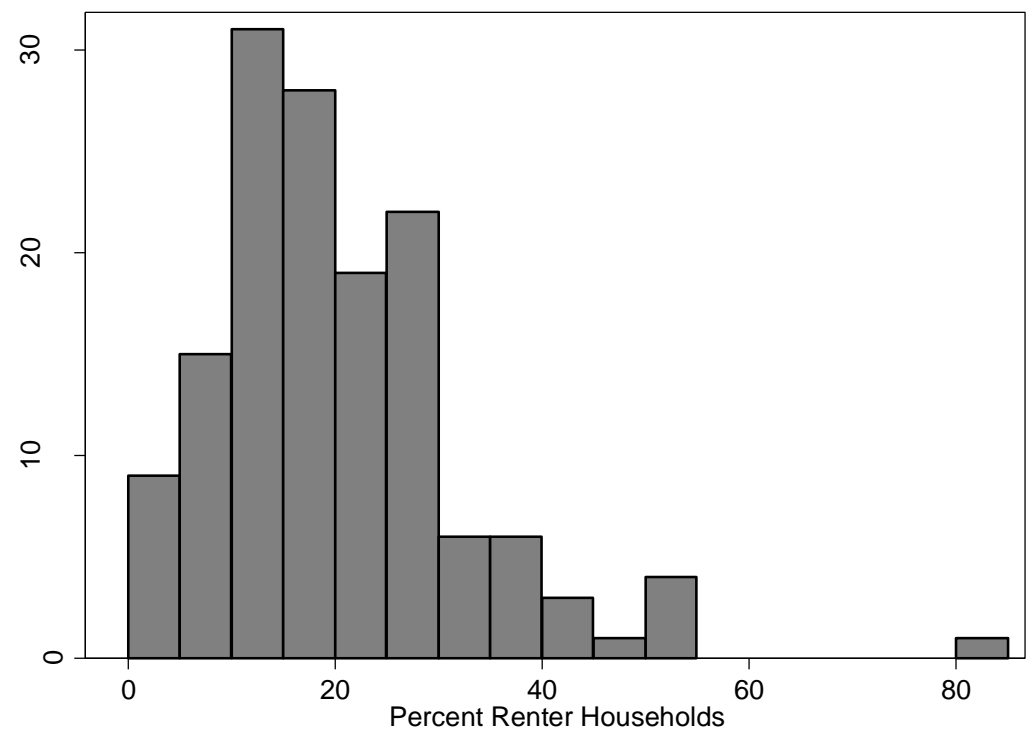

Figure 6.4. Sample Distribution of Percent Renter Households in Settlements with 40 or More Occupied Units (Dependent Variable) 


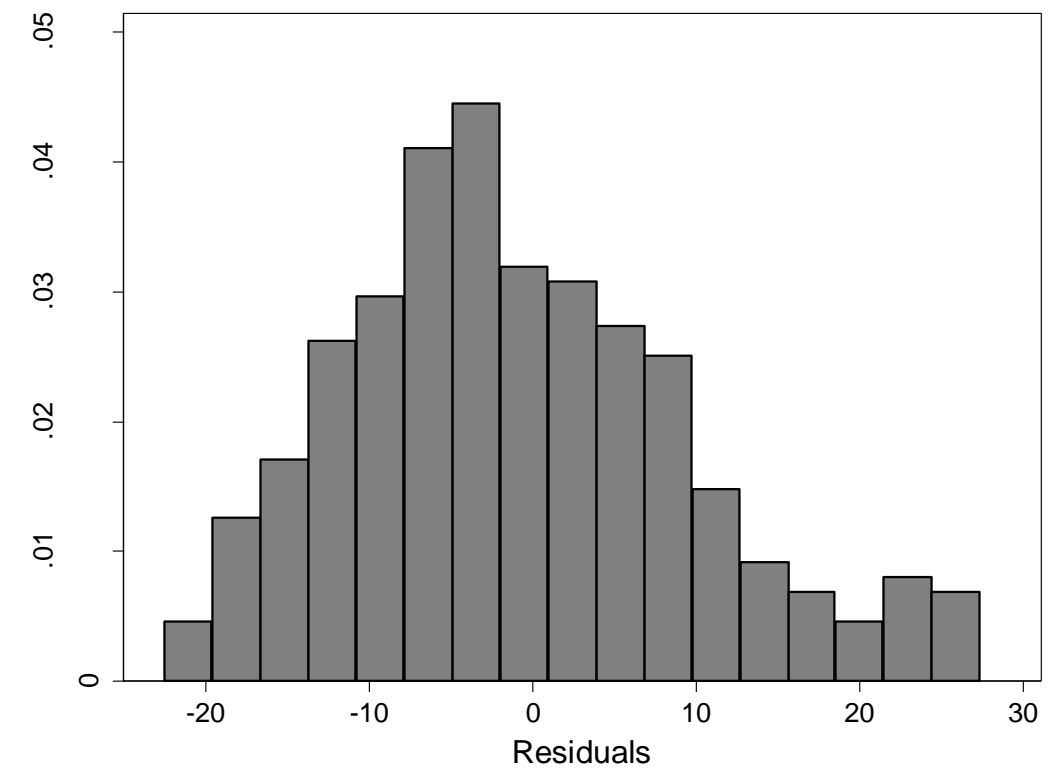

Figure 6.5. Histogram of Regression Residuals (Model 1) 


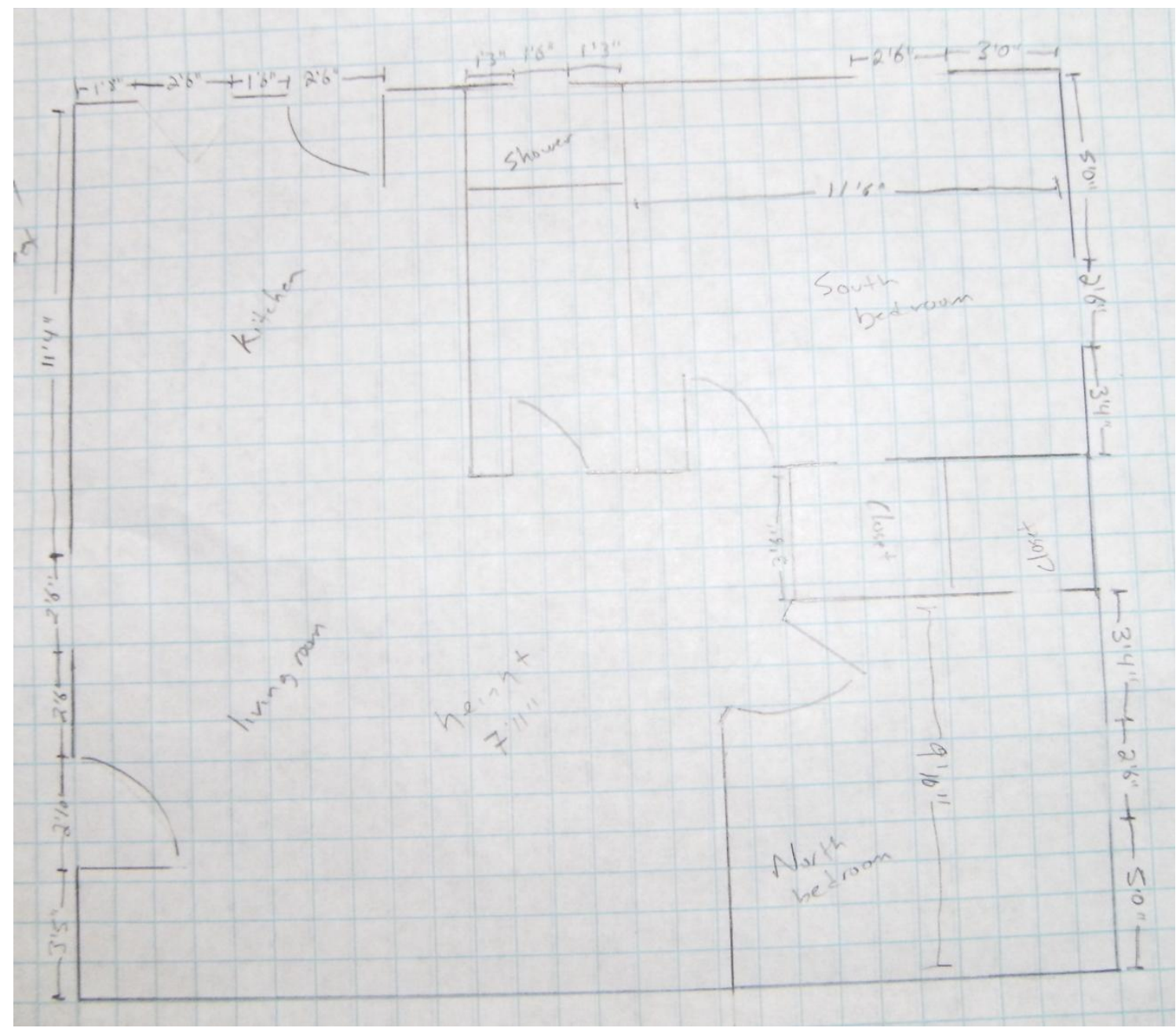

Figure 6.6. Diagrammatic Sketch of the Martinez Family Home 


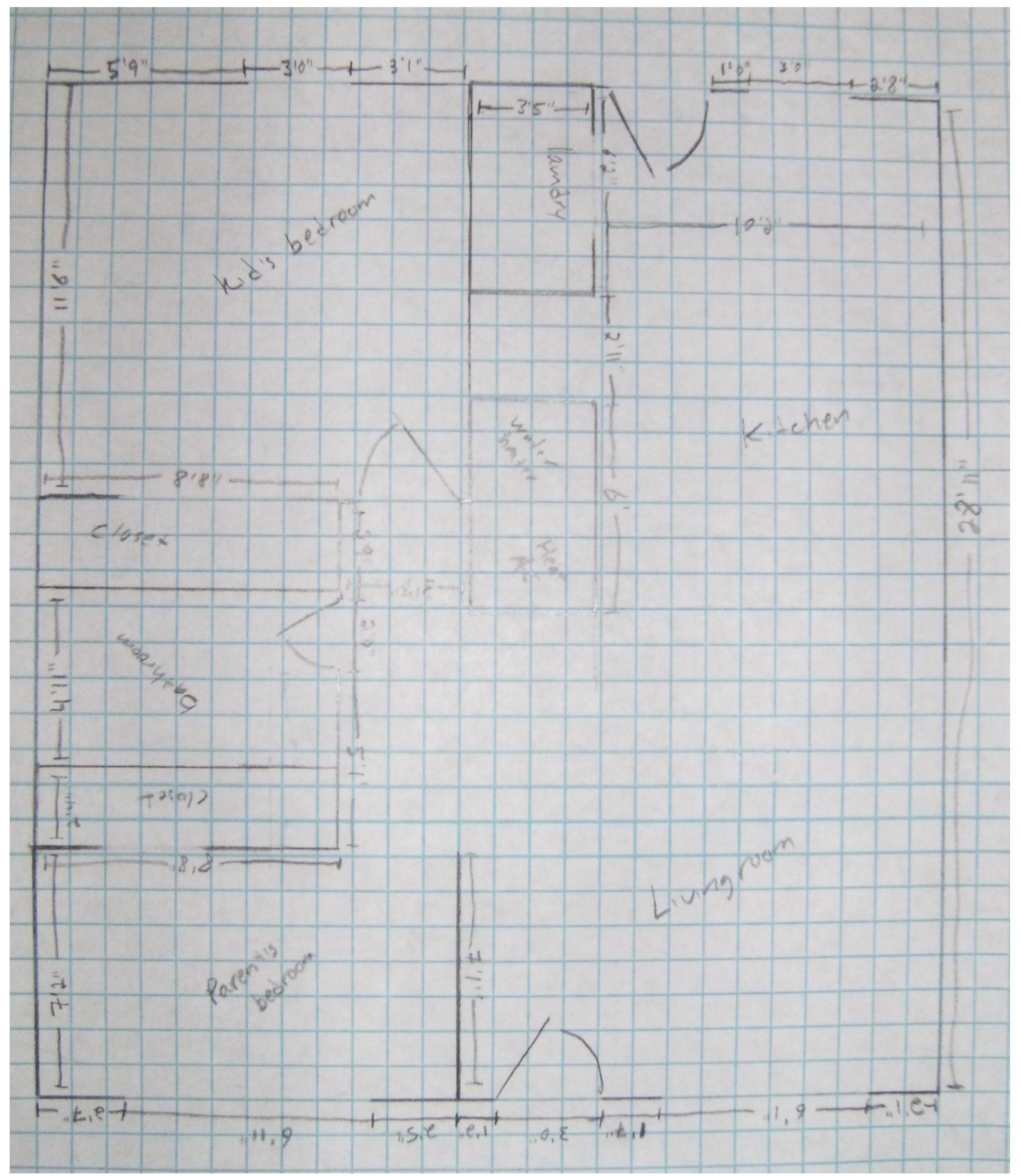

Figure 6.7. Diagrammatic Sketch of the Castillo Family Home 


\section{References}

Ahmad, Nuzhat. 1994. "A Joint Model of Tenure Choice and Demand for Housing in the City of Karachi.” Urban Studies 31 (10) (December 1): 1691-1706.

Andreasen, Jørgen. 1996. "Urban Tenants and Community Involvement.” Habitat International 20 (3) (September): 359-365.

Angel, Shlomo. 2000. Housing Policy Matters: A Global Analysis. Oxford.S

Arimah, Ben C. 1997. "The Determinants of Housing Tenure Choice in Ibadan, Nigeria." Urban Studies 34 (1) (January 1): 105-124.

Daniere, Amrita. 1992. "Determinants of Tenure Choice in the Third World: An Empirical Study of Cairo and Manila.” Journal of Housing Economics 2 (2): 159184.

Davidhizar, Ruth, and Gregory A. Bechtel. 1999. "Health and Quality of Life Within Colonias Settlements Along the United States and Mexico Border." Public Health Nursing 16 (4): 300-305.

Durst, Noah, Peter M. Ward, Carlos Olmedo, and Danielle Rojas. 2012. "Report \#2, Documenting a Decade of Change in Starr County Colonias: Survey Design and Results.” In Housing Sustainability, Self-help and Upgrading in Texas Colonias: A Longitudinal Perspective - 2002 plus 10. Final report of a study commissioned by the Ford Foundation in 2010.

Englund, Peter, Kim, Kyung-Hwan, Stephen Malpezzi, and Bengt Turner. 2005. "Housing Tenure Across Countries: The Effects of Regulations and Institutions." 
Working Draft. Presented to the International Meeting of the American Real Estate and Urban Economics Association, Los Cabos, Mexico. August: 34-42.

Fisher, Lynn M., and Austin J. Jaffe. 2003. "Determinants of International Home Ownership Rates." Housing Finance International. Septermber

Gilbert, Alan. 1983. "The Tenants of Self-Help Housing: Choice and Constraint in the Housing Markets of Less Developed Countries." Development and Change 14 (3): 449-477.

Gilbert, Alan. 1991 "Renting and the Transition to Owner Occupation in Latin American Cities." Habitat International 15 (1-2): 87-99.

Gilbert, Alan. 2012. Rental Market and Rental Policies in Less Developed Countries, International Encyclopedia of Housing and Home: 35-45.

Gilbert, Alan, and Ann Varley. 1990a. "Renting a Home in a Third World City: Choice or Constraint?" International Journal of Urban and Regional Research 14 (1): 89-108.

Gilbert, Alan, and Ann Varley. 1990b. "The Mexican Landlord: Rental Housing in Guadalajara and Puebla." Urban Studies 27 (1) (February 1): 23-44.

Gilbert, Alan, and Ann Varley. 1991. Landlord and Tenant: Housing the Poor in Urban Mexico. Routledge.

Gilbert, Alan, Jorge Enrique Hardoy, and Ronaldo Ramirez. 1982. Urbanization in Contemporary Latin America: Critical Approaches to the Analysis of Urban Issues. 1982. Chichester; New York: J. Wiley. 
Gilbert, Alan G., and Peter M. Ward. 1982. "Residential Movement Among the Poor: The Constraints on Housing Choice in Latin American Cities." Transactions of the Institute of British Geographers 7 (2). New Series (January 1): 129-149.

Gilbert, Alan, and Peter M. Ward. 1985. Housing, the State, and the Poor: Policy and Practice Inthree Latin American Cities. Cambridge Latin American Studies 50. Cambridge [Cambridgeshire] ; New York: Cambridge University Press.

Giusti, Cecilia. 2010. "Microbusiness in Texas Colonias," in The Colonias Reader: Economy, Housing and Public Health in US- Mexico Border Colonias., ed. Donelson, Angela J., and Adrian X. Esparza, (University of Arizona Press), 3043.

Giusti, Cecilia, and Luis Estevez. 2011. "Microlending for Housing in the United States. A Case Study in Colonias in Texas." Habitat International 35 (2) (April): $307-$ 315.

Holz, Robert K. 1993. Third World Colonias: Lower Rio Grande Valley, Texas. Working Paper / Lyndon B. Johnson School of Public Affairs no. 72. Austin, Tex.: Lyndon B. Johnson School of Public Affairs.

King, Mervyn A. 1980. "An Econometric Model of Tenure Choice and Demand for Housing as a Joint Decision." Journal of Public Economics 14 (2) (October): $137-159$.

Kumar, Sunil. 1996. "Landlordism in Third World Urban Low-income Settlements: A Case for Further Research.” Urban Studies 33 (4-5) (May 1): 753-782.

Larson, Jane E. 1995. "Free Markets Deep in the Heart of Texas." Georgetown Law Journal 84: 179. 
Lerbs, Oliver W., and Christian A. Oberst. 0. "Explaining the Spatial Variation in Homeownership Rates: Results for German Regions.” Regional Studies 0 (0): 123.

New Strategist Publications, Inc. 2011. Americans and Their Homes: Demographics of Homeownership. 3rd ed. Ithaca, N.Y: New Strategist Publications, Inc.

Office of the Texas Secretary of State. 2010. "Tracking the Progress of State Funded Projects that Benefit Colonias.” December 1.

Raya, Josep, and Jaume Garcia. 2012. "Which Are the Real Determinants of Tenure? A Comparative Analysis of Different Models of the Tenure Choice of a House." Urban Studies (Sage Publications, Ltd.) 49 (16) (December): 3645-3662.

Rojas, Danielle, Peter M. Ward, Noah Durst, and Carlos Olmedo. 2012. "Report \#1, Documenting a Decade of Lot Occupation Change in 22 Texas County Colonias and Subdivisions: Satellite image Analysis, Design, and Results.” In Housing Sustainability, Self-help and Upgrading in Texas Colonias: A Longitudinal Perspective - 2002 plus 10. Final report of a study commissioned by the Ford Foundation in 2010.

Rosen, Harvey S. 1979. "Housing Decisions and the US Income Tax : An Econometric Analysis.” Journal of Public Economics 11 (1): 1-23.

Schwartz, Alex F. 2010. Housing Policy in the United States. 2nd ed. Routledge.

Texas Attorney General. 2013. Accessed February 22. https://www.oag.state.tx.us/consumer/border/colonias.shtml.

Turner, John C. 1968. "Housing Priorities, Settlement Patterns, and Urban Development in Modernizing Countries." Journal of the American Institute of Planners 34 (6): $354-363$. 
US Census Bureau. 2013. "Cartographic Boundary Files. Accessed February 21. https://www.census.gov/geo/www/cob/pl_metadata.html.

Ward, Peter M. 1999. Colonias and Public Policy in Texas and Mexico: Urbanization by Stealth. University of Texas Press.

Ward, Peter M. 2012. “'A Patrimony for the Children': Low-Income Homeownership and Housing (Im)Mobility in Latin American Cities." Annals of the Association of American Geographers 102 (6): 1489-1510.

Ward, Peter M., Flavio de Souza, Cecilia Giusti, and Jane E. Larson. 2011. "El Título En La Mano: The Impact of Titling Programs on Low-Income Housing in Texas Colonias." Law \& Social Inquiry 36 (1): 1-82.

Ward, Peter M., Heather K. Way, and Lucille Wood. 2012 “The contract for deed prevalence project: A final report to the Texas Department of Housing and Community Affairs (TDHCA)." http://www.lahn.utexas.org/Texas\%20Colonias/TDHCA.html

Ward, Peter M., and Jeremiah Carew. 2000. "Absentee Lot Owners in Texas Colonias: Who Are They, and What Do They Want?" Habitat International 24 (3) (September): 327-345.

Ward, Peter M., and Paul A. Peters. 2007. "Self-help Housing and Informal Homesteading in Peri-urban America: Settlement Identification Using Digital Imagery and GIS." Habitat International 31 (2) (June): 205-218. 